\title{
Planning and design guidelines for accommodating non- motorized transportation in suburban office parks
}

Keith B. Bryant

West Virginia University

Follow this and additional works at: https://researchrepository.wvu.edu/etd

\section{Recommended Citation}

Bryant, Keith B., "Planning and design guidelines for accommodating non-motorized transportation in suburban office parks" (2005). Graduate Theses, Dissertations, and Problem Reports. 1579.

https://researchrepository.wvu.edu/etd/1579

This Thesis is protected by copyright and/or related rights. It has been brought to you by the The Research Repository @ WVU with permission from the rights-holder(s). You are free to use this Thesis in any way that is permitted by the copyright and related rights legislation that applies to your use. For other uses you must obtain permission from the rights-holder(s) directly, unless additional rights are indicated by a Creative Commons license in the record and/ or on the work itself. This Thesis has been accepted for inclusion in WVU Graduate Theses, Dissertations, and Problem Reports collection by an authorized administrator of The Research Repository @ WVU. For more information, please contact researchrepository@mail.wvu.edu. 


\title{
Planning and Design Guidelines for Accommodating Non-Motorized Transportation in Suburban Office Parks
}

\author{
Keith B. Bryant \\ Thesis submitted to the \\ College of Engineering and Mineral Resources \\ at West Virginia University \\ in partial fulfillment of the requirements \\ for the degree of
}

Master of Science

in

Civil Engineering

Ron W. Eck, P.E., Ph.D., Chair

Darrell R. Dean, Jr., Ph.D.

Lloyd J. French, Ph.D.

Department of Civil and Environmental Engineering

\author{
Morgantown, West Virginia \\ 2005
}

Keywords: Suburban Office Parks, Non-Motorized Transportation, Pedestrian and Bicycle Transportation, Sustainable Transportation, Planning and Design Copyright 2005 Keith B. Bryant 


\title{
Abstract \\ Planning and Design Guidelines for Accommodating Non-Motorized \\ Transportation in Suburban Office Parks
}

\author{
Keith B. Bryant
}

Recently, there have been many publications that chronicle suburban sprawl and the associated health risks, pedestrian safety concerns, economic impacts, and transportation consequences. Sprawl can be defined as dispersed, automobile-dependent development typically found along roadways outside of urban downtown areas.

Because of the problems associated with sprawl, planning and design guidelines have been developed for certain major land uses that offer guidance on more sustainable development practices. Other guidelines address the accommodation of non-motorized transportation in land uses such as residential, commercial, and retail. However, one land use for which such guidelines have not been developed is the suburban office park. Office parks have become prevalent in suburban areas over the past few decades. Suburban office parks are commonly large in size with low-rise office buildings, spatially separated by long distances, typically requiring an automobile to access them and travel within. Thus, a need was identified to develop design guidelines for accommodating non-motorized transportation in suburban office parks.

A literature review was performed to identify key principles, guidelines, and techniques related to this topic. This information was then synthesized into a single document: Planning and Design Guidelines for Accommodating Non-Motorized Transportation in Suburban Office Parks. The methodology used to develop the document is described. The document is included as an appendix.

The intended audience for the guide is broad, including but not limited to, planners, urban designers, developers, architects, transportation agencies, property managers, engineers and others who are involved in the planning, design, review or approval, and operations of suburban office park projects. Strategies for disseminating the results of this effort are included. 


\section{Acknowledgments}

First and foremost, I thank the Lord Jesus Christ. He has given light to my darkened path by His undying love and everlasting grace.

I would also like to thank Ashley, my true love, best friend, and wife. Many thanks to my Mom, Dad, Brother, all of my close relatives, co-workers, Bible study group, and close friends. Your love, prayers, and encouragement have been greatly appreciated.

I would like to extend thanks to Dr. Ronald W. Eck, thesis advisor, for his assistance and advice on this research. Thanks also to Dr. Darrell R. Dean and Dr. L. James French, committee members, for their advice and suggestions. 


\section{Table of Contents}

$\underline{\text { Page }}$

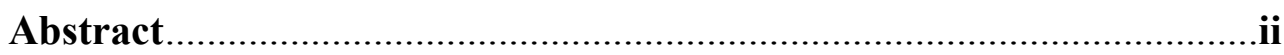

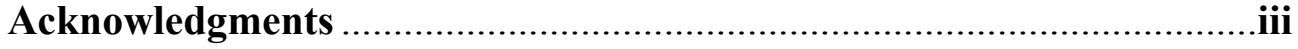

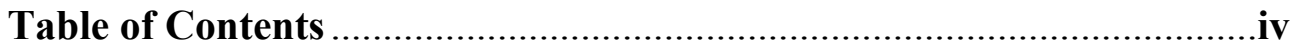

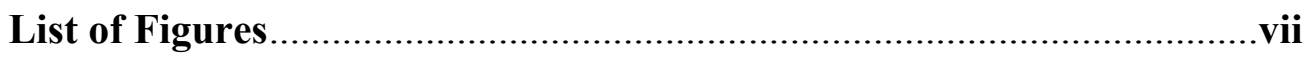

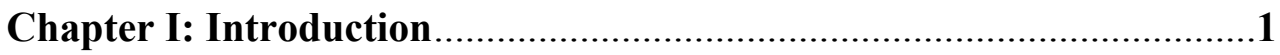

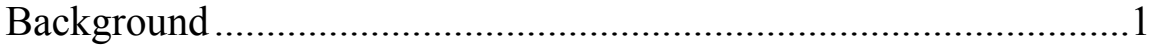

Problem Statement .........................................................................

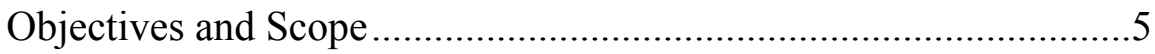

Organization of Report .............................................................6

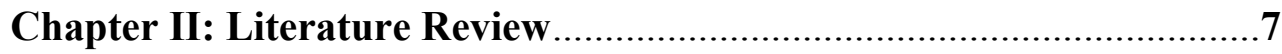

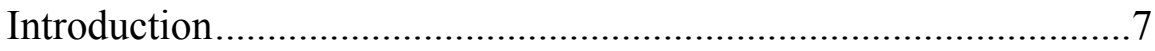

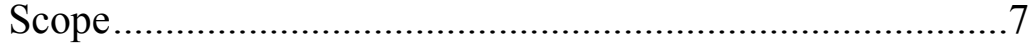

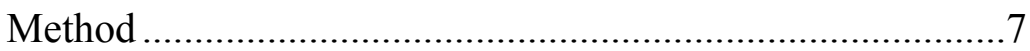

Evolution of Office Development.............................................. 9

Pre-World War II Era Office Buildings...............................10

Post-World War II Office Arrangements............................11

Contemporary Office Park Design.....................................15

Campus-Style Office Parks.....................................16

Free Standing, Independent Office Structures ...........17

Urban Villages .................................................... 18

Transportation Consequences .........................................19

Sustainable Development............................................................20

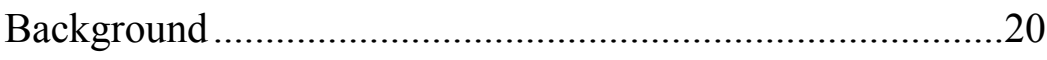

Sustainable Development Concepts.....................................22

Principles of Sustainable Development ...............................24

Create Direct Internal and External Linkages...........25 
Retrofit, Improve, or Create On-Site Features

to Encourage Non-Motorized Transportation.............26

Encourage Compact, Pedestrian-Friendly

Landforms

Create and Maintain a Safe and Secure Walking and Bicycling Environment ........................................28

Encourage Partnerships and Collaborative Efforts

Between All Entities Involved in the Development

Effort. .29

Accommodating Non-Motorized Transportation 31

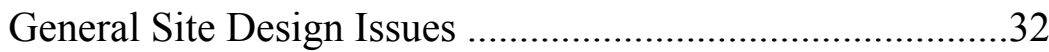

Land Use Planning .......................................................

Community Context......................................................33

Supporting Programs and Policies ...............................34

Site Layout and Pedestrian and Bicycle Site Amenities ........36

Building Location and Shape......................................36

End-of-Trip Pedestrian and Bicyclist

Considerations...............................................................

Elements of Pedestrian Places .....................................38

Landscaping ............................................................40

Site Infrastructure for Vehicular and Non-Motorized

Transportation ..................................................................... 41

Internal Pedestrian and Vehicular Circulation............41

Parking ..................................................................46

Public Transportation / Transit Connections ..............50

Concluding Remarks....................................................................... 51

Chapter III: Preparation of the Guidelines...........................................53

Identification and Organization of the Information ..............................53

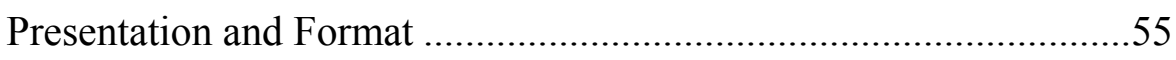

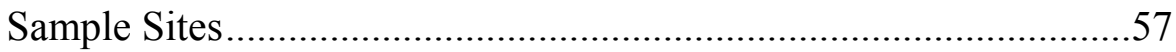




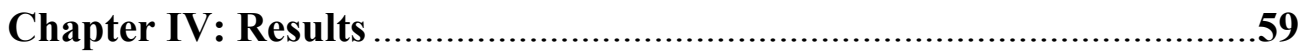

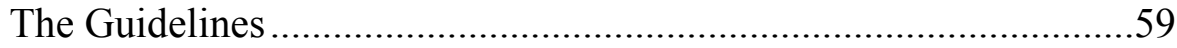

Application of the Guidelines to the Sample Sites .........................60

Sample Site 1: Southpointe .............................................60

Introduction.......................................................6

Discussion of Findings..........................................61

Application of the Guidelines ..................................65

Sample Site 1: Virginia Tech Corporate Research Center.....67

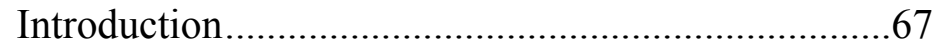

Discussion of Findings........................................68

Application of the Guidelines .................................72

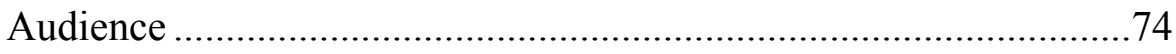

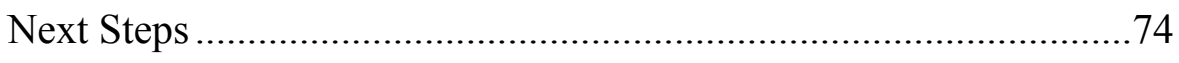

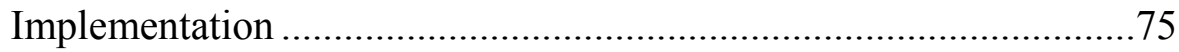

Chapter V: Conclusions and Recommendations ..................................78

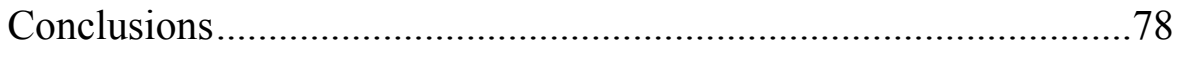

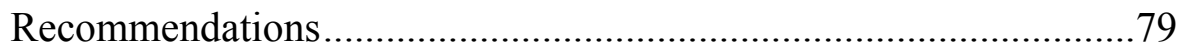

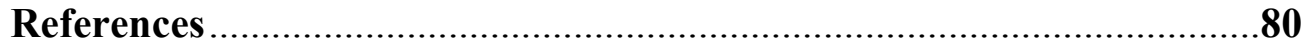

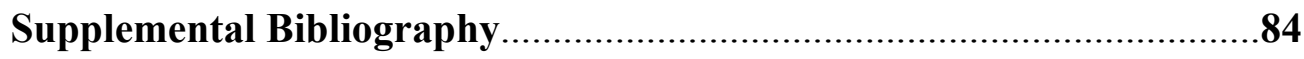

Appendix A: Planning and Design Guidelines for Accommodating

Non-Motorized Transportation in Suburban Office

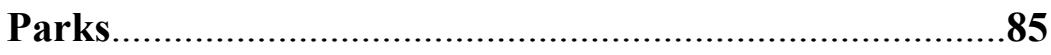

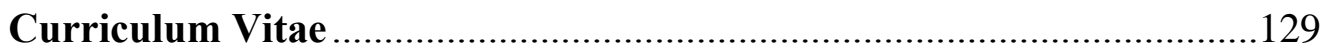




\section{List of Figures}

Figure 1: Concept of Booth's "Wave" Model for Office Development.......13

Figure 2: Sketch of Le Corbusier's Ville Radieuse ....................................17

Figure 3: Steps for Identifying and Organizing Relevant Literature ............54

Figure 4: View from the East Side of Southpointe, Looking West .............61

Figure 5: Complementary Residential Land Uses ...................................62

Figure 6: Pedestrian Amenities .................................................................66

Figure 7: Lack of Pedestrian Accommodations in a Parking Lot................65

Figure 8: Re-Occurring Visual Theme ...............................................67

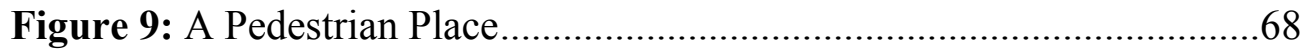

Figure 10: An Improperly Located Bike Rack ........................................69

Figure 11: An Interior Segment of the Shared-Use Trail ...........................70

Figure 12: VTCRC Internal Roadway and Trail Layout ...........................71 


\section{Chapter I: Introduction}

\section{Background}

Suburban office employment centers, or office parks, can be significant contributors to traffic congestion in suburban areas. One of the reasons is that such office parks typically require automobile trips to access them. Automobiles are necessary to reach these office parks given the spatial arrangement of land uses, development densities and distances involved.

Studies have shown (Gruen + Gruen Associates and Urban Land Institute, 1986) that a large percentage of suburban office park employees drive to work alone. Some office park managers have indicated that one hundred percent of their employees travel to and from work by automobile. Robert Cervero (1989a) states that the low-density, single-use character of suburban office centers, or office parks, has compelled many workers to become dependent on their automobiles for accessing work and circulating within such parks.

One of the most common forms of suburban office development is the traditional campus-style office park (Anderson, 1986 and Cervero, 1986). A recent study (Lang, 2003b) showed that most metropolitan rental office space exists in either high-density downtowns or low-density suburban areas, or "edgeless" cities. The study noted recent historical trends in office development that indicate a significant shift from downtown locations to suburban locations over the past several decades.

A study by the Livable Centres Program (2003) indicates that in the Vancouver, British Colombia, Canada, downtown area, the amount of available office space has 
modestly increased from 1990 to 2000, while the vacancy rate for downtown office space has also increased. Conversely, the amount of office space for business parks, which accounts for roughly $30 \%$ of the region's total office supply, has increased by over $400 \%$ during the same time period. This indicates a significant shift from denser urban areas, such as those found in central business districts, to suburban locations. Their report cites cheaper land costs, larger development area for larger buildings, and generous and cheap onsite parking opportunities as several reasons for this shift.

It is apparent, even to casual observers, that office parks have a considerable presence in the suburban office market today. Data suggest that the number of suburban office parks will continue to grow and represent a significant portion of the suburban office market in future years.

This phenomenon can be at least partially attributed to corporate headquarters that were traditionally located in downtown Central Business Districts, many of which are now located within suburban office parks. Miara (2000) states that newly relocated suburban technology parks “... are not the only culprits fueling sprawl, but in a number of U.S. cities there is no denying they are major contributors to it." Further evidence of this office shift can be seen on, or near university campuses. Research parks, technology parks, and biomedical parks are commonly located on, or near university campuses in locations throughout the United States.

Location, infrastructure and site design issues within office campuses affect mode choice. Availability of transit is also a factor. While commuting to and from an office park may present many trip barriers to pedestrians and bicyclists, the design of the office 
park itself can affect the mode used by employees to travel within the park. In many instances, little attention is given to non-motorized modes.

\section{Problem Statement}

Recently, there have been many publications that chronicle suburban sprawl and the associated health risks, pedestrian safety concerns, economic impacts, and transportation consequences. Sprawl can be defined as, "Low density development on the edge of cities and towns, poorly planned, land consumptive, auto-dependent, and designed without respect to its surroundings" (Community Preservation Initiative web site, 2005). In recent years, considerable attention has been focused on problems associated with sprawl. Some examples are:

1. A recent study (McCann and Ewing, 2003) showed a connection between body weight and urban form. People who lived in sprawl areas were likely to weigh more and were more likely to develop hypertension, or high blood pressure, than those who lived in compact areas with mixed land uses and greater utilization of non-motorized transportation. This may be attributed to the lack of opportunities to incorporate physical activities into daily lifestyle due to barriers that sprawl areas typically present. These barriers can include significant distances between destinations, lack of sidewalks and bicycle facilities, high-speed arterial roadways with uncontrolled vehicular access to individual properties, and other elements that are not supportive of walking and biking.

2. Many pedestrians and bicyclists are killed each year. Ernst and McCann (2002) showed a link between land use patterns and pedestrian fatalities per capita. Sprawl areas were identified as having higher per capita pedestrian fatalities. Since many 
new roadways in sprawl areas are designed specifically facilitate the efficient movement of vehicular traffic, pedestrian access and safety are adversely affected. Ernst and McCann's study (2002) showed that dangerous pedestrian environments coincide with areas that possess lower density development patterns; these areas typically include wide, high-speed arterials that do not support walking. Similarly, Litman (2003a) states that rates of walking and cycling tend to be lower in areas that have wide roads with high motor vehicle traffic speeds and volumes.

3. The average American family devotes 19.3 cents of every dollar earned to transportation expenditures (Surface Transportation Policy Project, 2003). However, this proportion can increase, or decrease depending on geographic location and community character. In sprawl areas (e.g., Tampa-St. Petersburg-Clearwater, FL), a household may spend up to 24.6 cents per dollar on transportation. However, in more compact urban regions, families may spend as little as 15.1 cents per dollar on transportation. This may be due to the fact that sprawl areas tend to segregate land uses spatially, requiring an automobile to travel between destinations.

Smart Growth and other sustainable development concepts are an alternative to sprawl land development patterns. The underlying principles of these movements encourage non-motorized transportation and place these modes on equal footing with the automobile. Creating walkable streets, mixing land uses, creating dense and compact development patterns, and arranging communities to foster transit usage are all common characteristics of sustainable development practices.

As a result, there have been best-practice planning and design guidelines written for some of the major land use categories. There are available publications and websites 
that offer design principles for land uses such as residential, commercial, and retail. Commonly, the principles identified in these resources are broad, and can be applied to other types of development to achieve similar desired results. However, one land use for which such guidelines have not been developed is the suburban office park or office campus. Perhaps this is because, with their aesthetically pleasing structures, surrounded by ample green space, they are not viewed in the same light as big box stores or strip development.

However, as noted above, most suburban office parks are auto-dependent land uses generating single-occupant vehicle trips. A logical question is, "Are there ways to encourage non-motorized and public transportation in office complexes by enhancing certain site design features?" What are the design features that currently inhibit nonmotorized and public transportation within office parks? Are there design elements or practices that could be implemented to encourage non-motorized modes of transportation to, from and within suburban office parks? There is, thus, a need to develop guidelines for the accommodation of non-motorized transportation in suburban office parks.

\section{Objectives and Scope}

The overall goal of this work was to develop planning and design guidelines for accommodating non-motorized transportation in suburban office parks. The end product will be a planning and design guide to aid civil engineers, planners, architects, developers, owners, elected officials and others in planning, designing, and retro-fitting suburban office parks to accommodate non-motorized transportation modes within and directly adjacent to the limits of office park property lines.

To meet the overall goal, several specific objectives were identified. 
1. To conduct a comprehensive review of relevant planning, engineering, land development, pedestrian/bicycle, community design, smart growth and sustainable development literature to identify principles and guidelines potentially applicable to the planning and design of suburban office parks.

2. To critically evaluate the published literature to identify specific principles, guidelines and practices applicable to and appropriate for planning and design of suburban office parks to accommodate non-motorized transportation.

3. To synthesize the applicable principles, guidelines and best practices into a document: "Planning and Design Guidelines for Accommodating Non-Motorized Transportation in Suburban Office Parks."

4. To examine several existing office parks to demonstrate the application of the planning and design guidelines.

5. To document the work in the form of a thesis.

\section{Organization of Report}

Chapter 1 has presented background information to the topic, identified the problem and outlined project objectives. Chapter 2 presents the results of the literature review. Chapter 3 describes the process used to develop the design guidelines. Chapter 4 describes the organization and content of the end product, i.e., the design guidelines. Several examples are included, showing application of the design guidelines. Chapter 5 discusses implications of the design guidelines and presents suggestions for implementation. Appendix A contains the design guidelines document. 


\section{Chapter II: Literature Review}

\section{Introduction}

\section{Scope}

The first section of this chapter describes the method used to conduct the literature review. The second section discusses the evolution of office development and its transportation consequences. The shift from pre-World War II office buildings to post-World War II office arrangements is described, along with contemporary office park design. This is followed by a section on "Sustainable Development", which introduces sprawl and its characteristics, i.e., the rationale behind sustainable development concepts. Also discussed in this section are sustainable development concepts/philosophies, such as Smart Growth and New Urbanism. An effort is made to relate their underlying principles to suburban office park design. The fourth section describes specific ways in which nonmotorized transportation is accommodated in office parks. This section reviews the literature used in developing the guidelines. The chapter closes with some concluding remarks.

\section{Method}

The process used for the literature review consists of 5 main parts: 1) development of keyword list, 2) keyword search, 3) review of literature, 4) development of outline, and 5) ongoing literature acquisition. 
The first step was to develop a key word list to locate relevant literature for this research. The list of keywords was used to query search engines. Primary keywords used in the literature search are listed below.

\author{
Business Park \\ Commerce Park \\ Connectivity \\ Edge City \\ Fringe Development \\ Guidelines \\ Industrial Park \\ Infill Development \\ Land Use Density \\ Mixed Use Development \\ Multi-Modal Connections \\ New Urbanism \\ Office Campus \\ Office Complex \\ Office Development
}

\author{
Office Park \\ Parking \\ Pedestrian and Bicycle \\ Pedestrian Linkages \\ Policies \\ Principles \\ Site Design \\ Site Planning \\ Smart Growth \\ Suburb \\ Suburban Business District \\ Suburban Parking \\ Sustainable Development \\ Sustainable Transportation \\ Zoning
}

Each keyword was entered into several search engines to identify relevant

publications. The search engines used were 1) Mountainlynx

(mountainlynx.lib.wvu.edu) - West Virginia University (WVU) library's main search

engine (includes only WVU's library resources), 2) WorldCat (newfirstsearch.oclc.org) a search engine linked to over 20,000-plus college and university libraries in the United States and abroad, 3) TRIS (trisonline.bts.gov) - a search engine specifically related to transportation topics, and 4) Google (www.google.com) - an internet search using the "Google" search engine.

When keywords were entered into these search engines, a large quantity of books, reports, journal and magazine articles, newsletter and newspaper articles, informational pamphlets, internet web sites, and other sources relevant to the topic were identified. While many of the publications identified were not relevant to the topic, all results were 
reviewed and relevant publications were noted. Once relevant publications were identified, they were obtained either via the Internet, through the inter-library loan process, or through WVU's library and reviewed for relevance. Note that the body of available literature addressing office park planning and design with respect to nonmotorized transportation was rather small. There were several journal articles and books that incidentally addressed pedestrian and bicycle accommodations in suburban office parks. However, no publications were identified that presented planning and design guidelines for accommodating non-motorized transportation in suburban office parks.

There was, however, a large quantity of available information that was relevant to the individual design elements involved with accommodating pedestrians and bicycles in site design, i.e., geometric design standards, transit connections, amenities, landscaping and bicycle storage. Such information was reviewed and filed for future use.

After a large portion of the identified literature was reviewed, a topical outline was created to provide a preliminary framework for the guidelines document. While the outline underwent a number of revisions, it was useful in guiding the search for additional literature on the individual topics noted above. For instance, publications that offer guidance on general site design were identified through the keyword search. However, additional information might have been needed for a sub-category of site design, such as landscaping. Additional literature on these sub-categories was sought as needed.

\section{Evolution of Office Development}

In order to gain an understanding of modern day office parks and their design and layout, the evolution of office space during the $20^{\text {th }}$ century must be understood. A 
culmination of noteworthy events led to a shift of office space from downtown business districts (CBD) to metropolitan fringe locations. This chain of events will be discussed in three parts: Pre-World War II Era Office Buildings, Post-World War II Era Office Arrangements, and Contemporary Office Park Design.

\section{Pre-World War II Era Office Buildings}

During the late 1800 s, a new category of worker, the "white collar" worker, began to populate the fringes of town and ride public transit or walk to offices in the CBD. These offices began to grow upward with the advent of the electric elevator and steel frame construction, as opposed to traditional block masonry (Gause, et al., 1998). Structures grew in height in the early twentieth century, and by 1930 the skyscraper was a symbol of modern office construction.

The urban design of this time period accounted for non-motorized modes of transportation. Walking, biking, and public transportation were the commonly utilized transportation modes during this era. Local streets were laid out on a grid pattern with short block lengths. Thus, people biked, walked or took a streetcar to run errands or commute to work. Although the impact was not immediately felt, the advent of the automobile assembly line in 1914 would eventually have far-reaching impacts on mode choice in the years to come (Dewberry Companies, 2002).

By the 1930s, office development came to a relative halt as the effects of the great depression were felt. The depression limited office construction for the next few decades. Most of the office buildings constructed in the 1950's took place in downtown locations in the form of high-rise buildings (White, 1993). Buildings such as the Inland 
Steel Building in Chicago and the Alcoa Building in Pittsburgh typified office buildings of the time.

\section{Post-World War II Era Office Arrangements}

The depression and World War II created a lull in office building construction during the 1930's and 1940's. As a result, after WWII, office space was in short supply and there was a backlog of projects that never got started during this time period. Whitecollar workers filled the available office jobs in downtown areas and the stage was set for a boom of office building (White, 1993).

Suburban (that is, on the metropolitan fringe) office development, as it is known today, came about in the 1960's. The first developments found in suburban locations were single-family residential subdivisions. The Interstate Highway Act of 1956 funded the construction of high-speed freeways that helped to facilitate the efficient movement of vehicles from the residences in suburban locations to the jobs downtown (Gause, et al., 1998). The new highways made it easier for people to live farther from their work and commute into the city via personal automobile (White, 1993). Thus, what had previously been walking, biking, or transit trips to work became single-occupant motor vehicle trips.

This trend marked the beginning of a demographic shift. As automobile ownership increased, the proportion of Americans moving to the earliest established suburban locations increased correspondingly. These earliest suburban locations possessed features common to traditional city downtown areas; there were employment, retail, entertainment and housing opportunities within relatively short distances from each other (Booth, 2001). With the emergence of the earliest suburban locations, families no longer simply lived in the suburbs and commuted to their jobs or retail stores in 
downtown areas. Travel patterns became much more complex as commuters traveled from the suburbs into downtown, and from their suburb to other suburban areas. As travel patterns became increasingly complex and travel distances increased, the feasibility of using public transit in these lower-density areas decreased correspondingly. Infrequent or non-existent transit service resulted in a lack of transit ridership, further perpetuating automobile dependency for many commuters.

By the mid-1960's, suburban office arrangements were appearing in and outside of the first suburban locations. Much of the new suburban office development grew in clusters along interstate highways, and frequently concentrated near highway interchanges (Booth, 2001). These suburban office locations appeared to offer many advantages over their CBD counterparts. Among the perceived advantages were (Booth, 2001): lower land and construction costs; liberal zoning ordinances and development incentives; opportunities for ample parking, and spacious, campus-like settings.

The advent of better communication technologies such as fax machines, teleconferencing, and email made face-to-face meetings less essential for businesses. During the first half of the $20^{\text {th }}$ century, businesses preferred locations downtown so they could be near other offices (Booth, 2001). Now businesses could be more geographically isolated, while maintaining communication with their clients and other businesses. Also during this time, technology advancements such as interior illumination and advances in HVAC technology permitted the construction of larger, more open floor plans as found in many suburban offices. Thus, buildings could stretch horizontally, instead of vertically, like the high-rise office towers of the early $20^{\text {th }}$ Century. 
The dispersion of employment centers over the past 40 years can be described by Booth's (2001) wave theory as illustrated in Figure 1. The first tier suburbs, or the first "wave" in a progressive series that concentrically spread farther outward from downtown, spread from CBD areas into outlying metropolitan regions. In theory, the first wave began in 1960, and ended in 1970. The next three waves occurred in concentric circles throughout the next three decades (1970 to 1980, 1980 to 1990, and 1990 to present day, respectively). During each successive wave period, offices became more spatially dispersed and low-density office arrangements became more common. Note in Figure 1 how in each successive wave of office development, buildings become more scattered, with small office agglomerations and office park land patterns.

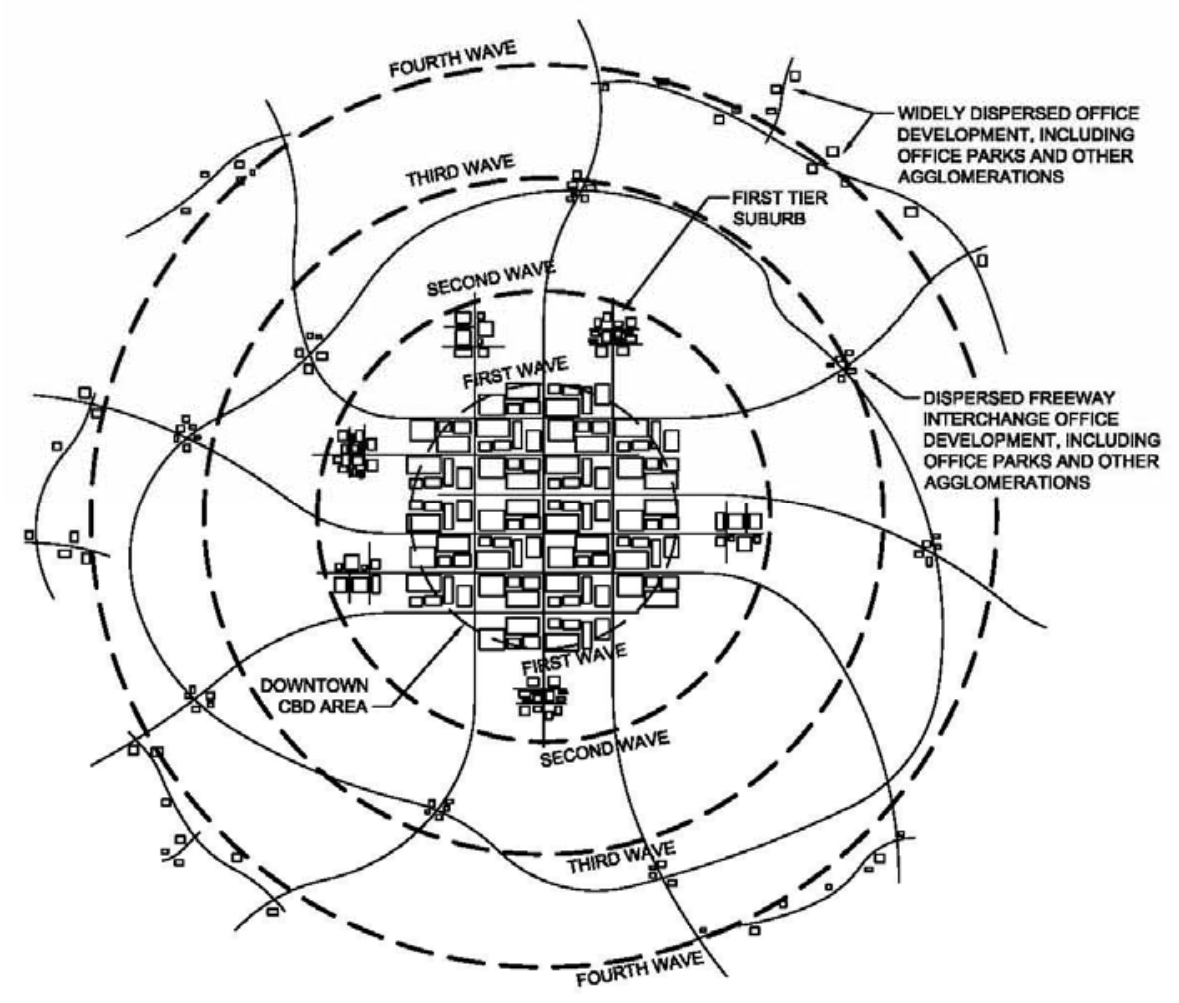

Figure 1: Concept of Booth's Wave Model for Office Development

Adapted from Transforming Suburban Districts (Booth, 2001). Each dashed line represents a different time period and its respective development pattern. 
The third wave, during the 1980's, has allegedly had the most notable impact on suburban traffic congestion and automobile dependency. Cervero (1989a) describes the third wave as such:

The migration of traffic jams to the suburbs has followed in the wake of what some have called America's "third wave" of suburbanization... The third wave of suburban expansion - the arrival of workers, particularly those in the office and high-technology sectors - has brought many American suburbs full circle ...Attracted by cheaper land, closer proximity to regional airports, smart buildings laced with fiber optic cables and advanced telecommunications equipment, and country-like amenities, the overwhelming majority of the nation's high-technology firms today have chosen a suburban address.

Similarly, Lang (2003b) performed research on office space in 13 metropolitan regions, to examine "metropolitan change" and analyze metropolitan form, in terms of office development. While his study does not follow the chronological grouping (as were Booth's “waves"), his study does demonstrate how offices have evolved and migrated from downtown CBD locations, to office parks and speculative, freestanding buildings and other arrangements near the metropolitan periphery.

Lang (2003b) describes four categories of office space location: 1) Primary Downtown, 2) Secondary Downtown, 3) Edge City, and 4) Edgeless City. These categories were primarily organized by "office density". High densities and compact landforms, such as those found in CBD areas characterize the former, while "very low" densities and widely dispersed office park landforms and other arrangements found at the metropolitan edge characterize the latter. The wave theory and Lang's (2003b) account 
of the four office location categories demonstrate how office parks, and similar dispersed office building agglomerations found in present-day suburbia, shifted from compact and dense downtown CBD areas.

Similar to Lang's (2003b) research, the Livable Centres Program (2003) identified a growing office shift from downtown locations to suburban office park locations. Their work indicates that office space for business parks accounts for roughly $30 \%$ of the region's total office space supply. This in itself is not as profound as the fact that this number has increased by over $400 \%$ from 1990 to 2000 . In contrast, downtown locations experienced only a modest increase in office supply, with an increasing vacancy rate during the same time period. This indicates a significant shift from sustainable land patterns, such as those found in central business districts, to less-sustainable suburban locations. This report cites cheaper land costs, larger development area for larger buildings, and generous and cheap on-site parking opportunities as several reasons for this shift.

\section{Contemporary Office Park Design}

Not all suburban office buildings found in outlying metropolitan regions are located within office parks. The relative proportion of office space found in free-standing office buildings, as opposed to office parks, business parks, office centers, or other cluster of office buildings, is not known. However, the office park is a common form of suburban office development.

Suburban office parks vary in form. Although a number of factors, including topography, climate, geographic area, community context, and recent development trends and styles affect an office park's form, three different categories of office parks have 
been identified. Cervero (1986) and Anderson (1986) identify three main categories of office park land development forms: 1) Campus-Style Office Parks, 2) Freestanding, Independent Office Structures, and 3) Urban Villages.

\section{Campus-Style Office Parks}

The most predominant form of suburban office park is the traditional campusstyle. This form of office park originated in the 1950's when construction of the Interstate Highway system accelerated a significant demographic shift to the suburbs. Cervero (1986) and Anderson (1986) indicate that campus-style office parks are generally situated on large sites, ranging in size from tens-of-acres up to as much as one thousand acres of land. These office parks are usually located near freeway interchanges for easy vehicular access and situated for maximum visual exposure from adjacent roadways.

As an alternative to working in a $\mathrm{CBD}$, workers were drawn to office park locations by abundant landscaping and green space. The large amounts of green space typically drive floor-area ratios (FAR) of office parks below 0.45 (Cervero, 1989b). In conjunction with low FARs, campus-style developments are usually comprised of buildings that are low to mid-rise. This further reduces the land use density for this type of development. These low densities limit opportunities for public transportation. Cervero (1989a) indicates that retail land uses within most campus-style office parks are typically less than 10 percent of the space designated to commercial office land use.

The overall office park site is commonly made up of individual parcels of land that can be developed autonomously from adjoining parcels. That is, each parcel usually has its own building and a surface parking lot served by a driveway or access road from 
the main site access road. Generally, the main site access road is either a loop or cul-desac street that branches off of a public right-of-way (Cervero, 1986; Anderson, 1986).

\section{Freestanding, Independent Office Structures}

In contrast to the traditional campus-style office park, some office clusters are arranged as freestanding, independent structures, also known as office centers and concentrations (Cervero, 1989a) as shown in Figure 2. Patterned after LeCorbusier's planning model named Ville Radieuse, or "Radiant City" (Barnett, 2003), this form of office development positions individual mid to high-rise office buildings in the center of parking lots. This form of office development is a hybrid of the "office park" and "largescale office corridor" groupings (Cervero, 1989a). Unlike campus-style office parks, this type of office building configuration is better suited for less-spacious strips of land.

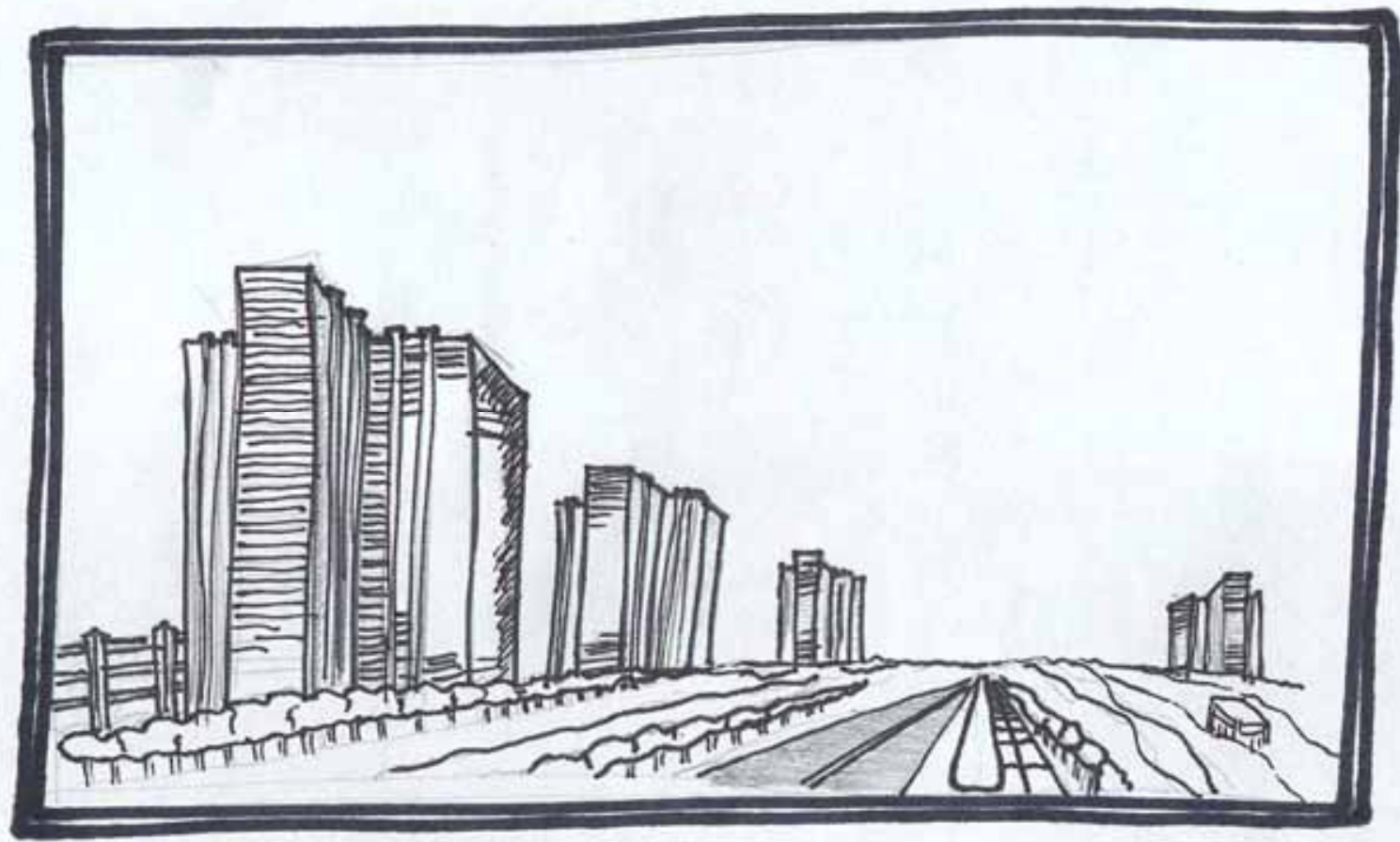

Figure 2: Sketch of Le Corbusier's Ville Radieuse

A sketch of Le Corbusier's Ville Radieuse adapted from Sustainable Communities (Van der Ryn and Calthorpe, 1986). 
Similar to the campus-style office park, freestanding office structures are commonly located along public right-of-way corridors, and can typically be found in non-CBD areas, in close proximity to regional airports (Cervero, 1986).

The space that separates these office towers is usually filled by surface parking lots. However, the greater densities offered by the taller buildings may possibly warrant a portion of the parking to be located within a parking structure(s) in urbanized areas. Generally speaking, freestanding office structures lack the generous amount of on-site landscaping common to the campus-style office parks (Anderson, 1986).

\section{Urban Villages}

Urban Villages are defined as mixed use development having over five million square feet of office and commercial floor space, and over ten thousand workers (Cervero, 1989a, 1989b). Also, they commonly have a significant portion of high-rise and high-density office towers (from 15-plus stories in height), and at least 10 percent of the total floor space dedicated to retail and commercial land uses. Urban Villages are often located near indoor shopping malls and/or convention centers.

Cervero $(1986,1989 a, 1989 b)$ indicates that urban villages, sub-cities, megacenters, satellite cities, or suburban business districts (Booth, 2001), are a form of office development gaining in popularity in some suburban locations. These upscale suburban areas are predominantly composed of office buildings, but are combined with hotels, eating establishments, convention centers, health clubs, enclosed shopping malls and other land uses. Urban Villages are mixed-use in character and have higher densities than most other forms of suburban office development. However, they commonly retain 
suburban qualities, such as large property offsets, contemporary suburban building facades, and abundant parking (Cervero 1989b).

\section{Transportation Consequences}

During the latter half of the $20^{\text {th }}$ Century, America experienced a shift in office space location from downtown central business district locations, to locations on the outlying metropolitan fringes. Most downtown locations are accessible by nonmotorized transportation and transit. That is, people can relatively easily walk or bike to a variety of nearby destinations within a CBD.

Conversely, office parks and other suburban office building arrangements usually do not easily accommodate non-motorized transportation. One of the main reasons that suburban office parks are less conducive to non-motorized travel is their design, layout, and location. Cervero (1989a) states that the land use pattern of many suburban employment centers is "inescapably linked" to congestion problems and declining mobility found in modern-day suburbs. He also states that the low-density, single-use, and non-integrated character of many suburban office/commercial centers and corridors necessitates that workers depend on the automobile to reach their work place. Lang (2000, 2003a) states that office space constructed at the metropolitan fringe extends commuter sheds for many miles into undeveloped rural area and fuels decentralization.

Low-density office parks with little or no transit access, and no sidewalk connections outside of the development forces people to drive (US Environmental Protection Agency and Local Government Commission, 2003). Thus, the layout of roads, sidewalks (or lack of sidewalks), and parking areas, can influence whether a nonmotorized mode of transportation is a realistic travel option. In other words, site design 
features can either encourage or discourage non-motorized transportation modes from accessing and traveling within suburban office parks (Anderson, 1986).

A study conducted by Gruen + Gruen Associates and the Urban Land Institute (1986) highlights the automobile-dependency of suburban office parks. This study showed that, on average, 93 percent of employees in a large number of suburban office parks drive to work in an automobile. Also, one half of the office park sites studied indicated that 99 percent of employees drive to work alone. A report by the Livable Centres Program (2003) showed similar data for office parks located in the Greater Vancouver (Canada) Area. The report indicated that 92 percent of employees in office parks commuted to work by automobile, while 5 percent used transit, and 3 percent commuted by walking or biking.

\section{Sustainable Development}

\section{Background}

The Sprawl Watch Clearing House (2004) defines sprawl as dispersed, automobile-dependent development found mostly outside of urban downtown areas, compact urban and village centers, along highways, and in rural countryside. Attributes of sprawl include: low land use densities (compared with compact urban areas), fragmented open space, separation of land uses into distinct categories separated by great distances and indirect paths, repetitive one-story building construction surrounded by large amounts of surface parking, and a lack of public spaces and community centers.

Duany, Plater-Zyberk, and Speck (2000) cite office and business parks, along with housing subdivisions, shopping centers, civic institutions, and modern roadways, as 
one of the "five major components of sprawl", although the latter are more commonly associated with sprawl. Miara (2000) concurs, stating that suburban office park campuses are not the only factor contributing to sprawl, but in a number of U.S. cities they are major contributors to it. He uses examples from the suburban areas of Seattle (WA), Washington DC (and Northern Virginia area), Austin (TX), New York City, and other areas to demonstrate how the increase in the number of suburban office parks has contributed to vehicular congestion and other problems associated with sprawl.

Problems associated with sprawl landforms include automobile dependency, adverse economic and social consequences, and negative health effects. These problems are briefly discussed in the next few paragraphs.

Sprawl landforms are automobile dependent due to widely separated, segregated land uses with limited travel alternatives. This type of environment creates barriers to walking, since separated land uses increase travel distances, making it difficult for pedestrians and bicycles to overcome these distances. Ernst and McCann (2002) concur, showing in a study that the most dangerous pedestrian environments coincide with areas that possess lower density development patterns and have many wide, high-speed arterials. Since automobiles dominate, wide roads and large surface parking lots characterize sprawl areas. Brooks (1988) indicates that surface parking lots are some of the most "dangerous and hostile" locations for pedestrian movement.

Sprawl also perpetuates automobile dependency. Ewing, Pendall, and Chen (2002), conducted a study illustrating a comparison between the "most sprawl" and "least sprawl" areas, with the former having higher average distances driven per day and higher average household vehicle ownership, along with a smaller percentage of transit 
commuter trips. Somewhat related, studies have shown that sprawl has also been linked to negative health consequences and reduced pedestrian and bicyclist safety. McCann and Ewing (2003) found that people in counties where sprawl predominated walked less for exercise and typically weighed more than those living in the counties with fewer characteristics of sprawl.

There are direct economic impacts associated with sprawl. One such direct cost comes in the form of increased annual transportation expenditures for people living in sprawl areas. According to one source (Surface Transportation Policy Project, 2003), the average American family devotes 19.3 cents of every dollar earned to transportation expenditures. However, this proportion can increase or decrease depending on geographic location and community character. In sprawl areas (e.g., Tampa-St. Petersburg-Clearwater, FL), a household may spend up to 24.6 cents per dollar on transportation. However, in areas with fewer sprawl characteristics, families may spend as little as 15.1 cents per dollar on transportation expenditures.

\section{Sustainable Development Concepts}

Porter and Platt (2000) describes "sustainable development" as change, growth, or expansion that is meant to endure and withstand time. Several sustainable growth concepts have been recently been developed as an alternative to, and to counteract the effects of sprawl-type development. Two well-known concepts are Smart Growth and New Urbanism.

While both of these concepts are similar in the fact that they encourage sustainable land development and transportation patterns, they differ slightly. New Urbanism is more of a design reform that follows "traditional" urban design principles to 
create features similar to the "human-scaled" towns and cities of the early $20^{\text {th }}$ Century. Smart Growth is more all-encompassing, and primarily focused on how to make decisions and supporting policies that encourage sustainable development. Smart Growth's principles are compatible with the principles of New Urbanism.

In general, Smart Growth principles are an alternative development model to conventional suburban sprawl land patterns (Litman, 2003b). Smart Growth principles integrate transportation and land use decisions, with the intent of encouraging more compact, attractive, livable communities where pedestrians, bicycles, and various forms of transit are viable forms of transportation. This concept encourages more complete suburban communities, and improved regional travel options such as ridesharing and transit (VTPI web site, 2004a).

While obviously related, in contrast, New Urbanism seeks to reform the design of the built environment to raise the quality of life and standard of living by creating better places to live (Congress for New Urbanism, 2004). New Urbanism promotes the creation of diverse, walkable, compact, vibrant, and mixed-use communities composed by elements of conventional development, but assembled in a more integrated fashion, in the form of complete communities. New Urbanism is based on urban design principles, that is, compact, human-scaled places with urban design features. These design features usually entail the creation of small open spaces placed among dense building clusters, ample amenities (such as benches, fountains, and trash receptacles), and a strong emphasis on architectural detailing. 


\section{Principles of Sustainable Development}

There are numerous publications that present principles of sustainable development. Because of differing philosophies and missions, there is some variation in principles between different groups, organizations, and authors. However, certain underlying principles are common to most publications. The Smart Growth Network (2002 and 2003) presents a representative list, with respect to non-motorized transportation issues. These principles are: 1) mix land uses, 2) take advantage of compact building design, 3) create a range of housing opportunities and choices, 4) create walkable communities, 5) foster distinctive, attractive communities with a strong sense of place, 6) preserve open space, farmland, natural beauty, and critical environmental areas, 7) strengthen existing communities, 8) provide a variety of transportation options, 9) make development decisions predictable, fair, and cost effective, and 10) encourage community and stakeholder collaboration in development decisions (Smart Growth Network, 2002 and 2003).

While the above principles are applicable to all land uses, some of them are rather broad in that they relate to development generally. Since this work focused on nonmotorized transportation in suburban office parks, the list was revised to create a limited number of principles that specifically relate to that topic, namely: 1) create direct internal and external linkages, 2) retrofit, improve, or create on-site design features to encourage non-motorized transportation, 3) encourage compact, pedestrian-friendly landforms, 4) create a safe and secure walking and bicycling environment, and 5) encourage partnerships and collaborative efforts between all entities involved in the development effort. 


\section{Create Direct Internal and External Linkages}

The presence of linkages and sidewalks are essential when planning for nonmotorized transportation. ITE's Smart Growth Task Force (2003) notes that continuity and interconnectedness are important principles of planning for pedestrian and bicycle transportation. The layout of internal street networks within suburban office parks is important. A grid with short block lengths is the most desirable street network, since long blocks lengths can discourage walking and bicycling (Ewing, 1999; ITE Smart Growth Task Force, 2003). Burden (2001) indicates that block lengths should range from 400 feet to 600 feet, however this may be difficult in suburban office park settings due to large land parcel sizes. The grid internal road network facilitates direct linkages between internal destinations and roadways, which makes this configuration conducive to nonmotorized travel, since pedestrians and bicyclists are more sensitive to distance than automobiles.

Brooks (1988) notes that barring a physical barrier, or a perceived threat to personal safety, pedestrians will always try to minimize the distance from their origin to their destination. With this in mind, measures should be taken to link suburban office parks with the surrounding community and to connect destinations within the site. Installing sidewalks or connecting missing links in sidewalk networks is an obvious place to start. Shared use paths may provide convenient linkages between an office park and nearby residential development. Bicycle lanes can be designated on perimeter roads. Destinations within office parks should also be well-connected. Linking internal land uses with sidewalks, trails and paths promotes walking and bicycling within the site. This may help to capture trips that would otherwise be made by automobile. Also, well- 
located transit connections and well-designed drop-off/pick-up areas encourage transit ridership.

\section{Retrofit, Improve, or Create On-Site Features to Encourage Non-Motorized Transportation}

Just as it is important to create internal and external linkages, it is also important to supplement linkages with design features that enhance, or encourage non-motorized transportation to and within the site. As the Smart Growth Network (2002) notes, the presence of sidewalks by themselves will not induce walking; there should be supporting amenities and public open spaces to complement the walking environment. Consideration should be given to creating pocket parks or plazas, with amenities such as outdoor seating, tables, trash receptacles, and other supporting street furniture.

Also, end-of-trip pedestrian and bicycle accommodations should be considered. Elements such as bicycle storage, showers, lockers, and change facilities encourage using non-motorized, or active, modes of transportation for commuting and/or for exercise (VTPI, 2004b). Placing these amenities at trip ends helps to promote an active lifestyle, while a lack of these facilities poses a barrier to non-motorized transportation.

FHWA (undated) notes that the presence of pedestrian places, with complementary pedestrian amenities is an important part of encouraging non-motorized transportation. Equally important is the scale of the pedestrian place. Instead of creating a large, open plaza, FHWA suggests that plazas be relatively small (2,500 square feet or less) to allow social interaction and slight "crowding" of pedestrians. Public gathering places should also be at grade or slightly above it, as it is a natural tendency of people not to convene in below grade areas. Other desirable attributes of pedestrian places are: 
adequate lighting; protection from elements, direct sunlight and wind; and clear sightlines for personal security.

\section{Encourage Compact, Pedestrian-Friendly Landforms}

Typically, suburban office parks range from tens-of-acres to hundreds-of-acres in size (Cervero, 1986 and 1989a). This, along with the absence of supporting land uses within the park, discourages people from using sustainable transportation to walk or bike, during employee break periods, to nearby destinations. As a result, employees are forced to use personal automobiles to get lunch or run errands.

Providing a mix of land uses on-site is a way of capturing these trips. Arranging complementary land uses along with commercial office land uses in a compact, urban form, brings these destinations closer to one another, thereby making walking and bicycling more feasible and attractive alternatives for internal trips. Holtzclaw (undated) notes that walking trips account for only 3 to 8 percent of all mid-day trips. However, in pedestrian-accessible mixed-use centers (or commercial offices combined with retail and other complementary land uses) walking increases to 20 - 30 percent of mid-day trips.

The Smart Growth Network (2003) makes a specific reference to suburban office parks, calling for more compact landforms. The publication lists negative implications of developing low-density, homogenous, campus-style suburban office parks: job/housing imbalance, increased vehicular congestion, and a lack of nearby amenities for lunchtime errands. The publication notes that constructing mixed-use town centers (such as Legacy Town Center in Plano, Texas, or The Reston Town Center in Reston, Virginia) in close proximity to, or on-site can help encourage pedestrian and bicycle travel in suburban office parks. 
In addition to supporting transit ridership, the EPA and Local Government Commission (2003) note that density is a key element of creating more compact, pedestrian-friendly suburban office parks. Denser building clusters helps to draw destinations closer to one another, making a more inviting environment for walking and bicycling. Additionally, land use density and arranging buildings in dense clusters helps to support on-site land uses by providing a nearby market for convenience stores, restaurants, and other complementary land uses.

\section{Create and Maintain a Safe and Secure Walking and Bicycling Environment}

The Canadian Institute of Transportation Engineers (2003) notes that safety and security ultimately influence whether people will choose non-motorized modes. Although safety and security both imply protection from bodily harm, they have two different meanings.

Safety implies protection from moving vehicles, fixed objects, falling objects, and hazardous surfaces. Pedestrians and bicyclists appreciate design features that reduce the chance of being struck by an automobile. Pedestrian facilities that are separated from vehicular traffic, and bicycle facilities that permit bicyclists to travel and maneuver without conflicts with automobiles, encourage non-motorized transportation.

Other design features such as surface condition are important (FHWA, undated). If a walkway, or any other surface where pedestrians travel is improperly designed or maintained, it may pose a threat for a slip or trip-type fall. Likewise, the traveled surface for bicycle facilities must be designed to eliminate dangerous drainage grates, speed bumps, or other surface hazards that could cause a bicycle crash. 
Security implies protection or freedom from fear or doubt (Canadian Institute of Transportation Engineers, 2003). Pedestrians are not likely to travel by foot or bicycle in environments that they feel uneasy, or have fear for their personal security or for being harmed by a person, animal, or some other threat. For example, lush landscaping around office buildings may appear to be inviting surroundings for a pedestrian during the day, but by night the same place may not seem as inviting. Large spatial separation between buildings, large parking lots, dense landscaping, and low lighting can create locations (or at least the perception of) where those with criminal motives can wait for their victims. If a pedestrian has concerns about the security of an area, they may opt for a motorized mode rather than a non-motorized mode.

Thus, maintaining adequate lighting levels and having good visibility to and from walkways can help to create a more secure pedestrian environment. There are other design features that increase security levels. Designing an environment that is inviting to pedestrians may actually increase perceived security levels. The Smart Growth Network (2002) states that including a variety of complementary land uses that have facades with window and door penetrations can help to stimulate pedestrian activity throughout the day and into the night by placing "eyes on the street".

\section{Encourage Partnerships and Collaborative Efforts Between All Entities Involved in the Development Effort}

Large-scale developments such as office parks require partnerships and collaborative effort from a wide array of public and private entities. While this is generally true with any type of large project, it is especially important when making provisions for non-motorized modes of transportation. Lack of coordination and vision can create disconnect when incorporating a large-scale office development into a 
community. Important design details such as building placement, parking layout, sidewalk placement, and linkages to adjacent destinations may be overlooked if the governing entity (public) places little or no emphasis on these issues. Likewise, owners/developers and those who are responsible for the design and layout of office parks (private) should be conscious of the impacts that these large-scale developments have on communities, and strive for excellence in planning, designing, and building.

Booth, Leonard, and Pawlukiewicz (2002) indicate that there must be cooperation from three main components when striving to create sustainable landforms in suburban areas. These are the private sector, local government, and community. This three-way partnership should be built on a foundation of shared goals and should include a fair and open process that allows all parties to be heard before decisions are made and implemented.

Similarly the Federal Highway Administration (2005) notes that successful partnerships can help link transportation and community in many ways. The formation of partnerships can help build consensus by bringing together groups with different viewpoints to discuss common visions and solutions. To work together effectively, partners should share a common vision for and commitment to the partnership. Organizations must learn how to work with and communicate with one-another (Creech and Willard, 2002). For communities discussing alternative transportation and land development scenarios, outreach to developers, financial institutions, and real estate professionals is critical. Partnerships with these groups will help educate all parties about the impacts of various development patterns and potential alternatives to existing patterns. At the same time, partnerships help planners, engineers, and other technical 
personnel understand issues from the viewpoint of those who are directly responsible for land development.

It is apparent that many people play a role in developing a multi-modal office park. For instance, an area that does not provide a clear vision for the type of development that is desired is likely to experience un-sustainable growth. By contrast, an area that provides a clear vision for the development that is desired in their community gives developers/owners, engineers, architects, and planners clear direction. Thus, it is imperative that community planning initiatives and engineering design efforts work handin-hand to coordinate transportation and growth to achieve sustainable development landforms.

\section{Accommodating Non-Motorized Transportation}

Sustainable development principles support, or serve as a framework, but do not offer specific design guidance on how to accommodate non-motorized transportation in suburban office parks. While the principles offer general direction in terms of a design philosophy, a planner, engineer, or developer needs more detailed guidance in order to implement the principles. Thus, the following sections review the key publications that were used in formulating the planning and design guidelines for suburban office parks. They are organized using the same major headings as the guidelines: 1) General Site Design Issues, 2) Site Layout and Pedestrian and Bicycle Site Amenities, and 3) Site Infrastructure for Vehicular and Non-Motorized Transportation. 


\section{General Site Design Issues}

This section discusses overarching land use considerations such as mixing land uses, land use densities, and supporting programs and policies. Also discussed is community context, or how office parks can be designed to better fit into the surrounding community. This section is less-detail oriented (i.e., written on a macro-level) than the following two sections, which focus on design specifics.

\section{Land Use Planning}

Several references provided information about mixing land uses and promoting higher densities in office parks. Two publications, Office Development Handbook (Gause, et al., 1998) and Business Park and Industrial Development Handbook, (Frej, et al., 2001) both offer information about mixing uses in suburban office and business parks. Of particular interest in each handbook are examples of how existing suburban office parks include complementary retail, commercial, and residential land uses to create a more complete and sustainable development. They also note that complementary activities within office buildings, such as cafeterias, gymnasia, day-care facilities, and recreation centers, help employees accomplish activities that would otherwise require mid-day or other travel by automobile.

Although the Smart Growth Network (2002 and 2003) does not address mixing land uses within office parks specifically, they present general considerations for mixing land uses to achieve more sustainable development. They note that providing housing near employment centers (such as suburban office parks) helps to encourage a job/housing balance that eliminates or reduces automobile travel, and encourages nonmotorized travel for commuting. They also encourage complementary retail and 
commercial land uses such as shops, restaurants, and service-oriented land uses, on the ground floor of buildings, with commercial offices on upper floors. Doing this places land uses that stimulate pedestrian activity at street level.

Schwanke, et al. (2003) provides general information about mixing uses, and specifically addresses mixing land uses in and around office parks. In $\underline{\text { Mixed-Use }}$ Development Handbook, he states that office and business parks are good locations for mixed-use activity centers because they usually lack a central focal point or pedestrian and bicycle accommodations and amenities. Schwanke, et al. (2003) give examples of how several conventional suburban office parks have added mixed-use town centers to create a more vibrant pedestrian environment. One of these is the Legacy Town Center at Legacy, an office park in Plano, Texas.

Cervero (1986) addresses mixing land uses and clustering buildings for a denser arrangement in his publication Suburban Gridlock. He states that many conventional suburban office parks are subdivided into parcels and sold to individual tenants. Thus, many conventional office parks are inwardly focused, without much consideration to adjacent land parcels. He calls for a denser clustering of office buildings with mixed uses within and among office buildings to reduce vehicular trips at lunchtime and to create a more pedestrian friendly environment. He states that if multi-and single-family housing is integrated into areas directly adjacent to and on the site, then it will be more likely that sustainable (non-motorized) modes of transportation will be used for commuting.

\section{Community Context}

The Smart Growth Network (2002 and 2003) addresses community context issues. To establish a sense of identity or continuity within large commercial 
developments (such as an office park), as well as relate to the community, they recommend using design features such as re-occurring visual cues, or themes.

The Congress for New Urbanism (2001) presents information about infill development for commercial developments to enhance community context. They identify large underutilized commercial areas such as old shopping malls and industrial sites as desirable areas to encourage the creation of new commercial development, such as a business park with a mixed-use town center, containing retail and other complementary land uses. Additionally, Gause, et al. (1998) note that opportunities to create infill projects on abandoned commercial and industrial properties, or "greyfield" projects, can be beneficial to developers since much of the access road and utility infrastructure is already in place to accommodate a large office park.

\section{Supporting Programs and Policies}

Cervero (1986) addresses programs such as transportation demand management (TDM) strategies and transportation management associations (TMA). He discusses TDM strategies such as ridesharing, flextime, and cycling programs. He also discusses TMAs, or groups of employers that participate in rideshare matching programs, finance transportation improvements, sponsor internal shuttle services, and other strategies to reduce single-occupant vehicle trips. Lastly, he discusses more controversial policy issues such as trip reduction requirements, traffic impact fees, and parking reductions, which are most applicable to office parks in large metropolitan ares.

Parking Alternatives: Making Way for Urban Infill and Brownfields Redevelopment (US Environmental Protection Agency, 1999) is a collection of guidelines that concentrates on parking management and reduction techniques mostly for 
Infill and Brownfield types of development. However, these guidelines are applicable to suburban office parks. Trip reduction programs, shared parking, in-lieu fees, and shuttle services from a central parking facility are discussed.

Litman (2000) discusses the costs of minimum parking requirements, in terms of over-supply/under-usage that is prevalent in suburban development. Strategies for reducing parking demand, such as: shared parking, TMAs, maximum parking ratios (versus the common suburban practice of requiring minimum parking ratios), and paid parking/cash out parking (paid parking - having to pay a fee to use a parking space, cashout parking - refunding of the parking fee if a person does not drive an automobile to work).

In addition to the aforementioned policy issues, developing a comprehensive plan that addresses non-motorized transportation in office parks is another way to encourage sustainable transportation for commuting to and travel within suburban office parks. A comprehensive plan is a tool used by an area (e.g., a town, county, city) to give direction for future infrastructure improvements and development directives (e.g. identifies needed transportation improvements and projects, gives a framework for where and what type of new development is desired in a particular area).

Prince William County, located in the rapidly growing Northern Virginia area, specifically addresses office development in its Comprehensive Plan. The Comprehensive Plan's “Community Design Plan" section includes a supplement titled Illustrative Design Guidelines for Office Development (Prince William County Comprehensive Plan, 2004). This document gives illustrations of site planning techniques for stand-alone offices, as well as office parks. The guide encourages 
sustainable land forms that mix land uses and cluster buildings, and encourages providing infrastructure (e.g. sidewalks, shared-use paths, greenways, etc.) to accommodate pedestrian and bicycle transportation.

\section{Site Layout and Pedestrian and Bicycle Site Amenities}

Unlike the discussion of general site design issues, this section addresses more detailed design issues. Although it does not directly deal with the design of pedestrian and bicycle facilities, it does deal with elements that support and encourage pedestrian and bicycle circulation. Issues such as building location and shape are discussed, along with end-of-trip pedestrian facilities, the elements of pedestrian places, and landscaping considerations.

\section{Building Location and Shape}

Building massing involves breaking building exteriors up into various geometric shapes to avoid "boxy" buildings. Creating setbacks entails stepping a building's upper floors back to create a less-intimidating and boxy building, while letting in sunlight and decreasing shadows near the building. Both techniques are intended to create a more pedestrian-friendly environment.

Several publications discuss building location and shape, as they relate to accommodating non-motorized transportation. Ewing (1999), Frej, et al. (2001), Gause, et al. (1998), and the Oregon Transportation and Growth Management Program (undated) address building placement relative to adjacent streets. They recommend that buildings be placed near the street, with parking in the rear, to create a pedestrian-friendly streetscape. Ewing (1999) presents findings from various urban design authors that indicate that the ideal building height to street width ratio is $1: 3$. This simply means that 
building heights should be no less that $1 / 3$ of the road width, thus creating a sense of enclosure for the streetscape.

The Canadian Institute of Transportation Engineers (2003) discusses building entrance placement relative to pedestrian desire lines. They state that building entrances should be placed to correspond with desired pedestrian routes. They suggest using building massing techniques and landscaping features at building access points to give visual cues to pedestrians about the location of the entrance. They recommend that passenger pick-up/drop-off areas be placed 'downstream' from a building's main entrance, thereby minimizing conflicts with pedestrians trying to access the building.

Stover and Koepke (2002) also discuss building entrances and passenger pickup/drop-off areas. They concur with Canadian ITE in that passenger pick-up/drop-off areas should be placed 'downstream' from a building's main entrance. Similar to the Canadian ITE, they give illustrations of best practices for passenger pick-up/drop-off areas, but provide more detail on the topic of pedestrian desire lines to building entrances.

\section{End-of-Trip Pedestrian and Bicyclist Considerations}

The Victoria Transport Policy Institute (VTPI, 2004b) defines end-of-trip facilities as bicycle parking areas and shower/change rooms. The VTPI Online TDM Encyclopedia offers design guidance for bicycle parking, including spacing and location considerations, bicycle rack selection considerations, and minimum dimension that provide adequate clearances. Two other publications that offer design guidance for bicycle parking and end-of-trip facilities are the Bicycle Parking Guidelines (Association of Pedestrian and Bicycle Professionals, 2002) and the City of Portland Office of Transportation Bicycle Parking Facilities Guidelines (City of Portland, 2004). Similar to 
the VTPI Online TDM Encyclopedia, these two publications offer design guidance for bicycle parking, including spacing and location considerations, bicycle rack selection and dimension considerations. The Canadian Institute of Transportation Engineers (2003) and VTPI (2004b) also provide design guidance to determine the appropriate number of showers and change stalls.

\section{Elements of Pedestrian Places}

Pedestrian places are generally outdoor areas designed for the purpose of social interaction or recreation. Examples of pedestrian places are plazas, parks, courtyards, and squares. Bohl (2002) discusses pedestrian places in his publication Place Making: Developing Town Centers, Main Streets and Urban Villages. Bohl (2002) notes that urban design tactics should be used when creating pedestrian places. Attention to architectural detail, the inclusion of details such as drinking fountains, trash receptacles, and outdoor service and retail venues (small food stands, cafés) are usually included in successful pedestrian places.

The Project for Public Spaces (2005a) indicates that the following attributes make a good pedestrian place: 1) uses and activities (a wide range of things to do), 2) access (it is easy to get to and is connected to the surrounding community), 3) comfort and image (it is safe, clean, and attractive), and 4) sociability (a place to meet other people). The Project For Public Spaces (2005b) notes that there are also elements that can make unsuccessful, or under-utilized pedestrian places. These include: 1) lack of seating (benches, chairs, picnic tables), 2) visual inaccessibility (is the area visible from nearby roads and buildings?), 3) paths that do not go where people want to go (disconnected or aimlessly meandering sidewalks that do not connect destinations), 4) domination of a 
space by vehicles (nearby roads are wide and lack crosswalks), and 5) blank walls around the edge of a public space.

FHWA (undated) presents design information on sizing pedestrian places. They recommend that pedestrian places should be no larger than 2,500 square feet, since smaller pedestrian-oriented places are more likely to be used than large, wide-open plazas. They also state that it is important to include amenities such as benches, shade trees, water fountains, and trash receptacles as components of a pedestrian place, since the presence of these features encourages walking and bicycling.

Safety and security, necessary elements of pedestrian places, are discussed in VTPI's Online TDM Encyclopedia (2004a). Environmental design techniques such as design features that create a sense of order, eliminate obvious hiding places, and maintain clear sight lines. VTPI argues that vibrant places that have buildings with many windows and other openings encourage pedestrian activity after normal working hours where other supporting elements are present.

Lighting is another important element of pedestrian places. The Lighting Design Lab Website (2004) is a comprehensive web resource that contains recommended lighting levels for a large number of applications, including pedestrian-scale lighting. The website recommends that medium-mount lighting fixtures ( 8 feet to 15 feet in height) or low-mount fixtures (lower than 8 feet in height) be used in pedestrian applications. Brooks (1988) concurs with this value, stating most pedestrian fixtures should be mounted at heights from 0 feet to 15 feet in height. Recommended lighting levels are between 1 to 5 footcandles for pedestrian applications. 
Rich (2003) discusses safety considerations for parking lots and large sites. He indicates that emergency communication devices, or emergency phones, can help to increase security on-site. He encourages the use of pedestal-mounted emergency phones with flashing beacons in large campus-like environments, such as those found in office parks.

\section{Landscaping}

Landscape design is generally associated with abstract art form as much as it is associated with practicality. Details such as color, line form, texture, and scale are often used by landscape architects to create an aesthetically pleasing "outdoor room". Ingram (1991) describes landscape design as a combination of art and science to create a functional, aesthetically pleasing extension of indoor living to the outdoors. The aesthetics of landscaping can increase pedestrian appeal. That is, an attractive streetscape punctuated with shade trees and other landscaping features may actually encourage walking and bicycling. While one of the reasons, if not the primary reason for landscaping, is to enhance the appearance of an outdoor area, there are more practical functions of landscape design that relate to non-motorized transportation.

Casazza and Derven (1986) present specific information on landscaping in suburban office parks. They offer guidelines on landscaping elements that support pedestrian travel. Most notably, they discuss the technique of using earth berms to hide unattractive areas such as parking lots. They also note that using berms to separate walkways from adjacent roadways can give pedestrians a sense of security by creating a buffer from vehicular traffic. Note, however, that this is at odds with the "eyes on the street" concept. 
Landscaping plays a role in accommodating and encouraging pedestrian and bicycle travel. Basic Elements of Landscape Architecture Design (Booth, 1983) and Introduction to Landscape Design (Motlock, 2001) include sections on using landscaping to enhance the pedestrian experience. Both describe how landscaping should support pedestrian desire lines by channelizing, or guiding pedestrians throughout a site.

The Canadian ITE (2003) publication suggests the use of trees to shelter pedestrians from direct sunlight, wind, and precipitation. Similarly, Brooks (1988) offers detailed information on the effect that vegetative screens have on wind. He demonstrates how trees can block and re-direct wind patterns in pedestrian places.

The Canadian ITE (2003) also addresses sight distance problems that vegetation too close to intersections and parking planter islands present. They recommend avoiding dense landscaping at these locations.

\section{Site Infrastructure for Vehicular and Non-Motorized Transportation}

This section discusses issues that directly affect motorized and non-motorized circulation and access for an office park site. Design elements for internal pedestrian and vehicle circulation, parking, and public transportation/transit are discussed here.

\section{Internal Pedestrian and Vehicular Circulation}

As mentioned earlier, pedestrians always take the path of least resistance (Brooks, 1988). This is an important characteristic that should be considered when planning for pedestrians, bicyclists, and transit riders in office parks. Cervero (1986) notes that many suburban office parks have curvilinear roads with adjacent sidewalks, if sidewalks are present at all. This decreases the directness of travel and increases walking distances for pedestrians. The Canadian ITE (2003) indicates that generally, walkways that better 
serve pedestrian desire lines should be considered in addition to, or in lieu of, walkways that require longer travel distances. Additionally, pedestrian connections should be provided that serve logical off-site locations. For example, the construction of a formal linkage from a commercial office land use to a complementary retail or commercial land use should be considered to encourage walking rather than driving between the two sites.

AASHTO's A Policy on Geometric Design of Highways and Streets (2001) is the main reference and design standard for geometric design of roadways. However, since the focus of this work is to accommodate sustainable transportation, guidance in the Green Book's must be considered in the appropriate context. Applying traditional design standards to internal road design often leads to roadways that promote high operating speeds. To support pedestrian and bicycle transportation, lower speed roadways are desired. Accommodating pedestrians and bicycles is a detail that is often overlooked in the planning and design of suburban office parks. As Gause, et al. (1998) points out, "The circulation systems of suburban office parks sometimes neglect the comfort and safety of pedestrians."

ITE’s (2003) Neighborhood Street Design Guidelines focuses on "residential and mixed residential/commercial subdivision development". This publication, like many other sustainable transportation-related publications, endorses interconnected street networks that allow direct pedestrian and bicycle travel. Thus, it is recommended that designers avoid transportation networks that cause indirect pedestrian and bicycle travel. The gridiron street network usually provides the most direct access for all modes of transportation, and is encouraged for use in suburban office parks. Note that sometimes a 
grid pattern is not always feasible due to topographical, dimensional, and environmental constraints.

In addition to the ITE (2003) Neighborhood Street Design Guidelines (2003), AASHTO (1999) and FHWA (undated) both make recommendations for roadway crosssections that support sustainable transportation. Since wide travel lanes can encourage high speeds, the general consensus of these publications is to use lane widths narrower than 12 feet in commercial applications. Lanes narrower than 12 feet should be sufficient for most vehicular traffic. However, if a significant percentage of large trucks is present, dimensions may be altered accordingly. One possible alternative to narrower roads is to provide separate vehicular access for large trucks.

It should be noted, however, that narrow lanes sometimes are a disincentive for bicycling. Thus, provisions should be made for bicyclists. The aforementioned publications also address accommodating bicycles in the road cross section. For a road cross section with curb and gutter, a 4-foot bicycle lane adjacent to the vehicular travel lane is recommended. For roads without curb and gutter, a 4-foot bicycle lane is recommended when there is no shoulder present, and a 6-foot shoulder is recommended if bicycle lanes are not indicated on the road surface.

Large turning radii at intersections make intersection throats wider, in turn creating a longer crossing distance for pedestrians. Large turning radii also allow motor vehicles to turn at higher speeds, thereby creating a more dangerous environment for pedestrians. Stover and Koepke (2002) collected data (e.g., vehicular turning radii, entry/exit speed, and off tracking distances) at a large number of intersections and 
developed criteria for suggested curb radii (versus driveway throat width) and suggested driveway design criteria.

Some publications address internal roads with regard to only automobile traffic. However, the configuration of internal roads plays a part in accommodating nonmotorized transportation. Frej, et al. (2001) addresses this issue, noting that, “Contemporary suburban business parks typically are not designed around the grids common in earlier business parks. Today, streets are more likely to curve and follow land contours." To the casual observer, this approach appears to predominate in many modern office parks. However, advocates of sustainable transportation (Burden, 2001 and Ewing, 1999) recommend using the grid pattern in roadway layout to reduce travel distances for pedestrians and bicyclists and create more direct routes for transit vehicles.

The Canadian Institute of Transportation Engineers (2003) also addresses various considerations for internal road configuration. For instance, they state that one-way internal road configurations are likely to encourage speeding. Also, unlike conventional two-way roads, one-way internal roads also increase travel distances for bicyclists.

It is also generally desirable to reduce the number of access points along an internal road. The Access Management Manual (Committee on Access Management, 2003) generally recommends combining driveway access points along a road to decrease the number of pedestrian/vehicle conflict points. Access management techniques can be applied in suburban office parks where buildings are clustered along internal roads. In identifying ways to minimize the number of access points, there may be potential opportunities to share, or consolidate, parking areas to create a more compact site. 
The layout of separate pedestrian and bicycle facilities is key to accommodating pedestrians and bicyclists in suburban office parks. As previously stated, the nonmotorized infrastructure needs to be direct and interconnected. It also needs to facilitate safe and efficient movement for users of the facility. There are several publications that present considerable detail about the design of pedestrian and bicycle facilities.

A publication that was used for recommendations for bicycle or shared use path design was the AASHTO (1999) publication AASHTO Guide for the Development of Bicycle Facilities. While the aforementioned pedestrian/bicycle publications contained information pertinent to shared use, or exclusive bicycle path design, the AASHTO guide is the most appropriate one for use by designers. This guide lists horizontal, vertical, and cross-sectional design recommendations for such facilities.

There are other publications that offer design guidance on pedestrian facility design from an accessibility standpoint. The basic reference document for designing accessible pedestrian facilities is the ADA Accessibility Guidelines (ADAAG) (US Access Board Website, 2004). Some of the topics covered by the Accessibility Guidelines are maximum cross slopes for pedestrian traveled ways, protrusions into the walkway, maximum allowable drainage grate openings, curb ramp slopes, and walking surface skid resistance and stability. Likewise, Accessible Sidewalks and Trails, Part II of II (Kirschbaum, Axelson, Longmuir, Mispagel, Stein, Yamada, 2001) focuses on best practices for design parameters that affect accessibility of pedestrian facilities and street crossings. The publication discusses sidewalk and trail user characteristics, sidewalk geometric design features, curb ramps, and road crossings, considerations at driveways, and information dissemination to non-motorized users. 
Several of the more noteworthy pedestrian and bicycle design guides were the aforementioned FHWA (undated) graduate-level text, Pedestrian Facilities Users Guide: Providing Safety And Mobility (Zegeer, et al., 2002), and Pedestrian and Bicycle Planning: A Guide to Best Practices (Litman, et al., 2002). All of these publications discuss cross-sectional elements important to accommodating pedestrians and bicycles. They generally agree that 5 feet is the minimum desirable sidewalk width. Additionally, shy distance should be accounted for in the pedestrian facility cross section when the facility abuts a vertical plane (e.g. a wall, shrub, storefront). The generally agreed upon shy distance is 2 to 3 feet. However, a 4-to 6-foot buffer should be added when a pedestrian facility directly abuts a roadway.

\section{Parking}

Parking is a major part of office park planning and design. Large areas of land are commonly dedicated for parking in office parks. Thus, pedestrians and bicyclists are sometimes forced to traverse parking lots in order to reach buildings. Many of the parking references identified in the literature review were general in nature (in terms of accommodations for pedestrians in parking lots). However, several publications discussed parking specifically related to suburban office parks. Casazza and Derven (1986) address parking issues in their publication Parking for Industrial and Office Parks: Planning, Design, Construction, and Maintenance. Although mostly focused on parking layout for automobiles, this older publication interestingly devotes a section to pedestrian walkways within parking lots. It encourages the placement of walkways to facilitate the safe movement of pedestrians within parking lots. 
Both Alroth (1988) and ITE Technical Council Committee 5D-8 (1994) agree that parking aisles that are oriented perpendicular to buildings allow for easier pedestrian travel within parking lots. Alroth (1988) indicates that parking areas within large employment centers, such as office and business parks, should be designed to focus on major walkways. He also encourages the use of crosswalks at major pedestrian crossing areas within parking lots. The ITE Technical Council Committee 5D-8 (1994) notes that pedestrian walkways within parking lots help to provide "more favorable walking conditions." However, they add that people walking to and from their cars often use the aisles, such that the value of interior walkways is debatable.

Alroth (1988) also encourages the grouping of smaller modularized parking lots, as opposed to large surface lots, at large employment centers. Not only does this break up the mass of a parking lot and improve aesthetics, but it can also reduce vehicle speeds and the erratic high-speed diagonal movements often observed in large parking lots. Stover and Koepke (2002) point out that raised medians, curbed end-islands, and other physical barriers are design elements that can be used to reduce high-speed diagonal maneuvers. Breaking-up, or modularizing, parking areas within a parking lot can effectively control vehicle movements and speed. Thus, designing parking lots with these features creates a safer place for pedestrians, bicyclists, and motorists.

While raised curbs and medians have benefits for non-motorized modes within parking areas, there are other design elements that should be avoided because of the hazards they pose for pedestrians. One element that should be avoided in parking lots is wheel-stops. Pline (1999), the ITE Technical Council Committee 5D-8 (1994), and 
Alroth (1988) all concur that wheel stops present a tripping hazard for pedestrians, and that they should not be used in parking lots.

Similarly, certain speed control techniques in parking lots create danger for pedestrians. Speed bumps should not be used since they can be produce driver discomfort at low speeds, and are self-defeating at higher speeds (Ewing, 1998). Moreover, speed bumps are abrupt in their physical design, and can catch a pedestrian's toe and cause a trip-type accident, or cause a bicyclist to lose control. Appropriate traffic calming measures for access roads and parking areas, such as speed humps, speed tables, corner bulges, traffic circles, and others, can be found in the publication, Traffic Calming: State of the Practice (Ewing, 1998).

As indicated by Gruen + Gruen and ULI (1986), the number of parking spaces found in suburban office parks is sometimes a maximum, meaning that many spaces in such lots remain vacant for all but a few days per year. Such an oversupply of parking is wasteful, generates excess storm water runoff, and is generally aesthetically unappealing. There are sources of information that offer guidance on appropriate parking requirements, and other alternative measures to reduce the amount of parking needed.

Technical publications, such as Parking Generation (McCourt, 2004) and The Dimensions of Parking (Urban Land Institute and National Parking Association, 2000), offer recommendations on parking supply requirements. Other publications offer recommended parking supply requirements applicable to sustainable development. The previously mentioned US EPA (1999) publication Parking Alternatives: Making Way for $\underline{\text { Urban Infill and Brownfields Redevelopment and Litman (2000) publication Pavement }}$ $\underline{\text { Buster's Guide, }}$ both discuss shared parking, providing shuttle services from a central 
parking facility, more efficient land use patterns, and establishing maximum parking standards.

The Canadian Institute of Transportation Engineers (2003) and Stover and Koepke (2002) both discuss design measures to encourage ridesharing among employees in commercial and retail land use applications. They recommend placing reserved ridesharing parking stalls, or segregated ridesharing parking lots, close to building entrances as an incentive to encourage employees to use high-occupancy vehicle modes instead of a single-occupant vehicle. Another design feature that can be used to reduce parking supply requirements is the shared-use parking facility, i.e., sharing parking lots with land uses that do not have traffic peaks that coincide with commercial office land uses.

Frej, et al. (2001) discuss the use of spillover lots in suburban office and business park locations. This approach allows individual buildings to meet unforeseen or seasonal parking demand on shared offsite lots without adding parking. "Green" spillover lots are desirable since they do not generate additional runoff that paving land for parking creates. These lots usually use alternative surface covers such as gravel, turf block, or porous pavement in lieu of bituminous or concrete pavement.

Stover and Koepke (2002) and the Canadian Institute of Transportation Engineers (2003) offer design measures for minimizing vehicular, pedestrian, and bicycle conflicts at service/loading areas. Many times, office and business parks require loading docks to ship or receive materials or goods. These areas can be dangerous for pedestrians and bicycles. Desirably, pedestrians should not be routed near or through such areas. At 
locations where pedestrians/bicycles and commercial motor vehicles must interact, it is recommended that adequate lighting and good sight lines be provided.

\section{Public Transportation/Transit Connections}

There are few design references that deal specifically with transit accommodations on large commercial, or office park sites. It should be noted that accommodating transit in suburban office parks might not be a realistic option, since suburban areas often do not have the required densities to support transit. However, in some instances, transit service in suburban office parks should be considered.

Cervero (1986) devotes a section of Suburban Gridlock to discussion of accommodating transit within suburban office parks. He notes that, many times, on-site transit stops within office parks are placed much farther away from building entrances than parking stalls. He also notes that off-site transit stops are sometimes located at distances from building entrances that exceed the maximum acceptable distance that commuters are willing to walk. In turn, he calls for front-door drop-off areas for transit vehicles and more thoughtfully located transit stops to encourage transit ridership in suburban office parks.

Likewise, the Canadian Institute of Transportation Engineers (2003) suggests design measures for on-site transit stops. They recommend providing direct linkages from transit stops to nearby buildings; eliminating or reducing circuitous routes. They also recommend passive security measures such as adequate illumination and clear sight lines near transit stops. Comfortable waiting areas are also critical to support transit onsite. Amenities such as benches, trash receptacles, awnings, and transparent enclosures can help encourage transit usage. 
The Texas Transportation Institute and Texas A\&M Research Foundation (1996) present detailed design information for transit stops. While this publication is not tailored specifically for on-site transit stops in office parks, the guidelines are general in nature and the design information is appropriate for many different types of transit stop locations. The guidelines present recommended dimensions and shelter layouts that promote accessibility and safety for all users. The guidelines also present shelter layout considerations based on environmental, or climatic factors. The publication notes that consideration of environmental factors when designing transit stops is important in creating a comfortable waiting area for pedestrians.

\section{Concluding Remarks}

Commercial office space has changed significantly throughout the $20^{\text {th }}$ Century and into the $21^{\text {st }}$ Century. Two of the most notable changes have been office space location and office building configurations. Office buildings have geographically shifted from downtown Central Business Districts (CBD) locations to suburban locations. Likewise, office space has gone from being housed primarily in high-rise buildings to a significant portion being housed in low-rise, dispersed office parks.

As a result of the aforementioned changes and the underlying factors that contributed to these changes (post-WWII demographic shift, increased automobile ownership, and construction of the Interstate Highway system), single-occupant vehicle travel has emerged as the dominant mode of choice to access and travel throughout suburban office parks. Thus, many people that work in suburban office park settings must rely on the automobile to run errands, eat lunch, and perform other mid-day activities. 
During recent years, sustainable design concepts have been promoted to encourage walking, bicycling, and transit usage, and to counteract the effects of sprawl. Smart Growth and New Urbanism are based primarily on traditional urban planning principles that were used to create towns and cities before the proliferation of automobiles. These concepts focus on creating compact, human-scale places by encouraging mixed land uses, increased land use density, improved walking and bicycling infrastructure, and creating a "sense of place". Both the underlying principles and specific techniques for implementing the principles are well documented in the literature.

Except for a few published sources that refer incidentally to accommodating nonmotorized modes in suburban office parks, there is no comprehensive source of techniques, practices, or guidelines for planning and designing suburban office parks that support non-motorized transportation. To help implement these principles, there is clearly a need for such a document. The following chapters describe the development of the guidelines and the document that presents them. 


\section{Chapter III: Preparation of the Guidelines}

This chapter describes the procedures used to prepare the guidelines document. The document outlines best practices and make specific recommendations regarding accommodation of non-motorized transportation in suburban office parks, but does not contain the detailed supporting and background material usually found in textbooks or design manuals. This chapter consists of three main sections: 1) Identification and Organization of the Information, 2) Format for Presenting the Guidelines, and 3) Description of the Sample Site Visit Process. Sample sites were examined to illustrate application of the guidelines.

\section{Identification and Organization of the Information}

The preparation of the guidelines document was an iterative process. The first step in preparing the guidelines was to conduct a review of literature. The literature review revealed a limited amount of information pertaining specifically to accommodating pedestrians and bicyclists in suburban office parks. However, a great deal of published information was identified pertaining to sustainable development concepts, site planning and parking design, and pedestrian and bicycle planning and design. These publications were general in nature, and not specifically related to suburban office parks.

The categories of literature reviewed were very broad. This included pedestrian and bicycle, planning, landscape architecture, civil engineering, transportation engineering, site development, and sustainable development literature. This body of literature was reviewed for relevant best practices, principles, specific techniques for 
incorporating sustainable development, and design guidance. Items deemed relevant generally pertained to office parks, or large commercial developments comparable to office parks (or of the same magnitude as office parks). For instance, a site planning guide for residential land uses would not be included, but a site planning guide for mixeduse commercial land uses would be included.

A topical outline was developed to provide a framework for preparing the guidelines. The outline was revised several times throughout the literature review process, as the content material was identified and inserted at the appropriate location in the outline.

The guidelines were written by synthesizing pertinent information gathered during the literature review in the organizational framework. This was an iterative process, as several drafts of the guidelines were prepared and revised. There was generally a succession of steps involved in conducting the literature review process. This process is illustrated in Figure 3 below.

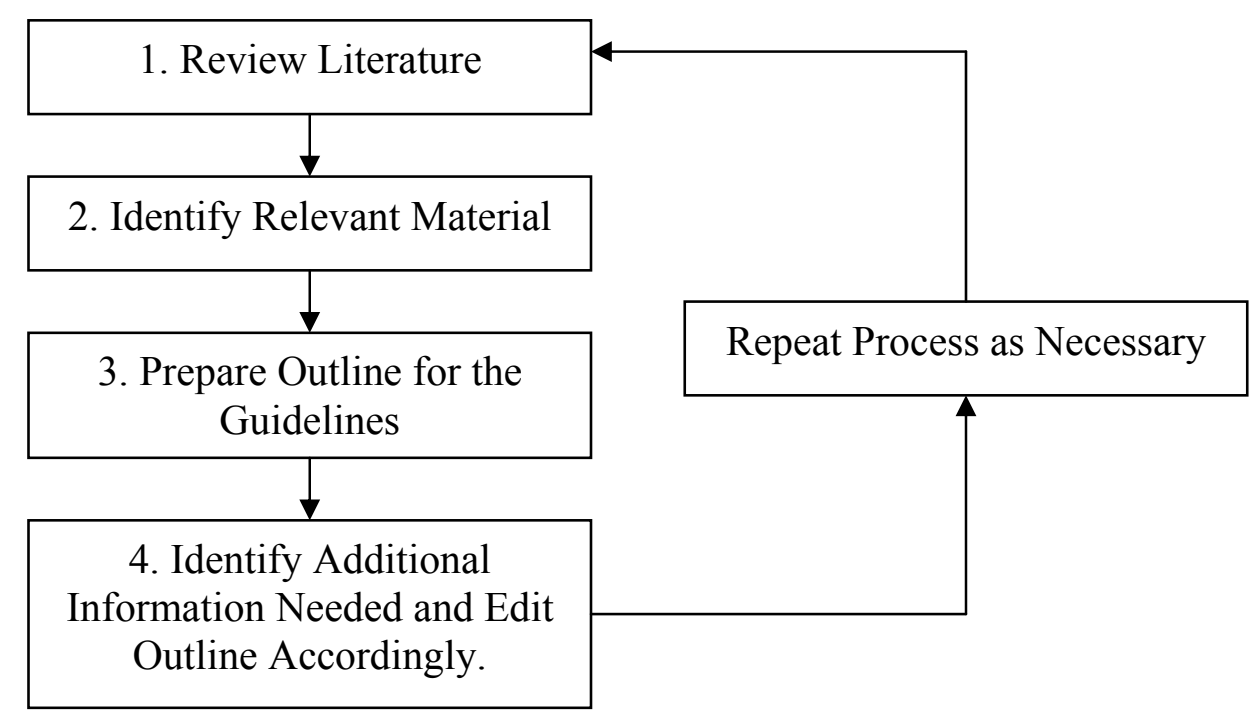

Figure 3. Steps for Identifying and Organizing Relevant Literature. 


\section{Presentation and Format}

The desired outcome of this work was to create an easy-to-use set of guidelines that support and encourage non-motorized transportation to assist a broad audience in planning and designing suburban office parks. To enhance its usefulness, an effort was made to keep the document concise. Each of the three main guideline sections (A. General Site Design Issues, B. Site Layout and Pedestrian and Bicycle Site Amenities, and C. Site Infrastructure for Vehicular and Non-Motorized Transportation) are organized in a similar fashion. Each section includes several overarching objectives that adhere to the principles of sustainable development and relate them to some aspect of planning and design. For each objective, there are a number of guidelines which represent the detailed means or implementation strategy consistent with the objective. In some cases, when additional information is needed, more detailed information is presented in the form of narrative description, graphic illustration, or reference citation to a source document.

In a document of this type, "how" information is presented is critical to creating guidelines that will be used by practitioners. Thus, an effort was made to identify presentation formats that were easy-to-read and user friendly. During the literature review, several publications were identified that had formats which were similar to the end product desired in this case. The arrangement and format of material in the following publications served as a model or framework for organizing the guidelines in this case:

1. The Canadian Guide to Promoting Sustainable Transportation Through Site Design: Draft Guidelines, (Canadian Institute of Transportation Engineers, 2003). 
2. Neighborhood Street Design Guidelines: A Proposed Recommended Practice of the Institute of Transportation Engineers, (Institute of Transportation Engineers, 2003).

3. Smart Growth Transportation Guidelines: An ITE Proposed Recommended Practice, (Institute of Transportation Engineers, 2003).

The guideline structure is organized as follows:

1) Section. There are three sections that present a group of topic headings that are similar in nature (e.g., Site Layout and Pedestrian and Bicycle Amenities)

2) Topic Heading. A category that falls within a section (e.g., End-of-Trip Pedestrian and Bicycle Considerations)

3) Objectives. An overarching goal that adheres to the underlying principles of sustainable development for that particular topic heading (e.g., Provide Bicycle Parking That is Accessible, Sheltered, and Secure)

4) Guidelines. Presents methods for implementing objectives (e.g., Configure Bicycle Parking Areas to Maximize Space, While Providing Easy Access to Racks)

Since the guidelines are intended to be a user friendly, easy-to-understand document, illustrations are used to convey data, describe spatial relationships, and present other information that is best described visually. Illustrations were identified as an important component of these guidelines, as an understanding of spatial relationships is extremely important when accommodating non-motorized modes. Thus, to supplement the narrative portion of the guidelines, illustrative figures, photographs, and/or tables are liberally provided throughout the document. 


\section{Sample Sites}

Several sample sites were examined to illustrate application of the guidelines in understanding how well existing suburban office parks accommodate non-motorized modes. The intent of this exercise was not to present a comprehensive study of any one site. Rather, it was intended to illustrate, to a non-technical audience, the application of the guidelines. Use of the sample sites in this regard will demonstrate how to analyze a suburban office park's strengths and weaknesses relative to accommodating nonmotorized transportation. In addition, application of the guidelines will demonstrate how to use them to identify enhancements that will encourage pedestrian and bicycle activity.

Resource constraints limited the area of interest to Pennsylvania, West Virginia, and Virginia. Because of the author's familiarity with several office parks within this region, background information was acquired to obtain a general description of the sites. Elements of interest when gathering background information were park size, park configuration, internal road configuration, and any access restrictions. Restricted-access or gated office parks were not of interest.

Sites that varied in characteristics were sought to illustrate a range of applications. Thus, the sites chosen were Southpointe in Canonsburg, Pennsylvania, and the Virginia Tech Corporate Research Center (VTCRC) in Blacksburg, Virginia.

One of the main reasons for selecting these sites was that they had distinctly different site characteristics. Southepointe contains many different land uses, but the buildings are widely separated with a curvilinear internal transportation infrastructure. The VTCRC was also suburban in character, but had an extensive shared-use trail, a transit-supportive road network, and pedestrian amenities. Thus, from a non-motorized 
transportation standpoint, both sites had desirable characteristics, but both had several limitations, with respect to non-motorized transportation, that could be addressed by the guidelines.

A visit was made to each sample site. At each site, a drive-through and walkthrough were performed. This entailed driving and walking around the site to take photographs, gain a familiarity with the site, and record observations to be used in applying the guidelines. Finally, all of this information was synthesized into a short report which is presented in Chapter IV.

Note that all information used in the sample sites analysis was obtained through the on-site visit and from the background Internet and literature search. No developers or occupants of the parks were contacted. 


\section{Chapter IV: Results}

The result of the efforts described in Chapter III was the "guidelines" document. The guidelines and their scope, application of the guidelines to sample sites are illustrated, and intended audience are briefly described in this section. Possible next steps for implementation of the guidelines are also presented.

\section{The Guidelines}

The document produced as a result of this effort, Planning and Design Guidelines for Accommodating Non-Motorized Transportation in Suburban Office Parks, is presented in its entirety in Appendix A. The main purpose of this guide is to assist professionals involved in the planning, design, review or approval, and operations of suburban office parks, in supporting, enhancing, and encouraging the use of nonmotorized modes in office parks. The document illustrates the many opportunities that parties involved in suburban office park development have to support and encourage sustainable transportation, including policy development, organizational practices, site layout and design, and agency review.

The guide has two main parts. The first part of the guide examines general characteristics of sustainable development. The relationship between land use and transportation is discussed briefly as it relates to suburban office park development. The characteristics and underlying principles of sustainable development are then discussed. The various commute mode alternatives, such as automobile, public transportation (including ridesharing), walking, and biking, are discussed in this section. Factors that affect transportation mode choice are outlined generally. The factors that influence use 
of sustainable modes are also identified, with a particular focus on how office park form can encourage or discourage non-motorized transportation.

The second part of the guide presents the actual guidelines in a user-friendly

format. Main topic areas covered are: A. General Site Design Issues, B. Site Layout And Pedestrian/Bicycle Amenities, and C. Site Infrastructure For Vehicular And NonMotorized Transportation. Under each topic, best practices that can be used in accommodating non-motorized transportation in suburban office parks are highlighted.

\section{Application of the Guidelines to Sample Sites}

Two sample sites are presented below: Southpointe (Canonsburg, Pennsylvania) and the Virginia Tech Corporate Research Center (Blacksburg, Virginia). Each section includes a brief introduction, followed by a discussion of findings, and application of the guidelines.

\section{Sample Site 1: Southpointe (Canonsburg, Pennsylvania)}

\section{Introduction}

Southpointe, located in southwestern Pennsylvania (Washington County), adjacent to Interstate 79 , is a large mixed-use office park terraced in strongly rolling terrain. Although some information was found using an internet search, background information for this site was limited. However, the site visit yielded the necessary information.

Southpointe can be best described as a sprawling office park, as illustrated in Figure 4. Although total number of acres is not known, the site is roughly 1.7 miles long in the east-west direction. At the time of the site visit (June 12, 2004) there were at least 
44 properties/lessees encompassed by the area of the site. There is a large golf course that comprises a significant portion of the land area, along with other commercial, retail and residential land uses. Many of the buildings appear to be new, or recently built, although buildings on the east side of the property appear somewhat older.

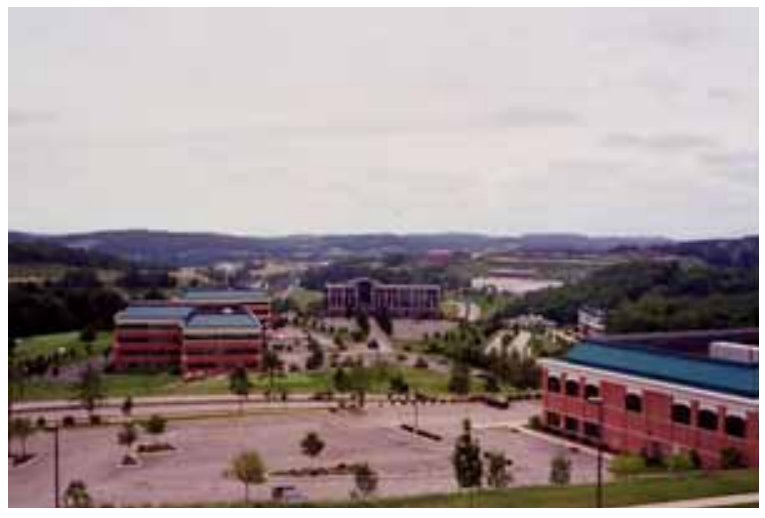

Figure 4: View from the East Side of Southpointe, Looking West.

Pedestrians must overcome long distances between buildings at Southpointe.

The general character of the site is "modern upscale golf community / office park". This site visit was conducted on a weekend, providing a good opportunity to see if the site possessed pedestrian activity beyond the 8-hour workday. Naturally, the golf course brings weekend recreational activity, and there are single-family homes and multifamily units that generate pedestrian activity.

\section{Discussion of Findings}

\section{General Site Design Issues:}

The mix and balance of uses are Southpointe's distinguishing characteristic. There are many different land uses including office and light industrial sites, single-family and apartment dwellings (shown in Figure 5), a golf course, college and university instructional facilities, hotel, a variety of moderately priced to expensive restaurants, bank, and health club.

Building character carries out a local theme, in terms of development within Southpointe, since it is part of a golf community. The buildings all reflect 
the same upper class theme within Southpointe. However, the office park does not carry out a local theme of the surrounding community since the area outside of Southpointe is rural with old towns that have lost once-thriving industries.

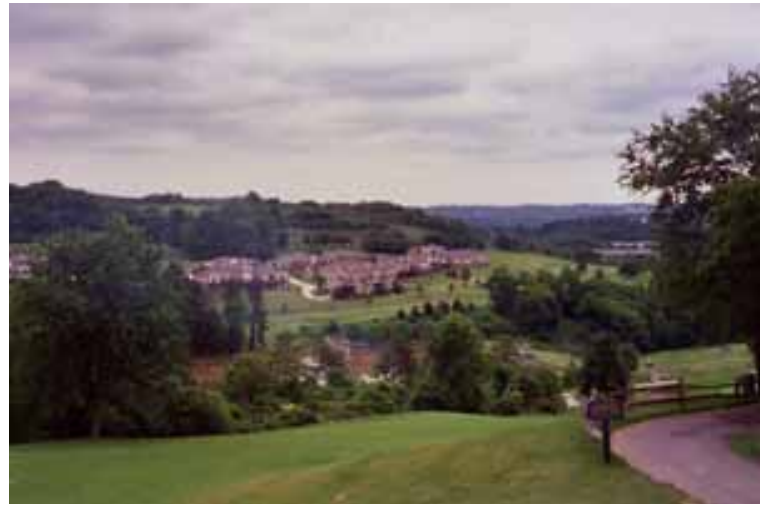

Figure 5: Complementary Residential Land Uses.

Multi-family apartment dwellings overlooking a golf course fairway at Southpointe.

2. Site Layout and Pedestrian and Bicycle Amenities:

Buildings are developed in autonomous fashion from one another. Although most of them have a sleek, steel-and-glass look, there does not seem to be an architectural signature. Most buildings are large geometric masses, positioned in the middle of its parcel of land. The buildings dominate the landscape and are surrounded by roads and parking lots. However, there are lakes, water features and pocket parks located throughout the site. Most of these features are built to support the golf course.

High-mounted overhead lighting is present throughout the site. The lighting is not designed to provide a well-lit walking path, rather the lighting is intended to illuminate the roadway environment and parking lots.

Most of the site landscaping is well-maintained and attractive. However, the landscaping is meant to serve as a backdrop for the buildings. Outdoor seating is minimal, however, there are several benches located throughout the site as shown in Figure 6. There are no areas with shade tree-lined walkways, or 
usable pedestrian plazas. The landscaping actually functions as a pedestrian barrier since it is mostly located on the periphery of individual sites.

The site is very large.

Many of the buildings are terraced into hillsides, so there is

considerable open space, but not an

abundance of usable open space.

Many of the sites have landscaped

traffic islands within the parking

lots, and large landscaped lawns.

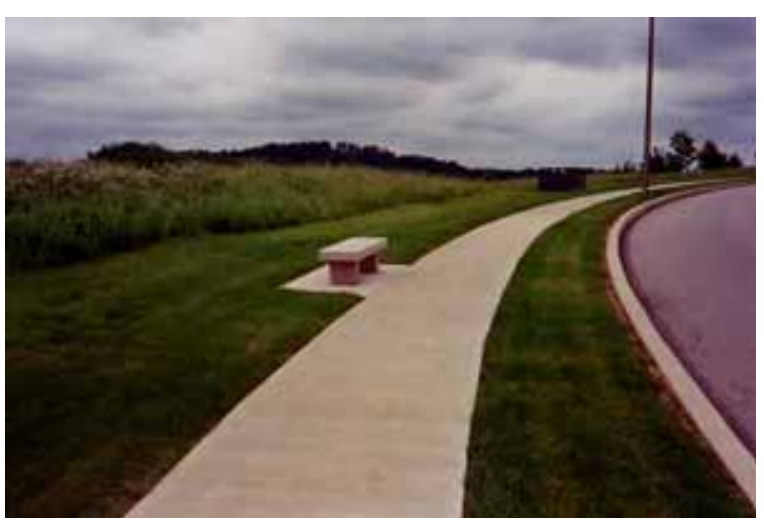

Figure 6: Pedestrian Amenities.

This bench provides a resting point along a steep internal road grade at Southpointe. There are several benches spaced far apart along internal roads.

However, this open space is not necessarily "usable" open space. In other words, it appears as if the lawns that surround buildings were not created to stimulate pedestrian activity.

Few pedestrian linkages to adjacent sites were observed. If a pedestrian wanted to reach an adjacent site, they must walk through a parking lot and across landscaped areas. No bike racks or outdoor bicycle amenities were observed. It is not known if showers and lockers are located in any of the buildings.

\section{Site Infrastructure for Vehicular and Non-Motorized Transportation:}

The site has several internal roads, and is connected to surrounding public roads and an interstate highway. Getting to the site by walking or biking is possible. However, the site is very large and the distance from one side of the site to the other (roughly 1.7 miles) may be prohibitive for non-motorized modes. It is probably not realistic to think that someone would walk to work, but the distance 
could be overcome by bicycle.

Southpointe's internal streets curve throughout the site, as they are not laid out in gridiron fashion. However, it should be noted that the rolling terrain precludes the use of a grid pattern from a practical, and economic standpoint. Some of the access roads terminate in cul-de-sacs. Block lengths are well in excess of 500 feet; so pedestrian routes are long and meandering. There is a wayfinding kiosk at the entrance to the development located in a vehicular turnout on the main road. It is not likely that pedestrians use this kiosk, as it is not easily accessible by any mode other than automobile.

A golf cart path meanders through most of Southpointe, which could be combined as a mixed-use path. The golf course's policy on path usage is not known. All of the site's main roads have sidewalks, but in most instances they are only on one side of the road. The sidewalks are continuous along the road throughout Southpointe, have an actual width of 5 feet, and are in relatively good condition. However, there do not appear to be sidewalks leading into Southpointe. Thus, if a person wants to walk to/from one of these buildings, they have to either walk through a parking lot and out the driveway to the sidewalk along the road, or walk through the grass/landscaping to the sidewalk.

Pedestrian routes within parking lots are non-existent in most instances, as shown in Figure 7. In other words, there is not a clearly defined or protected path for a pedestrian to travel from the periphery of an individual site to a building. Some parking stalls are laid out perpendicular to buildings and some are not. Although there are marked crosswalks along the major site roads, there are no 
crosswalks or signage within individual sites. Many surface parking lots are large and could benefit from crosswalks to accommodate people who walk to the site, but also for those who park their car and need a safe route to the door.

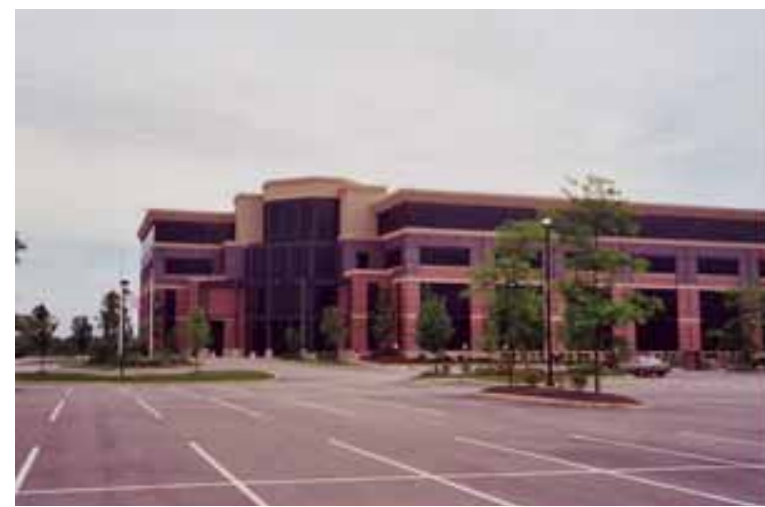

Figure 7: Lack of Pedestrian Accommodations in a Parking Lot.

This site at Southpointe has parking aisles located parallel to the building, forcing pedestrians to walk between parked cars.

There do not appear to be accommodations for transit at the site, e.g., no waiting shelters or bus stop signs. The only evidence of ridesharing is a nearby park-and-ride lot provided by the State Department of Transportation. However, it is not likely that someone who works at Southpointe would use this lot, since there seems to be ample surface parking for every building at the site.

\section{Application of the Guidelines}

\section{General Site Design Issues:}

This site has a wide variety of uses within its property boundaries; residences, office buildings, restaurants, and other land uses. However, the site is so large and widely dispersed that it requires employees and visitors to drive to and from destinations within the site. A large portion of the site has been builtout, so not much can be done for those sites. However, by subdividing the remaining properties into smaller lots, denser development could be accomplished. New buildings could be built at the front of the property with parking to the rear of the site. This would help to bring destinations closer to one 
another and foster pedestrian activity. In addition, a more compact streetscape environment would be created where the buildings were no longer the focal point. Individual sites could be situated to create a pedestrian-friendly streetscape.

2. Site Layout and Pedestrian and Bicycle Amenities:

Southpointe would benefit from general pedestrian amenity improvements, from a non-motorized transportation standpoint. Planting shade trees along the peripheral sidewalk system would make a long walk much more comfortable. More seating and additional street furniture would be desirable. Items such as trash receptacles, flowers and other landscaping, and periodic shade/shelter from the elements would also make a more pedestrian-friendly environment.

3. Site Infrastructure for Vehicular and Non-Motorized Transportation:

Constructing sidewalks that connect sites to the peripheral sidewalks would facilitate easier movement for pedestrians. Also, linkages between adjacent properties and better-delineated pedestrian crossings within parking areas would help to foster lunch-time walking. While the roads appear wide enough for bicycle travel, special provisions for bicyclists would encourage bicycle commuting. However, it should be noted that the steep roadway grades may discourage walking and bicycling. Other possible measures include striped bicycle lanes throughout the site's transportation network, and end-of-trip amenities such as bicycle storage. 


\section{Sample Site 2: Virginia Tech Corporate Research Center (Blacksburg,}

\section{Virginia)}

\section{Introduction}

The Virginia Tech Corporate Research Center (CRC) is a research and technology park located adjacent to US Route 460, in Blacksburg, Virginia. The CRC is located adjacent to Virginia Tech's main campus and a small regional airport. The site is roughly 120 acres in size, and currently has 17 completed buildings, with 2 under construction (www.vtcrc.com).

The CRC is a master-planned

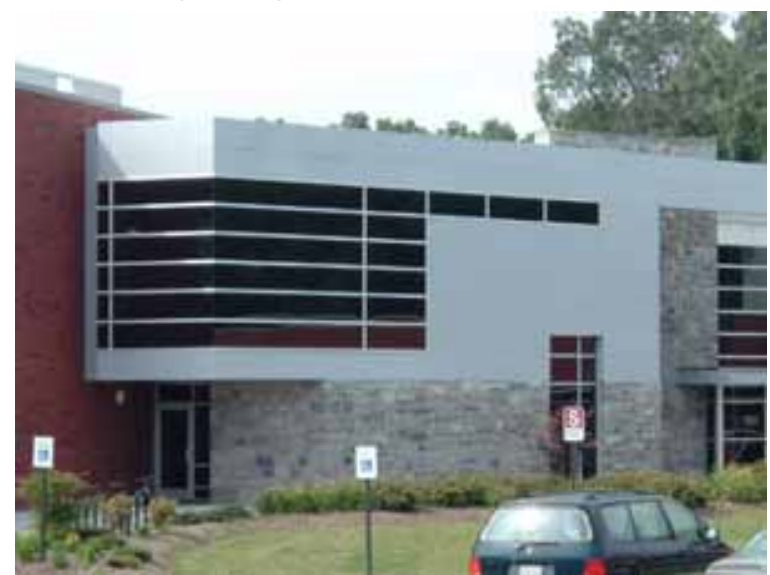

Figure 8: Re-occurring Visual Theme. Many of the buildings at the VTCRC incorporate the same stone patterns used in most campus and downtown buildings.

office park that has a campus-style environment that matches its neighboring university. The buildings that make up the office park are modern in design, with many appearing to be newly or recently constructed. The general character of the park's buildings resembles the construction of some of the buildings at Virginia Tech. Flagstone, a hallmark of the university's buildings, is used in the construction of several of the office buildings as shown in Figure 8.

The site was visited on a Friday afternoon and some pedestrian activity during the visit was observed. However, most of the pedestrian activity was probably due to a shared-use trail that serves the site. This trail runs through the Virginia Tech campus and extends into, around, and beyond the CRC campus. This trail circles the entire site and a 
spur bisects the main portion of the site. Despite the remote location of the park, the trail seems to be heavily utilized and generates pedestrian traffic throughout the day.

\section{Discussion of Findings}

1. General Site Design Issues:

Although the site is

physically separated from the

surrounding community by

distance, there are on-site

amenities and supportive land

uses. In addition to

research/technology office

buildings, VTCRC land uses

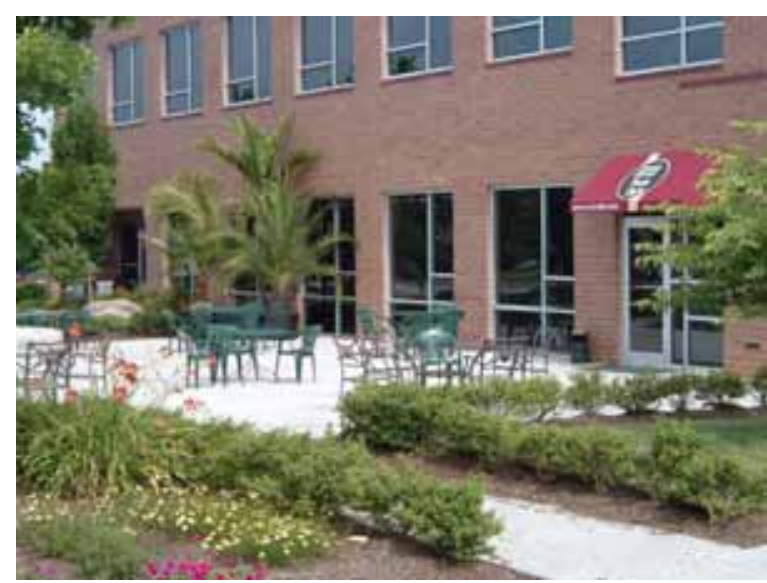

Figure 9: A Pedestrian Place.

This outdoor café creates an attractive and pedestrian friendly building façade on the rear of the on-site fitness center.

include an osteopathic medical school, an outdoor café (illustrated in Figure 9), fitness center, bank with two ATM terminals located nearby, dry cleaning services, daycare, and nearby residential developments.

This mix of uses is compatible with office commercial land uses, but the land use that likely generates the most activity after normal working hours is the nearby residential areas. There is a multi-family apartment complex and several single-family housing areas located close to the CRC.

The building design and construction materials of the CRC closely match the neighboring university. Many of the University's buildings use flagstone in their façade, and some of CRC's office buildings use flagstone also. Several of the office buildings use flagstone in prominent location such as building entries. 
2. Site Layout and Pedestrian and Bicycle Amenities:

The CRC has a variety of land uses and is served by modes other than automobile. However, most of the buildings are similar to those in conventional office parks, in that they are geometric masses that were constructed without regard to the other buildings. The buildings seem to be laid out in the middle of their respective property boundaries with small parking lots flanking them; sometimes on all sides.

As discussed earlier, the buildings of this site commonly replicate conventional office park construction. Although some of the buildings possess elements of architectural interest, several of the buildings appear plain and lack architectural features. However, there are several well-maintained wetlands, heavily wooded areas, and pocket parks located in and around the site, which add a natural "feel" to the park's ambiance.

Many of the buildings have bike racks. The most common bike rack observed was the "wave" style rack. These racks appear to be included as an afterthought in some instances, as some of the bike racks are not conveniently located near the

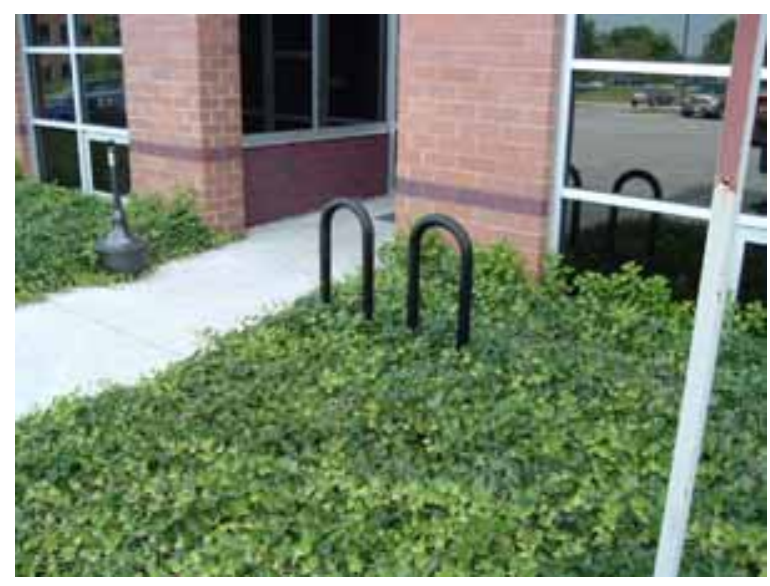

Figure 10: An Improperly Located Bike Rack. entrance of the building that they serve, or they are improperly located, as illustrated in Figure 10. Also, there does not appear to be preferential parking for 
ridesharing.

One positive attribute is the functionality of open space. There are several pocket parks and recreational areas that enhance the trail. One particularly enjoyable area is a trail spur that runs through the middle of the site. There are several areas located off of this trail segment that have picnic tables, benches, and pedestrian-scale lighting. The trail runs along the rear of several

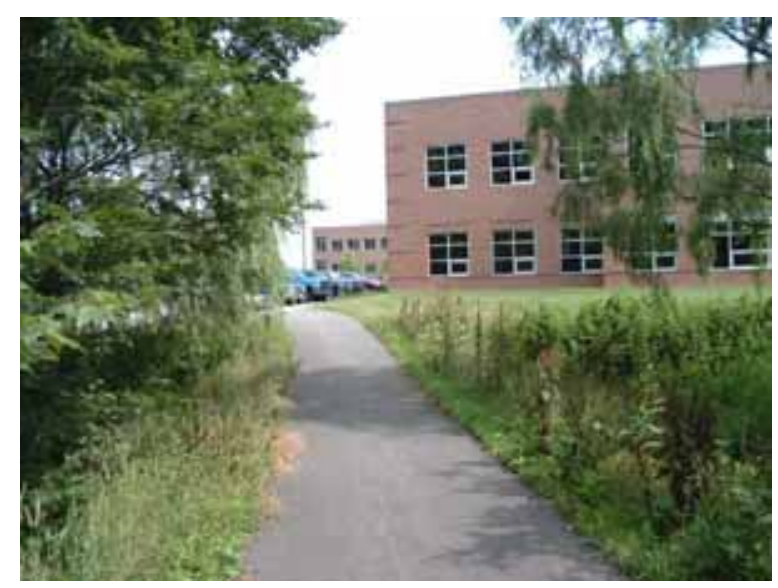

Figure 11: An Interior Segment of the SharedUse Trail.

The trail runs through wooded portions of the site. This is an attractive and useful pedestrian amenity. However, there may be security concerns in heavily vegetated areas such as this one.

of the buildings and winds through a heavily wooded portion of the site.

Most of the parking lots are illuminated by large overhead lighting standards. In some instances, there are short, pedestrian-scale lights, but these lights are not universally used throughout the entire site.

\section{Site Infrastructure for Vehicular and Non-Motorized Transportation:}

Generally speaking, the office park is located near existing development and transportation infrastructure. The site is accessed via an internal road that serves the CRC, an airport, and residential development in the area. Although the park is located several minutes (by automobile) from Downtown Blacksburg, the network of sidewalks and the shared trail make it possible to access the park by means other than automobile.

The internal vehicular infrastructure of the site is not laid out in a 
traditional grid pattern.

The road infrastructure, as

depicted in Figure 12, is

laid out as two loop roads.

This type of infrastructure

allows for semi-direct

linkages. Although block

lengths are rather long, the

loops support internal

transit routes. That is, a

transit bus can easily

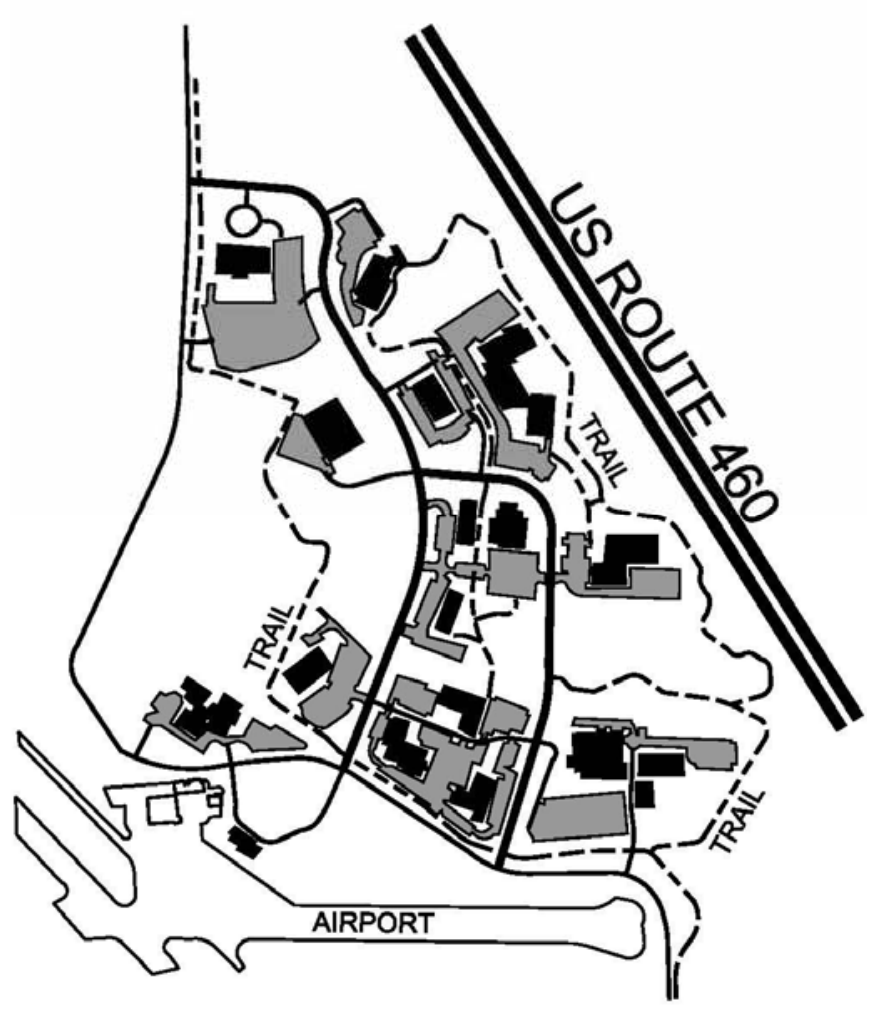

service the site by making a

loop on the main road. For

Figure 12: VTCRC Internal Roadway and Trail Layout.

The hybrid road layout does allow transit vehicle circulation. Note the extensive shared-use trail system.

first-time visitors, there is an information kiosk at the entrance to the site that is easily accessed by pedestrians and motorists.

The sidewalks have adequate width and are in good condition. However, there are certain problems. The trail encircles and bisects the site, and there are parking lots within individual building lots. However, there is usually no link between the two. That is, there are not sidewalk connections to the trail from individual building sites in some instances. The parking lots are generally small, so distances are short from internal roads to buildings, and from parking lots to buildings. However, there are several access roads that either bisect one of the "loops" or serve a portion of the site that does not have sidewalks. In addition to 
the lack of sidewalks, these portions of road have gravel shoulders that appear to have ruts and erosion damage, which could impede non-motorized travel on the shoulders.

During the site visit, several forms of transit were observed. Large buses were seen running at less-frequent intervals than several small shuttle busses. These busses circulate through the site, stopping at designated bus stops. There are several transit shelters, but the majority of the stops are delineated by signage and offer few amenities, such as seating or shelter from the elements.

\section{Application of the Guidelines}

\section{General Site Design Issues:}

Many of the individual building sites at the CRC were developed as automobile-oriented sites. That is, with large parking lots, and without regard to the adjacent sites or pedestrian infrastructure. It is clear that there have been attempts to make this office park pedestrian-friendly, but the development methods of individual sites creates a disconnect that affects the entire site. Techniques to retrofit these problems could help existing sites, and the undeveloped sites present an opportunity to create compact landforms and pedestrian-friendly places.

Placing new buildings close to the trail and / or roadway, and locating the parking to the side and rear lots would help to enhance the streetscape and increase pedestrian safety. Decreasing the distance between buildings would also create opportunities for shared parking, bring origins and destinations closer together, and encourage compact landforms. 
2. Site Layout and Pedestrian and Bicycle Amenities:

Adding more shade trees near the walkways would offer refuge from the sun for workers who desire to walk at lunchtime. Also, there were not many benches along the trail. The addition of benches at frequent intervals throughout the site would offer pedestrian resting points. One final enhancement would be the addition of pedestrian-scale lighting. In addition to general beautification, this type of lighting creates an intimate atmosphere for pedestrians that may lead to greater perceived security.

\section{Site Infrastructure for Vehicular and Non-Motorized Transportation:}

The trail that encompasses and bisects the site is a major pedestrian amenity. It connects the surrounding areas to the office park and improves pedestrian travel within the office park. However, the addition of pedestrian amenities to the trail and sidewalk infrastructure would enhance the office park.

One glaring deficiency that could be corrected is the lack of a direct linkage from the nearby residential areas to the office park. There are a significant number of single and multi-family dwellings within walking distance to the office park. There appear to be even more being built. A small investment in an attractive connector sidewalk to the site would be a nice incentive for someone to purchase a home or rent an apartment in this area. The connector sidewalk would create a safe walking environment for pedestrians, and may potentially be a selling point for the nearby residential neighborhood. Also, more interconnected internal sidewalks leading from the parking lots to the buildings would increase pedestrian safety within parking lots. 


\section{Audience}

The breadth of the intended audience for the guidelines is wide and diverse. This audience includes, but is not limited to, planners, urban designers, developers, architects, transportation agencies, property managers, engineers and others who are involved in the planning, design, review or approval, and operations of suburban office park projects. Each of those mentioned are involved in facilitating the accommodation of nonmotorized transportation, in some form or another.

The guidelines apply to the planning and design process, but individual guidelines may not be applicable in both phases. The broader guidelines, such as those dealing with overall site design, will apply at the planning phase. More detailed guidelines, such as those dealing with pedestrian amenities, will apply at the detailed design phase. Additionally, some of the objectives and guidelines can be applied to retro-fit sites that are already developed.

Since the focus is planning and design, the guidelines do not address construction and maintenance issues. Note, however, that since construction and maintenance affect non-motorized transportation, attention needs to be given to pedestrians and bicycles in these phases of a project as well.

\section{Next Steps}

Publication of the guidelines is only the first step in the implementation process. Availability of a document does not necessarily mean that it will be used or that it will be useful to practitioners. A multi-step technology transfer process is proposed to disseminate the results of this work. 
A peer review of the document should be conducted. The guidelines should be distributed to a sample of practitioners in the area of sustainable development, pedestrian and bicycle transportation, private engineering firms, public and private planning entities, and those involved in the management and operation of office parks. Formal feedback should be sought through an evaluation instrument. Allowing a diverse audience with a range of experiences to review the document will help to assure a comprehensive and usable set of guidelines. This will also allow suggestions for additional topics to be incorporated into the guidelines.

\section{Implementation}

In their current form, the guidelines are immediately usable. However, to be used, they need to be disseminated to potential users. The following strategies can be used to distribute the guidelines.

1. Local Technical Assistance Program (LTAP) - The LTAP program is a viable way to distribute the document. The LTAP organization is a national network that shares information pertaining to planning, design, operation, and maintenance of transportation facilities. Since the LTAP program is national in extent, making the document available to LTAP centers is one way of reaching a national audience. The guidelines could be posted on the LTAP Clearinghouse Website (www.ltapt2.org).

2. Internet - The final electronic version of this thesis, including Appendix A which contains the guidelines document, will be posted on WVU's electronic thesis and dissertation web page (http://www.libraries.wvu.edu/etds/). It should be noted that the thesis document and the guidelines document can 
each have separate links, to make finding the guidelines document easier. If the author submitting the electronic thesis so wishes, the information can be made accessible to the public. Thus, emails containing this link can be sent to different organization's listservs to reach a large audience. Submitting a link to the document to an organization such as the Pedestrian and Bicycle Information Center can be a way to share the document with many people specifically looking for technical information regarding accommodation of non-motorized transportation.

Also, key word combinations will be linked to the thesis web page, which will permit Internet users to access the document through use of a search engine. This will allow the guidelines to be accessed by those who enter one or more keywords using a search engine.

3. Workshops or Training - The information contained in the guidelines could be condensed into a training or workshop module. Based on the amount of information presented in the guidelines, a one-half-day module seems appropriate. Given the expertise and topic coverage in transportation-related training, LTAP could play a key role in developing, facilitating, or offering this workshop. Many centers currently offer workshops dealing with pedestrian and bicycle transportation. The proposed workshop would be a logical supplement to that course.

The intended audience for the workshop would be planners, urban designers, architects, transportation agency personnel, engineers, and public works officials. However, non-technical personnel would also benefit from 
the information in the guidelines. This includes property managers, developers, contractors, elected officials, and others who are involved in the planning, design, review, approval, and/or operations of suburban office park projects. 


\section{Chapter V: Conclusions and Recommendations}

This chapter presents conclusions regarding the guidelines and the effort involved in their preparation. Also included are recommendations for follow-up work and for dissemination of the guidelines document.

\section{Conclusions}

With the exception of a few authors, there is limited acknowledgement of the problems associated with the automobile-dependent nature of suburban office parks. There is a wealth of information available on the topics of sustainable development and planning and design techniques to enhance pedestrian and bicycle transportation. Most of these publications are generally geared towards residential, retail, or commercial (excluding the suburban office park) land uses. However, little published information was found on planning and designing suburban office parks to support non-motorized modes of transportation.

The available literature on sustainable development, pedestrian and bicycle transportation, site planning, parking design, and office parks, generally, was critically reviewed to identify guidelines that could be applied to suburban office parks. The information was then organized into a document intended for technical (e.g., engineers, architects, and planners) and non-technical (e.g., property managers, developers, contractors, and elected officials) audiences.

The desired outcome was to create an easy-to-use set of guidelines to assist a wide array of users in planning and designing suburban office parks that support and encourage non-motorized travel within and at boundaries. The guidelines are concise and 
user friendly. The format presents several main overarching principles, and, under each heading, details best practices that apply to the principle. Detailed information is presented in narrative and/or graphic form. Reference citations allow readers to go to the original source for more detailed information.

\section{Recommendations}

The guidelines document developed specific methods for planners and designers to use in creating sustainable office parks. Incorporating the applicable guidelines into office park planning and design will enhance non-motorized transportation both within park boundaries, and between the park and the surrounding community. It is recommended that practitioners use the guidelines in the planning and design of new office parks and in the retrofit of existing office parks. Constructive comments and feedback from users will help to improve the quality and utility of the document.

The guidelines should be disseminated to those involved in suburban office park planning, design, development, and review for use in their day-to-day activities. Potential strategies for distributing the guidelines include the Internet, the Local Technical Assistance Program, and workshops or training sessions. It is recommended that each of these be explored in more detail. 


\section{References}

American Association of State Highways and Transportation Officials, A Policy On Geometric Design Of Highways And Streets ( $4^{\text {th }}$ Edition), American Association of State Highways and Transportation Officials, Washington DC, 2001.

American Association of State Highways and Transportation Officials, Guide for the Development of Bicycle Facilities, American Association of State Highways and Transportation Officials, Washington DC, 1999.

Alroth, Willard A., Employment Center Parking Facilities: An ITE Information Report, Institute of Transportation Engineers, Washington DC, 1988

Anderson, Charles Arthur, Site Design And Traffic Generation In Suburban Office Park Developments, Thesis (Master of City Planning)--University of California, Berkeley, Dec. 1986.

Association of Pedestrian and Bicycle Professionals, "Bicycle Parking Guidelines", www.bicyclinginfo.org/pdf/bikepark.pdf, 2002.

Barnett, Jonathan, Redesigning Cities: Principles, Practice, Implementation, Planners Press, Chicago, 2003.

Bohl, Charles, Place Making: Developing Town Centers, Main Streets and Urban Villages, Urban Land Institute, Washington DC, 2002.

Booth, Geoffrey, Transforming Suburban Business Districts, Urban Land Institute, Washington, DC, 2001.

Booth, Geoffrey, Bruce Leonard, and Michael Pawlukiewicz, Ten Principles for Reinventing America's Suburban Business Districts, Urban Land Institute, Washington DC, 2002.

Booth, Norman, Basic Elements of Landscape Architectural Design, Waveland Press, Illinois, 1983.

Brooks, R. Gene, Site Planning: Environment, Process and Development, Prentice Hall Career and Technology, Englewood Cliffs, New Jersey, 1988.

Burden, Dan, “Building Communities with Transportation”, Transportation Research Record 1773, Transportation Research Board, Washington DC, 2001, p. 5-20.

Canadian Institute of Transportation Engineers, The Canadian Guide to Promoting Sustainable Transportation Through Site Design: Draft Guidelines, Canadian Institute of Transportation Engineers, 2003.

Casazza, John and Ronald Derven, Parking For Industrial And Office Parks: Planning, Design, Construction, And Maintenance, National Association of Industrial and Office Parks, Educational Foundation, Arlington, Va. 1986.

Cervero, Robert, America's Suburban Centers: The Land Use - Transportation Link, Unwin Hyman, London, 1989a.

Cervero, Robert, "Suburban Employment Centers: Probing The Influence Of Site Features On The Journey-To-Work ", Journal of Planning Education and Research, vol 8, no. 2, 1989b, p. 75-85.

Cervero, Robert, Suburban Gridlock, Center for Urban Policy Research, New Brunswick, NJ, 1986.

City of Portland Offices of Transportation, Bicycle Parking Facilities Guidelines, The City of Portland Offices of Transportation, www.trans.ci.portland.or.us/ bicycles/parkingguide.htm, accessed 7/08/04.

Committee on Access Management, Access Management Manual, Transportation Research Board, Washington DC, 2003.

Community Preservation Initiative web site, http://Commpres.env.state.ma.us/content/glossary.asp, accessed 2/25/05.

Congress for the New Urbanism web site, www.cnu.org, accessed 9/08/04. 
Congress for the New Urbanism, Strategies for Successful Infill Development, Congress for the New Urbanism and the Northeast Midwest Institute, Washington DC, 2001.

Creech, Heather and Terri Willard, Working Together for Sustainable Development, International Institute for Sustainable Development, Winnipeg, Manitoba, Canada, 2002.

Dewberry Companies, Land Development Handbook: Second Edition, McGraw-Hill Professional Publishing, New York, 2002.

Duany, Andres, Elizabeth Plater-Zyberk, and Jeff Speck, Suburban Nation: The Rise of Sprawl and the Decline of the American Dream, North Point Press, New York, 2000.

Ernst, Michelle and Barbara McCann, Mean Streets 2002, Smart Growth America Surface Transportation Policy Project, Washington, DC, 2002.

Ewing, Reid, Pedestrian and Transit-Friendly Design: A Primer for Smart Growth, Smart Growth Network, Washington DC, 1999.

Ewing, Reid, Rolf Pendall and Don Chen, Measuring Sprawl And Its Impact, Smart Growth America Surface Transportation Policy Project, Washington, DC, 2002.

Ewing, Reid, Traffic Calming: State of the Practice, Institute of Transportation Engineers, Washington DC, 1998.

Federal Highway Administration, "Creating Partnerships", www.fhwa.gov/tcsp/partner.html, accessed $2 / 5 / 05$.

Federal Highway Administration, FHWA Course on Bicycle and Pedestrian Transportation, Federal Highway Administration, undated.

Frej, Anne, Marvin Christensen, William D’Elia, Mark Eppli, Libby Howland, James Musbach, Frank Spink, and Dorothy Verdon, Business Park and Industrial Development Handbook, Urban Land Institute, Washington DC, 2001.

Gause, Jo Allen, Mark Eppli, Michael Hickok, and Wade Ragas, Office Development Handbook: Second Edition, Urban Land Institute, Washington, DC, 1998.

Gruen + Gruen Associates and Urban Land Institute, Employment and Parking in Suburban Business Parks: A Pilot Study, Urban Land Institute, Washington, DC, 1986.

Holtzclaw, John, "Community Characteristics Promoting Transit and Walking", Transportation Issues, Sierra Club, undated, www.sierraclub.org/sprawl/articles/characteristics.asp.

Ingram, Dewayne, "Basic Principles of Landscape Design”, University of Florida IFAS Extension, www.edis.ifas.ufl.edu/scripts/htmlgen.exe?DOCUMENT_MG086, 1991.

ITE Neighborhood Street Design Committee, Neighborhood Street Design Guidelines: A Proposed Recommended Practice of the Institute of Transportation Engineers, Institute of Transportation Engineers, Washington DC, 2003.

ITE Smart Growth Task Force, $\underline{\text { Smart Growth Transportation Guidelines: An ITE Proposed Recommended }}$ Practice, Institute of Transportation Engineers, Washington DC, 2003.

ITE Technical Council Committee 5D-8, Guidelines For Parking Facility Location And Design, Institute of Transportation Engineers, Washington DC, 1994.

Kirschbaum, Julie, Peter Axelson, P. Longmuir, Kathleen Mispagel, Julie Stein, Denise Yamada, Accessible Sidewalks and Trails, Part II of II, FHWA - Federal Highway Administration, Washington DC, 2001.

Lang, Robert E., Beyond Edge City: Office Sprawl in South Florida, The Brookings Instituttion, Washington, DC, 2003a.

Lang, Robert E., Edgeless Cities: Exploring the Elusive Metropolis, The Brookings Institution, $2003 \mathrm{~b}$.

Lang, Robert E., Office Sprawl: The Evolving Geography of Business, The Brookings Instituttion, Washington, DC, 2000. 
Lighting Design Lab Website, http://lightingdesignlab.com/articles/pedestrian/pedestrian.htm, accessed $8 / 04$.

Litman, Todd, Economic Value of Walkability, Victoria Transport Policy Institute, Victoria, BC, 2003a.

Litman, Todd, Evaluating Transportation Land Use Impacts, Victoria Transport Policy Institute, Victoria, BC, 2003b

Litman, Todd, Pavement Busters Guide: Why and How to Reduce the Amount of Land Paved for Roads and Parking Facilities, Victoria Transport Policy, Victoria, BC, 2000.

Litman, Todd, Robin Blair, Bill Demopoulos, Nils Eddy, Anne Fritzel, Danelle Laidlaw, Heath Maddox and Katherine Forster, Pedestrian and Bicycle Planning: A Guide to Best Practices, Victoria Transport Policy Institute, Victoria, BC, 2002.

Livable Centres Program, "Regional Town Centres and Office Development: Promoting Employment in Accessible Locations", Livable Centres Task Group, Vancouver, Canada, 2003, www.gvrd.bc.ca/ livablecentres/ PDFs/RTC_and_Office_Devel_2004.pdf.

McCann, Barbara A., and Reid Ewing, Measuring the Health Effects of Sprawl: A National Analysis of Physical Activity, Obesity and Chronic Disease, Smart Growth America Surface Transportation Policy Project, Washington, DC, 2003.

McCourt, Ransford S., Parking Generation $3^{\text {rd }}$ Ed., Institute of Transportation Engineers, Washington DC, 2004.

Miara, Jim, "Fueling Sprawl", Urban Land, vol. 59, No. 5, 2000, p.78 thru 79, 111.

Motlock, John, Introduction to Landscape Design: Second Edition, John Wiley \& Sons, Inc., New York, 2001.

Oregon Transportation and Growth Management Program, Commercial and Mixed Use Development Code Handbook, Oregon Transportation and Growth Management Program, Salem, OR, Undated.

Pline, James L., Traffic Engineering Handbook 5th Edition, Institute of Transportation Engineers, Washington DC, 1999.

Porter, Douglas, and Rutherford Platt, The Practice of Sustainable Development, Urban Land Institute, Washington DC, 2000.

Prince William County Comprehensive Plan, "Illustrative Design Guidelines for Office Development", www.pwcgov.org/docLibrary/PDF/001876.pdf, accessed 10/8/04.

Project for Public Spaces, “Good Places”, http://www.pps.org/info/placemakingtools/casesforplaces/

goodplaces, accessed 2/26/05a.

Project for Public Spaces, "Why Many Public Spaces Fail”, http://www.pps.org/info/placemakingtools/ casesforplaces/failed_place_feat, accessed 2/26/05b.

Rich, David, "Strategies to Improve Security in Your Parking Facility", Parking Today, June 2003, p. 3839, 46-47.

Schwanke, Dean, Patrick L. Phillips, Frank Spink, Charles Lockwood, David Versel, Steven Fader, Leslie Holst, Oliver Jerschow, Deborah Myerson, Mixed-Use Development Handbook, Urban Land Institute, Washington DC, 2003.

Smart Growth Network, Getting to Smart Growth: 100 Policies for Implementation, Smart Growth Network, International City/County Management Association, 2002.

Smart Growth Network, Getting to Smart Growth II: 100 More Policies For Implementation, Smart Growth Network, International City/County Management Association, 2003.

Sprawl Watch Clearing House web site, www.sprawlwatch.org, accessed 12/6/04.

Stover, Virgil G. and Frank J Koepke, Transportation and Land Development, Institute of Transportation Engineers, Washington DC, 2002. 
The Surface Transportation Policy Project, Transportation Costs and the American Dream: Why a Lack of Transportation Choices Strains the Family Budget and Hinders Home Ownership, A Special Report from the Surface Transportation Policy Project, Washington DC, 2003.

Texas Transportation Institute and Texas A\&M Research Foundation, TCRP Report 19: Guidelines for the Location and Design of Bus Stops, Transit Cooperative Research Program and Transportation Research Board, National Academy Press, Washington DC, 1996.

Urban Land Institute and National Parking Association, The Dimensions of Parking: Fourth Edition. Washington DC, 2000.

US Access Board Website, ADA Accessibility Guidelines (ADAAG), The US Access Board, www.accessboard.gov, Accessed 10/04/04.

US Environmental Protection Agency and Local Government Commission, Creating Great Neighborhoods: Density In Your Community, Local Government Commission in cooperation with U.S. EPA, Sacramento, CA, 2003.

US Environmental Protection Agency, Parking Alternatives: Making Way for Urban Infill and Brownfields Redevelopment, U.S. Environmental Protection Agency, Washington DC, 1999.

Van der Ryn, Sim, and Peter Calthorpe, Sustainable Communities: A New Design Strategy for Cities, Towns, and Suburbs, Sierra Club Books, San Francisco, 1986.

Victoria Transport Policy Institute Web Site, www.vtpi.org, accessed 9/08/2004a.

Victoria Transport Policy Institute, Bicycle Parking, Online TDM Encyclopedia, www.vtpi.org/tdm/tdm85.htm, accessed 7/08/2004b.

White, John Robert, The Office Building: From Concept to Investment Reality, Counselors of Real Estate, Appraisal Institute, Society of Industrial Office Realtors, Washington DC, 1993.

Zegeer, CV, C. Seiderman, P. Lagerwey, M. Cynecki, M. Ronkin, and B. Schneider, Pedestrian Facilities Users Guide: Providing Safety And Mobility, Report FHWA-RD-01-102, Federal Highway

Administration, Washington DC, 2002. 


\section{Supplemental Bibliography}

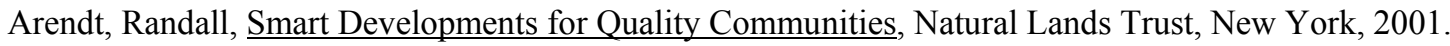

Barnett, Jonathan, Redesigning Cities: Principles, Practice, Implementation, Planners Press, Chicago, 2003.

Bernick, Michael and Robert Cervero, Transit Villages in the 21st Century, McGraw-Hill, New York, 1997.

Cervero, Robert, The Transit Metropolis: A Global Inquiry, Island Press, Washington DC, 1998.

Ditmar, Hank and Gloria Ohland, The New Transit Town: Best Practices in Transit-Oriented Development, Island Press, New York, 2004.

Duany, Andres, Elizabeth Plater-Zyberk, Alex Kreiger, and Others, Towns and Town-Making Principles, Harvard University Graduate School of Design, Cambridge, Massachusetts, 1991.

Duany, Andres and Jeff Speck, Smart Growth Manual, McGraw Hill, New York, 2004.

Ewing, Reid and Robert Hodder, Best Development Practices: A Primer for Smart Growth, International City/County Management Association and Smart Growth Network, 1998.

Hall, Kenneth and Gerald Porterfield, Community By Design: New Urbanism for Suburbs and Small Communities, McGraw-Hill, New York, 2001.

Kelbaugh, Doug, The Pedestrian Pocket Book: A New Suburban Design Strategy, Princeton Architectural Press, New York, 1989.

Moudon, Anne, Paul Hess, Mary Snyder, Kiril Stanilov, "Effects of Site Design on Pedestrian Travel in Mixed Use, Medium Density Environments", Transportation Research Record 1578, 1997, p. 48-55.

Moudon, Anne, Paul Hess, Mary Snyder, Kiril Stanilov, "Site Design and Pedestrian Travel", Transportation Research Record 1674, 1999, p. 9-19.

New Urban News, New Urbanism: Comprehensive Report and Best Practices Guide: Second Edition, New Urban Publications, Chicago, 2001.

NALGEP and Smart Growth Leadership Institute, Smart Growth is Smart Business: Boosting the Bottom Line and Community Prosperity, NALGEP and Smart Growth Leadership Institute, downloaded from www.smartgrowth.org, accessed 5/11/04, published 2004.

Porter Douglass, Making Smart Growth Work, Urban Land Institute, Washington DC, 2002.

Shaw, Jane and Ronald Utt, A Guide to Smart Growth: Shattering Myths, Producing Solutions, The Heritage Foundation and PERC, 2000. 
Appendix A: Planning and Design Guidelines for Accommodating Non-Motorized Transportation in Suburban Office Parks 


\section{Planning \& Design Guidelines}

For Accommodating Non-Motorized

Transportation in Suburban

Office Parks

\section{Author: Keith Bryant}

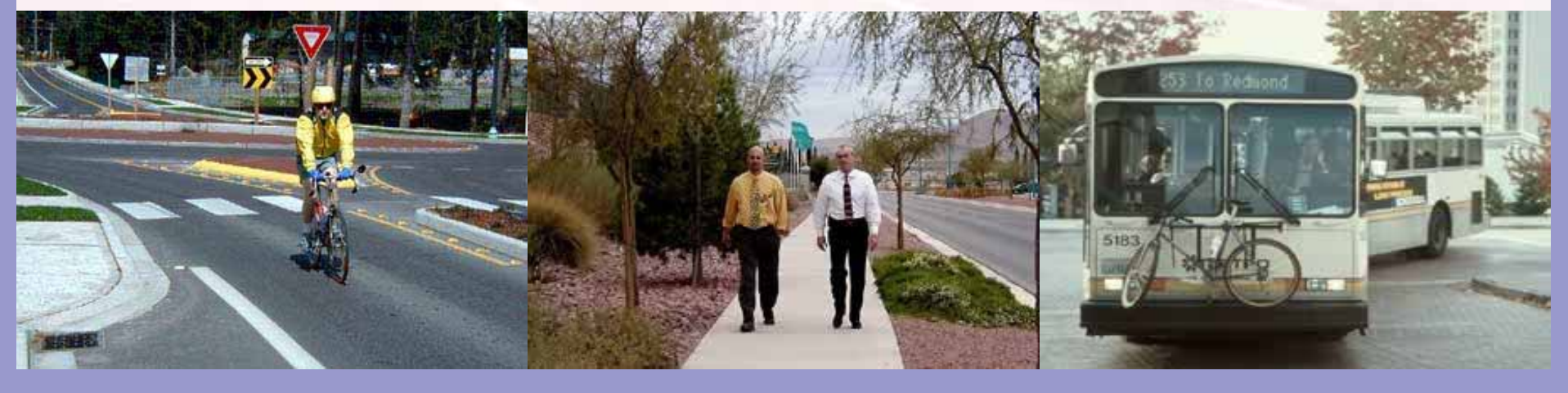




\section{Table of Contents}

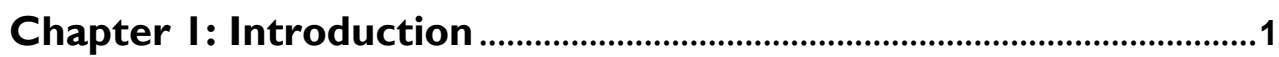

Purpose

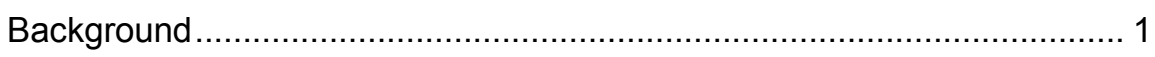

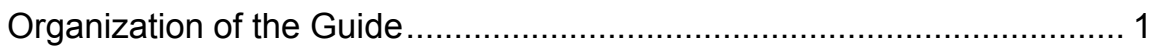

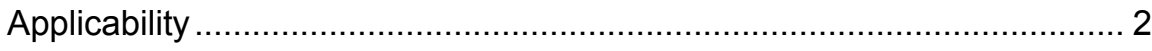

Chapter 2: Characteristics of Sustainable Transportation .............3

The Relationship Between Land Use and Transportation ........................ 3

Factors Influencing Use of Sustainable Transportation Modes.................. 4

Principles of Sustainable Transportation Modes ..................................... 6

Chapter 3: Guidelines ..................................................................9

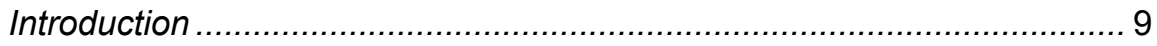

Organization of the Guidelines ........................................................... 9

A: General Site Design Issues ..............................................10

Land Use Planning ................................................................ 10

Community Context................................................................ 13

Supporting Programs and Policies....................................... 14

B. Site Layout and Pedestrian and Bicycle Site Amenities ........16

Building Location and Shape .................................................. 16

End-of-Trip Pedestrian and Bicycle Considerations ............... 19

The Elements of Pedestrian Places (Common Space) ............ 21

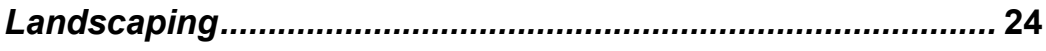

C. Site Infrastructure for Vehicular and Non-Motorized

Transportation.....................................................................28

External Office Park Pedestrian and Bicycle Access .............. 28

Internal Pedestrian and Vehicular Circulation......................... 29

Parking................................................................................. 34

Public Transportation/Transit Connections............................. 38

Selected Bibliography .....................................................................40 


\section{Chapter}

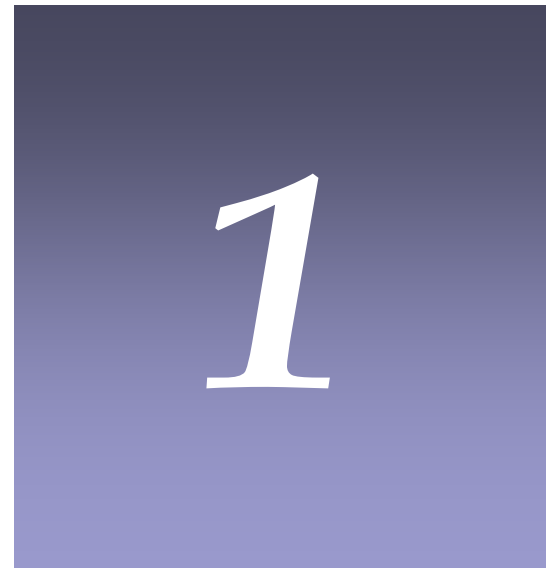

\section{Purpose}

The main purpose of this guide is to assist professionals involved in the planning, design, review or approval, and operations of suburban office parks, to enhance and encourage non-motorized travel. The document illustrates the many opportunities that parties involved in suburban office park development have to support sustainable transportation, including policy development, organizational practices, site layout and design, and agency review.

\section{Background}

Suburban office parks can be significant contributors to traffic congestion in suburban areas. One of the reasons is that such office parks typically require automobile trips to access them. Automobiles are necessary to reach these office parks given the spatial arrangement of land uses, development densities and distances involved.

Location, infrastructure and site design issues within office campuses affect mode choice. Availability of transit is also a factor. While commuting to and from an office park may present many trip barriers to pedestrians and bicyclists, the design of the office park itself can affect the mode used by employees to travel within the park. In many instances, little attention has been given to non-motorized modes.

Thus, a need was identified for guidelines to enhance design elements that encourage nonmotorized transportation in suburban office parks. To facilitate the creation of these guidelines, a literature review was performed to identify key principles, guidelines and implementation strategies. This information was then synthesized into a single document.

\section{Organization of the Guide}

The guide has two main parts. The first part presents definitions and principles. The second part presents the actual guidelines.

The first part of the guide examines general characteristics of sustainable development. The relationship between land use and transportation is discussed briefly as it relates to suburban office 
park development. The underlying principles of sustainable development are then discussed. Factors that affect transportation mode choice are discussed generally, with a particular focus on how office park form can encourage or discourage non-motorized transportation. The factors that influence use of sustainable modes are also identified. The various commute mode alternatives, such as automobile, public transportation (including ridesharing), walking, and biking, are discussed in this section. The underlying principles and characteristics of the various modes of transportation are outlined.

The second part of the guide presents the actual guidelines by topic, including recommended practices that can be used in accommodating non-motorized transportation in suburban office parks. Topics covered are general site design issues, site layout and pedestrian/bicycle amenities, and site infrastructure for vehicular and non-motorized transportation.

\section{Applicability}

The intended audience for the guide is rather broad, including but not limited to planners, urban designers, developers, architects, transportation agencies, property managers, engineers and others who are involved in the planning, design, review or approval, and operations of suburban office park projects. Each of those mentioned is involved in facilitating the accommodation of nonmotorized transportation, in some form or another. For instance, a building architect may not directly be involved with the design that occurs outside of the building envelope. However, some of the decisions made by the architect have an impact on pedestrians, bicyclists, and transit riders. This is true of the other involved parties. 


\section{Chapter}
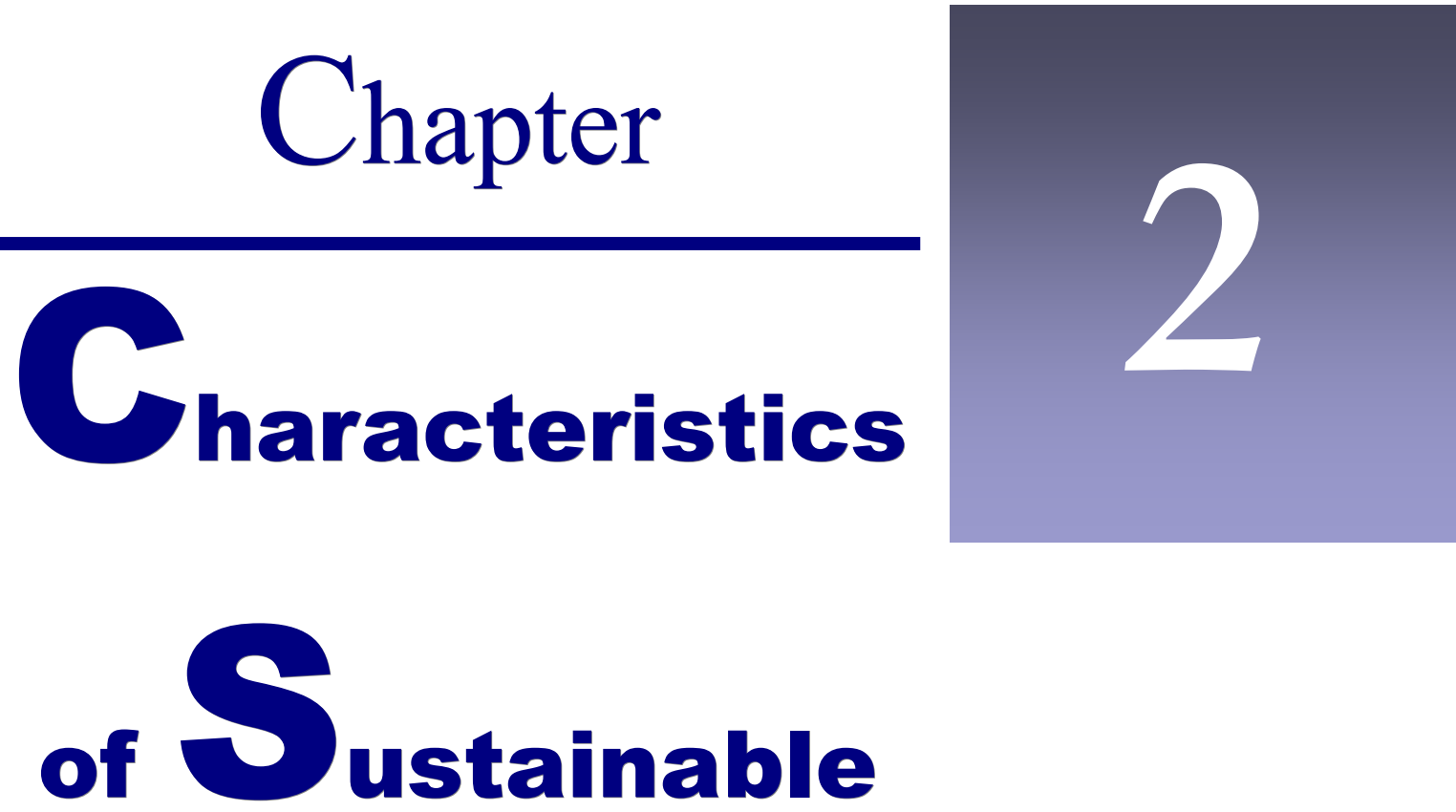

\section{ransportation}

\section{The Relationship Between Land Use and Transportation}

Transportation and land development have always been closely related. As towns and cities grow, the transportation system develops accordingly. Stover and Koepke (2002) point out that construction of a new street or major reconstruction of an existing thoroughfare changes the accessibility of an area, which leads to development and increased traffic demands. This development results in reduced capacity, traffic delays, high levels of motorist discomfort, crashes and a reduced quality of traffic service. To accommodate the increased traffic demand, additional roadway improvements are needed and a cycle of events occurs that requires continuing capital investment for arterial improvements or relocation.

The traditional suburban development pattern just described and exacerbated by zoning regulations developed for the post World War II era, have led to the phenomenon referred to as sprawl. Sprawl is characterized by low land use densities, large property setbacks, segregation of different land uses requiring a motor vehicle to travel between them, high-speed arterial streets, and lack of accommodation of pedestrians and bicycles. 
Regulatory and policy techniques and transportation infrastructure enhancements help manage or control sprawl. Regulatory and policy techniques include modifying zoning laws to encourage sustainable land development patterns, transportation demand management (TDM) techniques (to encourage ridesharing, flextime work hours, alternate work week schedules, and other non-design tactics that can be implemented by employers), and land use planning policies that encourage development to be more closely coordinated with and enhance the transportation infrastructure.

In response to increasing traffic congestion, pedestrian/bicycle inaccessibility, and other consequences of sprawl, sustainable development concepts have been touted as offering guiding principles to help curb the undesirable effects of sprawl. Sustainable development concepts are consistent with traditional land use planning concepts, i.e., mixing uses, increasing land use densities, encouraging transit use, and enhancing the non-motorized transportation infrastructure to increase walking and bicycling for transportation and recreation.

\section{Factors Influencing Use of Sustainable Transportation}

\section{Modes}

Sustainable transportation generally means modes of transportation other than single-occupantvehicle (SOV) travel. Modes include walking, bicycling, transit/public transportation, and ridesharing. Of all the modes listed above, the SOV mode is the least sustainable (for reasons described later in this chapter). As shown in the figure below, for office parks, the automobile is by a large margin, the dominant mode used for commuting. Furthermore, the percentage of automobile usage for office parks is greater than the U.S. average for daily commute mode selection.

Daily Trips by Mode (United States)

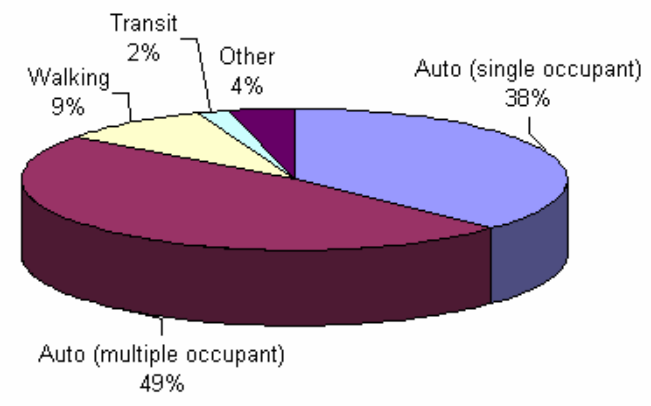

Source: The National Bureau of Transportation Statistics (Pocket Guide to Transportation 2004, www.bts.gov/ publications/pocket_guide_to_transportation/2004/).

\section{Commute Trips by Mode for Office Parks}

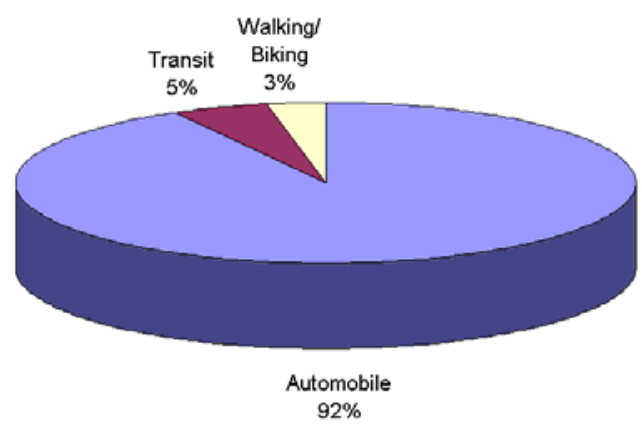

Source: Livable Centres Program, Regional Town Centres and Office Development: Promoting Employment in Accessible Locations, Livable Centres Task Group, Vancouver, Canada, 2003 (www.gvrd.bc.ca/ livablecentres/ PDFs/RTC_and_Office_Devel_2004.pdf).

There are many factors that ultimately determine which mode will be selected for a particular trip. Currently, automobile travel predominates in suburban office park environments. To integrate nonmotorized modes of transportation more widely into the overall transportation system and for office parks, a number of factors must be addressed. Principal factors are: 
1. Distance and Time - How far away is the destination? How long will the trip take?

2. User Convenience - Is there flexibility in the travel schedule? Will it be possible to make side trips or run errands at lunch or after work? Will there be a convenient way to carry belongings?

3. Safety and Security - Will the mode chosen make the traveler feel unsafe or uneasy? Or, will the mode chosen offer a perceived sense of security?

4. User Cost - How much will it cost to own, operate, maintain, or to use a particular transportation mode? Will cost be prohibitive for the traveler's income?

5. Environmental Conditions - Will the traveler be exposed to rain, sleet, snow, temperature extremes, or other elements for a prolonged period of time? Will the traveler be able to comfortably make the trip?

6. Varying Abilities, Health Conditions, and Lifestyle - Will ambulatory, ocular, or other impairments prohibit the traveler from reaching their destination? What are the physical characteristics of the traveler? Are they young (strong in stature, above-average stamina), or elderly (reduced endurance, limited strength)? Are there individuals who wish to use non-motorized transportation specifically for personal health benefits?

7. Psychological or Social Factors - How will the traveler be perceived by others? Are there underlying social or cultural preferences (e.g., active community or sedentary lifestyle patterns)?

8. End-of-Trip Considerations - Will there be a parking stall, bus shelter, bicycle rack, change area, shower, or other end-of-trip amenity at the destination?

These factors and others play a part in the mode choice decision. Each mode also has different operating characteristics and features that play a part in mode choice.

- Single Occupant Vehicles (SOVs) easily overcome distances, are flexible in choosing departure time and route taken, are useful in hauling personal belongings, offer shelter from the elements, and offer a high level of perceived comfort, safety, and security. However, SOVs are the most expensive mode in terms of user cost, are the most detrimental to the environment, and do not offer personal health benefits that non-motorized modes may offer.

- Walking does not offer some of the same 'convenience' benefits as SOVs. For instance, pedestrians cannot haul significant amounts of personal belongings, do not quickly overcome distance, they are exposed to perceived dangers, and they are exposed to the elements. However, walking has negligible user costs, is not detrimental to the environment, can reduce vehicular traffic, and is a good source of exercise that may lead to personal health benefits.

- Bicycling is similar to walking in that it has low user costs, is not detrimental to the environment, can reduce vehicular traffic, and is also a good source of exercise. In addition, bicycling offers added 'convenience' benefits, such as the ability to overcome much longer distances, and allows a limited amount of personal belongings to be hauled. However, bicycling does not provide a high level of personal security, i.e., there is a higher level of perceived exposure to dangers and the elements compared to SOVs.

- Transit/Ridesharing can overcome distances easily; similar to SOVs. These modes offer shelter from the elements en-route and a moderately low user cost. However, there is little flexibility in departure time and route selected, one may have difficulty hauling belongings, and these modes may have negative effects on the environment. It should be noted that this effect is minimized since high-occupancy levels of ridership capture trips that may otherwise be taken 
by SOV mode. Transit modes are not generally perceived as a comfortable way to travel. For instance, a person may feel uncomfortable when seated in a crowded bus. Additionally, some may not use transit because of the perceived image sometimes associated with transit.

\section{Principles of Sustainable Transportation Modes}

Many sustainable development principles are applicable to suburban office park design. However, sustainable development principles are typically all-encompassing, and not specifically aimed at suburban office parks. Consequently, this set of guidelines combines and synthesizes the principles presented in the sustainable development, site planning and parking, and pedestrian/bicycle transportation literature that are specifically applicable to encouraging sustainable transportation modes in suburban office park design. The following underlying principles can be applied to adapt or create suburban office parks that support non-motorized transportation.

\section{Create Direct Internal and External Non-Motorized Linkages}

Barring a physical barrier, or a perceived threat to personal safety, pedestrians will always try to minimize the distance from their origin to their destination. With this in mind, measures should be taken to link suburban office parks with the surrounding community and to connect destinations within the park. Installing sidewalks or connecting missing links in sidewalk networks is an obvious place to start. Shared use paths may provide convenient linkages between an office park and nearby residential development. Bicycle lanes can be designated on perimeter roads. Destinations within office parks should also be well-connected. Linking internal land uses with sidewalks, trails and paths promotes walking and bicycling within the site. This may help to capture trips that would otherwise be made by automobile. Well-located transit connections and well-designed drop-off/pickup areas encourage transit ridership.

\section{Retrofit, Improve, or Create On-Site Features to Encourage Non-Motorized}

\section{Transportation}

Just as it is important to create internal and external linkages, it is also important to supplement the linkages with features that enhance, or encourage non-motorized transportation to and within the park. Consideration should be given to creating "pedestrian places", or common space, within office parks. This can range from creating pocket parks or plazas to adding amenities such as outdoor seating, tables, and trash receptacles.

End-of-trip pedestrian and bicycle accommodations are important. Features such as bicycle storage, showers, lockers, and change facilities make biking and walking attractive for commuting and/or exercise. Placing these amenities at trip ends helps to promote an active lifestyle, while lack of these facilities may discourage non-motorized transportation.

Lastly, landscaping can enhance the pedestrian environment if planned and installed properly. In addition to the overall aesthetic enhancements that landscaping can produce, it can be used to highlight pedestrian connections, channelize pedestrians along walkways and at intersections, and provide shelter from the elements. A row of densely foliated trees along a walkway can help shelter pedestrians from precipitation and sunlight, while also providing protection from the wind. 


\section{Encourage Compact, Pedestrian-Friendly Landforms}

Typically, suburban office parks range from tens-of-acres to hundreds-of-acres in size. This, along with the absence of supporting land uses within the park, discourages people from using sustainable transportation modes during employee break periods. Consequently, employees must use personal automobiles to get lunch or run errands.

Providing a mix of land uses on-site is a way of capturing these trips. Arranging complementary land uses along with commercial office land uses, in a compact, form brings these destinations closer to one another; thereby making walking and bicycling more attractive alternatives for internal trips. Land uses that are compatible in office park settings include retail stores, restaurants, hotels, fitness centers, day care centers, and banks.

Using urban design techniques such as arranging buildings into more compact landforms can also enhance opportunities for the site to be served by transit. A transit stop better serves a large site if buildings are situated closer to one another, provided that there are adequate densities to support the transit service.

\section{Create and Maintain a Safe and Secure Walking and Bicycling Environment}

When choosing a commute mode, safety and security are important factors in the decision. In terms of non-motorized transportation, safety implies being free from personal injury due to conflicts with other modes (e.g., cars, buses). An area where pedestrians are forced to frequently commingle with automobile traffic may be intimidating, or deter walking or bicycling. Designing a transportation infrastructure that considers all users can help to create a more pedestrian-friendly site. Providing separation from vehicular traveled ways and periodic crossings can help achieve a more "balanced" transportation infrastructure that considers all users.

Additionally, safety implies being free from personal injury due to dangerous surface conditions (e.g. slippery, irregular, or unstable surface). If a walkway surface is improperly designed or maintained, it may pose a risk of a slip or trip-type fall. Likewise, the travel surface for bicycle facilities must be designed and maintained to eliminate those things that severely affect bicycle control, e.g., open grates, metal surfaces, and loose materials.

Security implies protection or freedom from fear or doubt when walking, bicycling, or using transit. Non-motorized modes have a more intimate relationship with their environments. Thus, nonmotorized modes are generally more exposed to the elements, animals, other people, and vehicles. Pedestrians are not likely to travel by foot in environments where they feel uneasy or fear harm from a person, animal, or some other threat. For example, dense landscaping and upscale office buildings may appear to be inviting surroundings for a pedestrian during the day. By night, the same place may not seem as inviting. Under conditions of darkness (or dim lighting), these features create visibility concerns which in turn can cause apprehension about personal security.

Therefore, maintaining adequate lighting levels, creating good visibility, and providing emergency communication devices all help to create a more secure pedestrian environment. There are other design features that increase a feeling of security. Designing an environment that is inviting to pedestrians may actually increase perceived security. Including a variety of complementary land uses with numerous window and door openings can help to stimulate pedestrian activity throughout the day and into the night. 


\section{Encourage Partnerships and Collaborative Efforts Between All Entities Involved In the Development Effort}

Large-scale developments such as office parks require partnerships and collaborative effort from a wide array of public and private entities. While this is generally true with any type of large project, it is especially important when making provisions for non-motorized modes of transportation. Lack of coordination can create a disconnect when incorporating a large-scale office development into a community. Important design details such as building placement, parking layout, sidewalk placement, and linkages to adjacent destinations may be overlooked if the governing entity (public) places little or no emphasis on these issues. Likewise, owners/developers and those who are responsible for the design and layout of office parks (private) should be conscious of the impacts that these large-scale developments have on communities, and strive for planning, designing, and construction that are compatible with the surrounding area.

Successful partnerships can help link transportation and community in many ways. The formation of partnerships can help build consensus by bringing together groups with different viewpoints to discuss common visions and solutions. To work together effectively, partners should share a common commitment to the partnership. Organizations must learn how to work with and communicate with one-another. For communities discussing alternative transportation and land development scenarios, outreach to developers, financial institutions, and real estate professionals is critical. Partnerships with these groups will help educate all parties about the impacts of various development patterns and potential alternatives to existing patterns. At the same time, partnerships help planners, engineers, and other technical personnel understand issues from the viewpoint of those who are directly responsible for land development.

\section{Players Involved in the Development Process}

\section{$\underline{\text { Public }} \quad \underline{\text { Private }}$}

- Local government members (building and development, planning, engineering, and economic development)

- $\quad$ Reviewing Agencies, DOT / Transit Agency

- Local Media

- Community Leaders

- Community Members

- $\quad$ Special Interest Groups
- $\quad$ Engineers

- Architects

- Planners

- Project Managers

- Realtors

- Financial Institutions

- Developers

- Owners/Investors

- Contractors

- Local Media 


\section{Chapter}

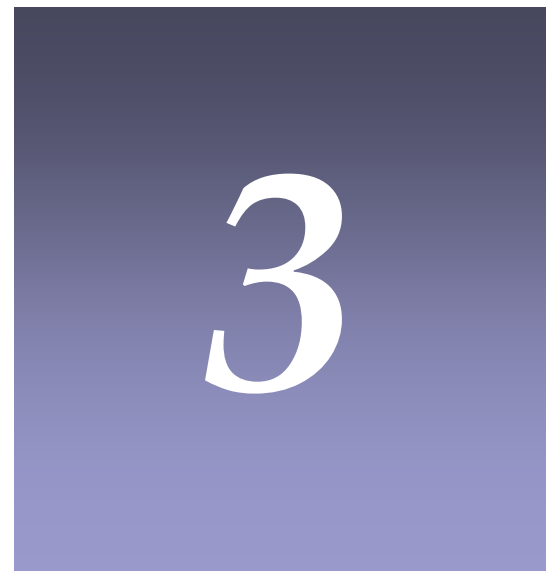

\section{Introduction}

This chapter presents overall objectives and specific guidelines that can be used to design suburban office parks that accommodate and support non-motorized transportation. The guidelines apply to the planning and design process but individual guidelines may not be applicable in both phases. The broader guidelines, such as those dealing with overall site design, will apply at the planning phase. More detailed guidelines, such as those dealing with pedestrian amenities, will apply at the detailed design phase. Additionally, some of the objectives and guidelines can be applied to retro-fit sites that are already developed.

Since the focus is planning and design, the guidelines do not address construction and maintenance issues. Note, however, that since construction and maintenance affect non-motorized transportation, attention needs to be given to pedestrians and bicycles in these phases of a project as well.

It is recognized that there is tremendous variability in suburban office parks and that all of the guidelines will not be applicable to every office park. However, given the breadth of coverage of the guidelines, users should find applicable portions (whether part of the initial design or to accommodate future build-out) of the park. For example, even though a semi-rural park may not be served by transit initially, the building layout and streetscape can be designed to accommodate future transit service. Finally, it should be noted that these guidelines are intended for office parks that do not have special security restrictions.

\section{Organization of the Guidelines}

The guidelines are presented in three sections:

A: General Site Design Issues - This section discusses overarching land use considerations (mixing land uses, land use densities, and supporting programs and policy issues) for office parks, and is written on a macro-level (i.e., less detail-oriented than sections $3 \mathrm{~B}$ and $3 \mathrm{C}$ ).

B: Site Layout and Pedestrian and Bicycle Amenities - Issues such as building location, and shape are discussed, along with end-of-trip pedestrian facilities, the elements of pedestrian places, and landscaping considerations.

C: Site Infrastructure for Vehicular and Non-Motorized Transportation - Pedestrian and bicycle access at a site's periphery, internal pedestrian and vehicle circulation, parking, and public transportation/transit connections are discussed. 


\section{A: General Site Design Issues}

\section{Land Use Planning}

Although these guidelines focus on site design rather than land use and transportation planning matters, decisions at the site level can affect urban form when considered from a regional viewpoint. This section includes a general discussion of key land use and transportation planning considerations that affect non-motorized transportation and more sustainable landforms in suburban office park development.

\section{Objective: Promote Mixed-Use, Higher-Density Development that Increases}

\section{the Potential for Walking, Cycling, and Transit Use.}

\section{Guidelines}

- Mix Complementary Land Uses In and Around Office Parks to Create a Self-Contained Environment. Such an environment is more sustainable than a single-land-use office park that relies on personal automobile for travel within and outside of its boundaries. Office parks can include residential, commercial/retail, cultural, and entertainment/recreational land uses on-site. Some key considerations are outlined below.

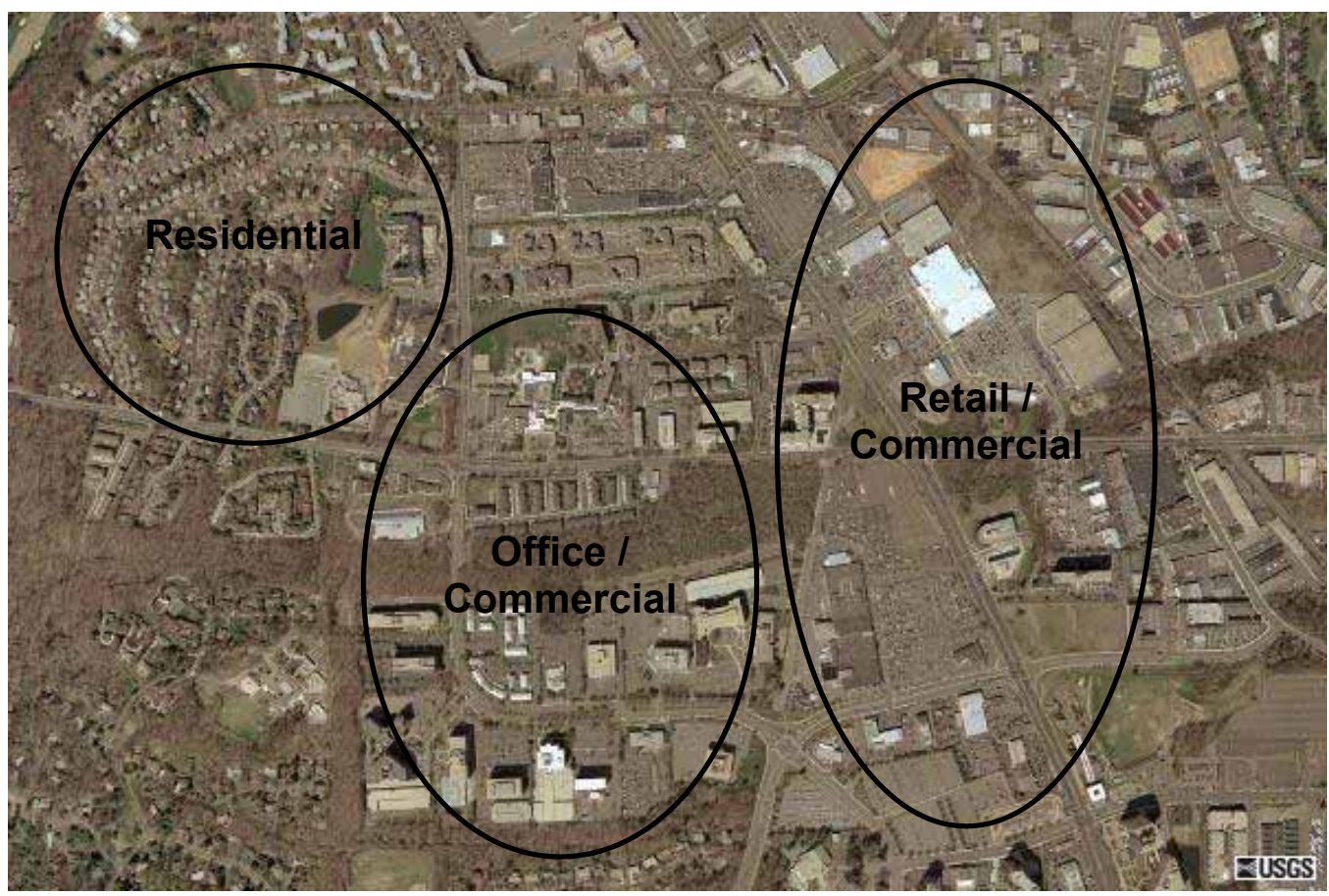

Spatially Segregated Single Land Use Areas

Traditional suburban development methods, like those shown in the aerial photo above, increase travel distances for non-motorized modes by spatially separating land uses (source: http://terraserver.microsoft.com). 


\section{Residential}

Whether on-site, or nearby off-site, housing can be an effective way for office parks to encourage non-motorized commuting. Housing that is within $1 / 4$ to $1 / 2$ mile of the majority of office buildings in an office park, corresponds a 5-to 10-minute walk for employees. However, direct non-motorized linkages must connect nearby housing to the office buildings. Lack of convenient linkages can lead to a circuitous journey that discourages walking.

As a rule of thumb, multifamily housing (row houses and apartment buildings) should be located closer to the core of development. Multi-family housing typically has higher densities than single-family housing, and thus, is better able to support transit, retail land uses, and other services that are dependent on higher densities. Conversely, residential areas with lower densities should be located near the periphery of the core development area.

Including housing as a part of large-scale office parks, not only offers benefits in terms of encouraging non-motorized transportation; it can lead to economic and social benefits. Developers who choose to build housing or locate an office park in close proximity to housing may enjoy savings in the form of parking reductions, density bonuses, and other regulatory credits. Living in close proximity to an employment center can also lead to employee benefits such as transportation-related savings (vehicle fuel and maintenance costs), lower financing costs (some lending institutions offer location-efficient mortgages), health benefits (reduced risk of heart disease and other illnesses associated with physical inactivity), and social benefits (sense of community and avoiding rush hour traffic).

\section{Retaill and Commercial}

Retail and commercial land uses can also be included in suburban office parks. However, the absence of people after normal work hours can limit these opportunities in homogenous suburban office park settings. An environment that includes nearby residents, in addition to weekday workers, supports retail establishments. Adding retail and commercial establishments to residential and office-commercial land uses promotes a self-sustaining environment. That is, residents and workers can travel short distances for essential goods and services.

Examples of supportive retail and commercial establishments are: day care centers, convenience stores, dry cleaners, restaurants/cafes, automotive services (washing, detailing, oil change), video rentals, banking services, and hotels. 


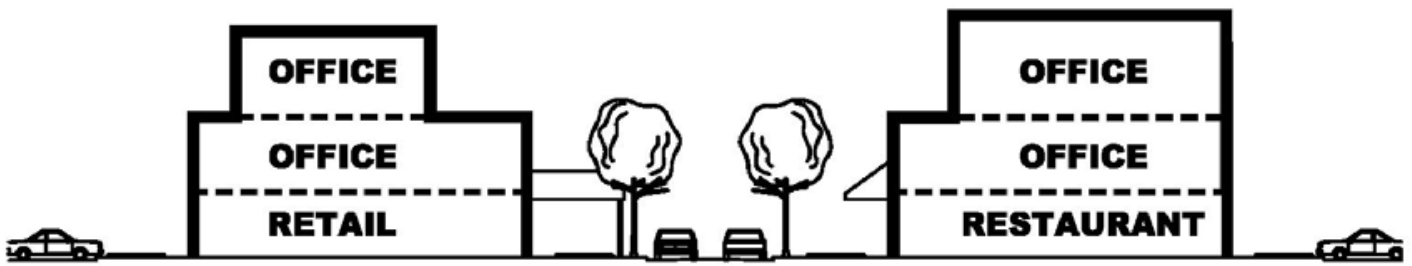

Office Over Retail

Encourage land uses that stimulate pedestrian activity by placing complementary land uses at ground level, with office space on subsequent floors.

\section{Entertainment, Recreational, and Cultural}

Including entertainment, recreational, and cultural land uses to complement residential, commercial, and retail land uses provides opportunities to live, work, and play on-site. A growing number of office parks include recreational facilities such as swimming pools, gymnasia, health clubs, and multi-use trails to benefit their employees and the surrounding community. Some office parks include entertainment and cultural establishments, such as theaters, art galleries, outdoor stages, upscale lounges, and other social gathering places.

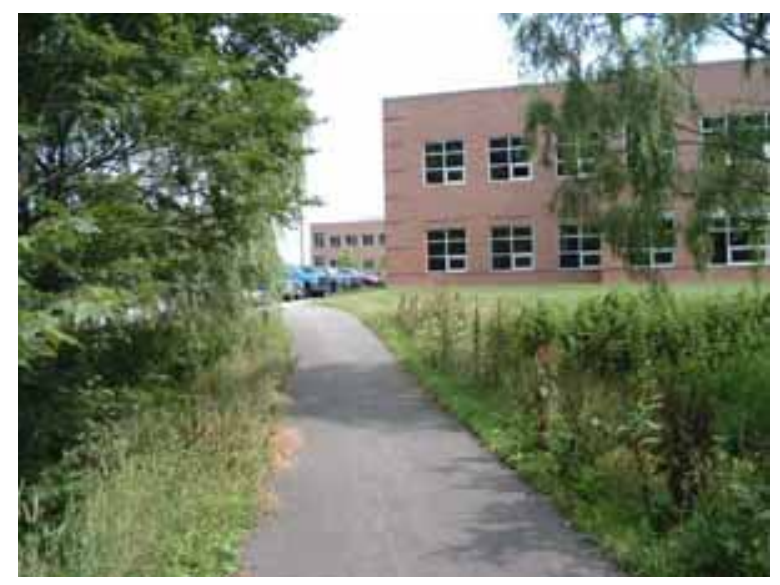

Trails for Transportation and Recreation This office park is enhanced by a shared-use trail. The existing shared-use trail was incorporated into this office park's overall site

- Encourage Compact, Urban Form to Create plan. Trails, such as this one, can be an attractive pedestrian Usable Open Space. Creating denser, amenity. compact landforms presents opportunities to establish "usable" open space. When buildings are arranged closer to one another to form a

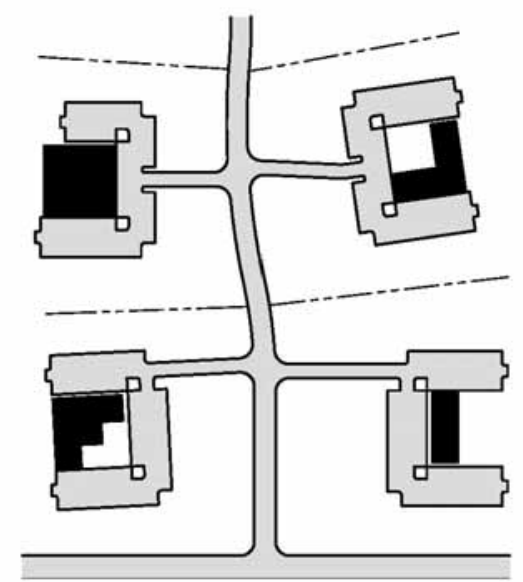

TYPICAL CAMPUS STYLE OFFICE PARK LAYOUT WITH INDIVIDUAL PARKING LOTS AND INDIVIDUAL OPEN SPACE

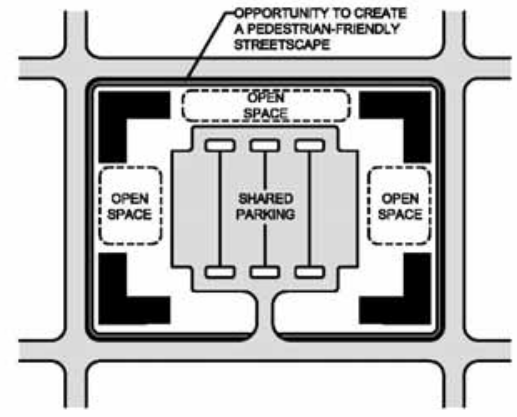

CLUSTERED OFFICE ARRANGEMENT WITH INTERIOR COURTYARD, SHARED PARKING ARRANGEMENT AND SHARED OPEN SPACE 
dense core, the remainder of land that would otherwise be covered with buildings or parking lots can be utilized for recreational facilities such as parks, plazas, greenways, and other aesthetically pleasing and pedestrian-friendly landforms. Traditional suburban development practices usually place a small percentage of open space on each parcel of land. This creates a small amount of open space on multiple properties, with limited opportunity to coordinate shared, open space into a more usable landform.

- Use Higher Land Use Densities To Support Transit Ridership. Higher densities increase the number of potential transit passengers per square mile, which contributes to greater transit service efficiencies and higher levels of service. The land use densities for office-commercial land uses are usually measured in terms of floor-area-ratio (FAR). The FAR is the ratio of the gross floor area of all buildings on a lot, to the area of the land on which it is situated. Typical FAR values for traditional campus-style suburban office parks usually range from 0.25 to 0.50 . As shown above, this is substantially less than the density needed to support transit. Density can also be measured in employees per acre. Generally, an average of 50 employees per acre (Ewing, 1999) are needed to support transit service.

\begin{tabular}{|c|c|}
\hline \multicolumn{2}{|c|}{ Service for Multiple Land Uses } \\
\hline \multicolumn{2}{|c|}{ Office Commercial } \\
\hline Within $1 / 8$ Mile & 1.0 to 2.5 FAR \\
\hline Within $1 / 4$ Mile & 0.75 to $2.0 \mathrm{FAR}$ \\
\hline \multicolumn{2}{|c|}{ Retail } \\
\hline Within $1 / 8$ Mile & 0.5 to $1.0 \mathrm{FAR}$ \\
\hline Within $1 / 4$ Mile & 0.40 to $0.75 \mathrm{FAR}$ \\
\hline \multicolumn{2}{|c|}{ Mixed Commercial / Residential } \\
\hline Within $1 / 8$ Mile & 1.5 to $2.5 \mathrm{FAR}$ \\
\hline Within $1 / 4$ Mile & 1.0 to $1.5 \mathrm{FAR}$ \\
\hline $\begin{array}{l}\text { Note: Table Adapted from } \\
\text { Engineers (2003) }\end{array}$ & te of Transportation \\
\hline
\end{tabular}

- Increase Land Use Densities to Create Compact Urban Form That Minimizes Walking and Bicycling Distances. Higher-density, mixed-use development brings a variety of land uses closer together, thus increasing the potential for walking and bicycling. Higher densities also support a wider variety of land uses, such as retail, service, and entertainment, which also promote walking and bicycling.

\section{Community Context}

\section{Objective: The Suburban Office Park Should Blend Into and Enhance the}

\section{Surrounding Community.}

\section{Guidelines}

- Use Visual Cues and/or Themes From the Surrounding Community to Instill a Sense of Place. For example, using local building materials and architectural styles within the office park helps to integrate it with the local community or region.

- Master Planning Allows Planners, Designers, and Other Decision Makers to Address Key Issues Affecting the Overall Project. Issues such as vehicular infrastructure, building placement, non-motorized transportation infrastructure, and common space allocation can be planned in the initial stages of the project, versus a 'build site-by-site and hope for the best' 
approach. Master plans can also be flexible in their design to accommodate multiple scenarios and alternatives that may not be accounted for in the initial planning phases.

- Seek Opportunities to Adaptively Re-Use Obsolete Buildings to Form More Sustainable Landforms. Prime candidates are buildings of historical or local significance, or other underutilized buildings that can fit into a larger overall scheme of an office park's main campus, or even in a town center-type development to supplement the main campus.

- Seek Opportunities to Enhance the Surrounding Community By Making Better Use of Existing Land Through Infill or Re-Use of Existing Structures. Greyfield projects seek to redevelop abandoned commercial property, such as shopping malls, obsolete office buildings, and other underutilized commercial properties. Greyfield projects are usually large in acrage and already include transportation infrastructure such as parking lots and access roads, which can easily be reconfigured to adapt additional office buildings or other land uses.

\section{Supporting Programs and Policies}

\section{Objective: Focus Programs and Policies on Encouraging Sustainable Transportation Modes and Reducing Vehicular Traffic Volumes.}

\section{Guidelines}

- Use Transportation Demand Management (TDM) Tactics to Help Manage and Reduce Vehicular Traffic. TDM refers to various strategies that change travel behavior (how, when and where people travel) in order to increase transport system efficiency and achieve specific objectives such as reduced traffic congestion, road and parking cost savings, increased safety, improved mobility for non-drivers, energy conservation, and pollution emission reductions (VTPI TDM Encyclopedia, 2005). TDM tactics can usually be implemented by a single employer; however, TDM can be more effective when several nearby employers participate and coordinate with each other in such programs. Examples of TDM strategies include:

- Staggering work hours so that arrival and departure times do not coincide. With this technique, traffic peaks are more evenly distributed over the course of several hours throughout the day.

- Instituting flex time, where individual employees can chose (within limits) their starting and ending times. A worker can choose to come in early, late, or at the "normal" starting time.

- Allowing alternate workweek schedules is effective at reducing and spreading out traffic peaks. A 4-day or 6-day workweek causes the duration of individual workdays to be altered. Thus, traffic peaks will be affected also.

- Telecommuting, or working out of one's home either part-time or full-time, is an alternative to working full-time in a traditional work setting. Advances in telecommunications technology allow employees to connect to employer computer networks, attend meetings, and perform other everyday tasks from their home. This alternative has obvious traffic benefits in that it reduces the overall volume of traffic.

- Encouraging ridesharing, carpooling, or any other High-Occupancy Vehicle (HOV) mode for commuting. 
Additional sources of information on TDM strategies include:

- VTPI Online TDM Encyclopedia (http://www.vtpi.org/tdm/): an online resource that gives an expanded definition of TDM and offers numerous detailed descriptions of TDM tactics.

- A Guidance Manual for Implementing Effective Employer-based Travel Demand Management Programs (http://ntl.bts.gov/DOCS/474.html): a online resource that offers general information on TDM strategies and implementation methods. Generally geared towards employers.

- Promote the Formation of Transportation Management Associations (TMAs). TMAs are associations usually formed by a group of private employers to deal with the traffic congestion and other problems that suburban employment centers encounter. Multiple groups (usually 5 or more developers, property owners, or employers) form a cooperative agreement where they participate in, and finance, a variety of traffic and transportation-related activities. However, implementation costs may be potentially large. TMA activities include:

- Promoting ridesharing and providing computerized rideshare matching programs.

- Financing nearby transportation improvements, such as intersection/signal upgrades or adding/enhancing a highway interchange.

- Purchasing and maintaining a fleet of vehicles for rideshare activities.

- Financing internal shuttle bus services.

Additional sources of information on TMAs include:

- VTPI Online TDM Encyclopedia (http://www.vtpi.org/tdm/tdm44.htm): an online resource that gives an expanded definition of TMAs.

- Suburban Gridlock (Cervero, 1986): a publication that thoroughly covers TMA associations as they can be applied to suburban office parks.

- Office Parks Should be Addressed in an Area's Comprehensive Plan. Issues such as density, land use mix, how transit is incorporated, and how pedestrians are accommodated can be addressed in the comprehensive plan. Prince William County, located in the fast-growing Northern Virginia area, specifically addresses office development in the County's Comprehensive Plan. The "Community Design Plan" section, includes Illustrative Design Guidelines for Office Development. This document includes illustrations of desirable characteristics of office building form (e.g. massing and upper story set backs), and suggests site planning techniques for stand-alone offices, as well as office parks. The guide can be found at www.pwcgov.org/docLibrary/PDF/001876.pdf. 


\section{B: Site Layout and Pedestrian and Bicycle Amenities}

\section{Building Location and Shape}

\section{Objective: Locate Buildings to Encourage Non-Motorized Transportation}

Buildings should be situated in a manner that minimizes walking distances and is inviting for nonmotorized modes.

\section{Guidelines}

- Enhance the Streetscape Through Proportioning of Buildings. Create a

proportional building height to street width ratio to enhance the streetscape and help to create a sense of enclosure or "outdoor room". Opinions on appropriate height to width ratio vary from $1: 1$ as ideal, to $1: 6$ as a minimum; a ratio of $1: 3$ is often

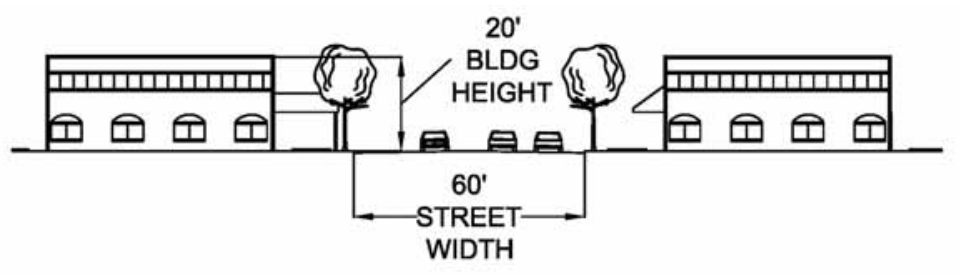

\section{1:3 HEIGHT-TO-WIDTH STREET} ENCLOSURE RATIO used as a rule of thumb.

- Include Pedestrian-Friendly Features on Building Facades Facing Pedestrian Travel Ways. Buildings with facades that lack windows, doors, or other exterior items of architectural interest, tend to discourage street-level pedestrian activity. Mixing land uses (see also Section $3 A$ ) on the ground level of buildings can help to create interesting and lively facades. Ground level retail or other service-oriented land uses that have windows, entrances, and other features can help to stimulate pedestrian traffic. For instance, a restaurant or café with an outdoor seating area can help to break up the monotony of the facade and create a lively pedestrian environment.

- Small Building Setbacks Allow More Compact and Sustainable Development Patterns to Occur. Placing buildings in close proximity to one another, especially if coupled with a mix of land uses, enhances non-motorized travel and creates a more pedestrian-scale environment. This is especially true

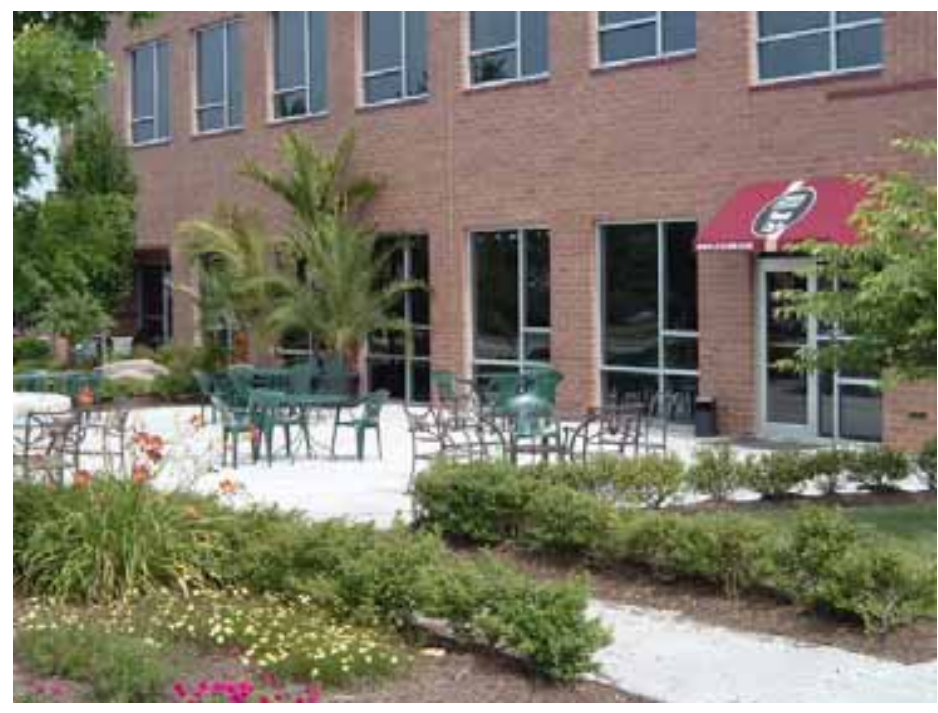

Pedestrian-Friendly Building Facade Building features can be incorporated to create pedestrian-friendly building facades. This office park building includes an attractive outdoor café, complete with seating, awnings, and a wide variety of landscaping features. 
if a building, rather than surface parking, exists at the front of the property, adjacent to roads and sidewalks. This creates direct pedestrian access to buildings, and can also contribute to a more defined streetscape when combined with other pedestrian amenities.

- Position Buildings Close to the Street to Enhance Pedestrian Access and Safety . Bringing buildings closer to the street provides a continuous and well-defined edge. Buildings close to the street help to create an enclosed streetscape and shorten pedestrian travel distances. Also, people in buildings located closer to the street can more easily monitor the environment; thereby enhancing pedestrian security.

- At Ground Level, Use Transparent Windows for "Eyes on the Street". Providing windows and doors that offer views of nearby walkways and parking lots helps to place "eyes on the street". A vibrant streetscape increases pedestrian comfort and security, whereas a vacant or barren streetscape with no windows or doors discourages walking.

- Encourage Clustering of Buildings With Complementary Land Uses. Organizing buildings this way minimizes walking distances, provides central locations for transit stops, and reduces the need to lock/ unlock bicycles for multiple stops.

- Locate Parking at the Rear or Side of Buildings. Pedestrian-vehicle conflicts can be reduced if pedestrians do not have to walk through a parking area. Pedestrians,

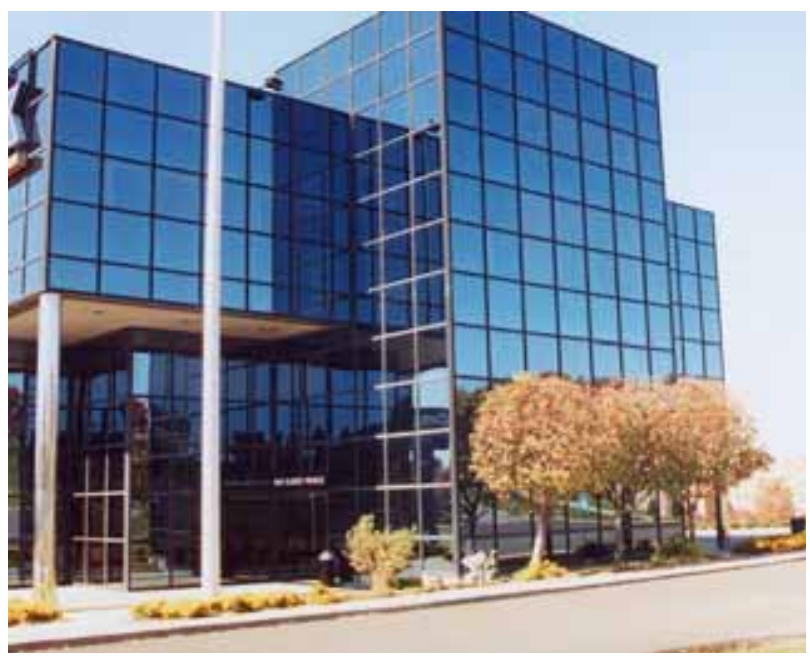

Lack of Transparent Windows

While this building façade has plenty of windows at street level, they are all reflectorized. This type of façade is not inviting to pedestrians since there is not a perception of eyes on the street. bicyclists, and transit riders can reach destination buildings more easily.

\section{Objective: Use Building Form to Enhance the Pedestrian Environment}

A building's exterior should be divided into smaller shapes to create a more inviting streetscape for pedestrians.

\section{Guidelines}

- Use Building Massing Techniques. Building exteriors should be divided into different shapes to avoid creating a boxy geometric mass. Place a one-story "bump out" containing shops and restaurants around the main structure to help to conceal the rest of the structure's mass.

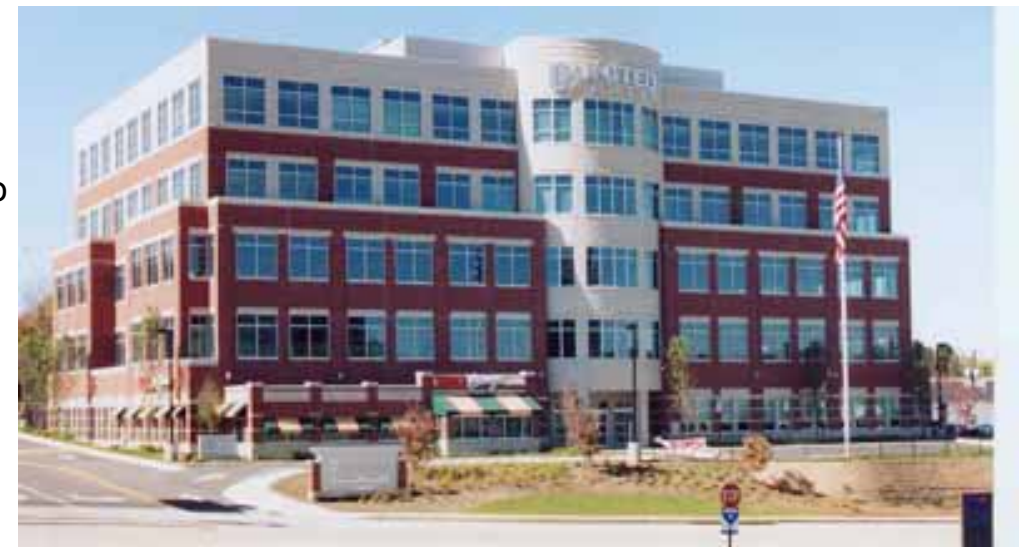

Massing Techniques and Set-Backs

This office building uses massing techniques as well as upper story set-backs to reduce its overall mass. Notice the ground floor "bump-out" for the restaurant.. 
- Set Back Upper Stories of Taller Buildings. Create upper story set backs in the exterior of taller office buildings to maximize natural light at street level. Doing this also softens the visual impact of taller buildings.

\section{Objective: Locate Building Entrances to Minimize Travel Distances}

Long walking distances from the street to a building entrance inhibit walking and transit use. Frequent entrances also increase a pedestrian's sense of security. Entrances should be flush with the sidewalk to facilitate access by pedestrians with mobility impairments.

\section{Guidelines}

- Locate Primary Entrances So They Correspond To Pedestrian Desire Lines. Locate main entrances to minimize unnecessary walking. Position main entrances near major pedestrian routes and parking areas, and provide additional entrances if there are multiple distinct building tenants at ground level.

- Use Visual Cues to Clearly Define Building Entrances. Architectural and landscaping treatments can be effective in directing people towards a building's entrance.

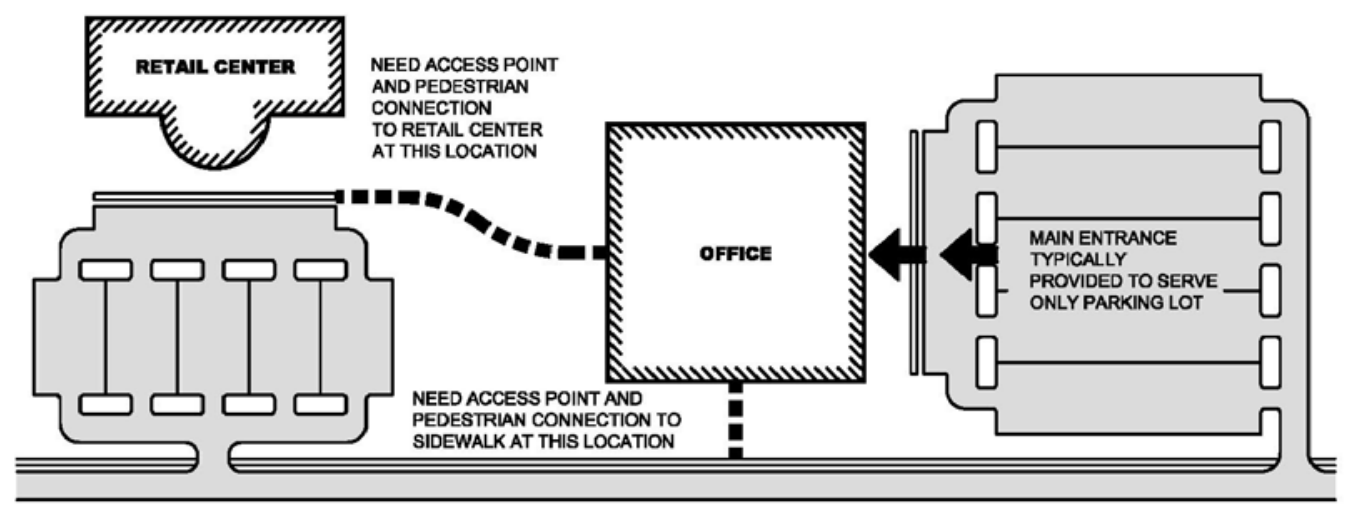

Building Entrance Placement

As shown above, entrances are typically provided to serve only associated parking areas. Entrance locations convenient to nearby pedestrian desire lines are sometimes neglected.

\section{Objective: Minimize Vehicular and Pedestrian Conflicts at Passenger Pick-Up/ Drop-Off Areas}

Locating passenger pick-up/drop off areas such that orderly and safe pedestrian and vehicular flows are maintained, can help to encourage ridesharing. Section $3 \mathrm{C}$ presents guidelines for transit stops.

\section{Guidelines}

- Locate Pick-Up/Drop-Off Areas (PUDOA) Away from Primary Pedestrian Routes. Vehicle circulation routes to/from pick-up/drop-off areas should not pass in front of main building entrances.

- Locate PUDOA Out of the Traveled Way. Locate the drop-off area downstream of the building entrance. This improves visibility and prevents waiting vehicles from interrupting traffic. Consider placing the PUDOA on the rear or side of the building to keep vehicular traffic on primary roads and minimize vehicular traffic within individual sites. 
- Minimize Walking Distances from PUDOA to Building Entrance. The Canadian Institute of Transportation Engineers (2003) recommends that the maximum walking distance from a drop-off area to building entrance be no more than 100 feet.

- Provide Comfortable and Secure Waiting Areas. Provide illumination at the PUDOA. Consider building overhangs or awnings to shelter pedestrians.

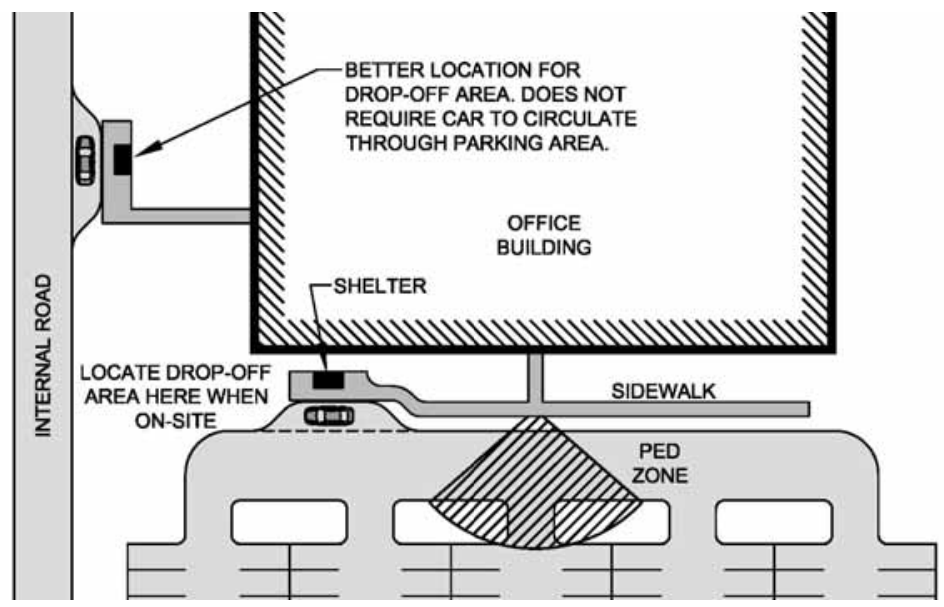

Pick-Up / Drop-Off Area Location

Configure the PUDOA so that it does not interfere with pedestrian or vehicular traffic.

\section{End-of-Trip Pedestrian and Bicycle Considerations}

\section{Objective: Provide Bicycle Parking Areas That are Accessible, Sheltered, and Secure}

Bicycle parking facilities should be easily accessed, close to main entrances, and well-lit. Choose bicycle racks that protect bicycles against theft and damage.

\section{Guidelines}

- Locate Bicycle Parking Close to Building Entrances. Bicycle parking should be no more than 120 feet, and preferably 50 feet from a main building entrance. Provide racks at each entrance if there are multiple tenants per building.

- Provide Sufficient Parking for Bicycles.

Guidance on the number of bicycle parking stalls can be found in the accompanying table. The Canadian Institute of Transportation Engineers (2003) recommends that bicycle parking be calculated as a function of the number of people in the building, rather than a function of motor vehicle parking stalls. For existing facilities, visual cues such as overcrowded bicycle racks and bicycles locked to fixed objects may indicate the need for additional bicycle parking.

\begin{tabular}{|c|c|}
\hline \multicolumn{2}{|c|}{ Supply } \\
\hline $\begin{array}{c}\text { Number of Spaces } \\
\text { Required }\end{array}$ & Unit \\
\hline 1.0 to 3.0 & $\begin{array}{c}\text { Per } 1000 \text { square feet Gross } \\
\text { Floor Area (GFA) }\end{array}$ \\
\hline $5 \%$ to $10 \%$ & $\begin{array}{c}\text { Number of Automobile } \\
\text { Spaces }\end{array}$ \\
\hline
\end{tabular}

- Locate Bicycle Parking Where Cyclists Want to Park. Provide bicycle parking in areas where bicyclists lock their bicycles to trees, light poles, and other fixed objects. 
- Configure Bicycle Parking Areas to Maximize Capacity, While Providing Easy Access to Racks. Allow sufficient clearance on all sides of parked bicycles for easy access. See the accompanying figure for suggested dimensions.

- Provide Secure Location for Bicycle Parking. Locate bicycle parking in visible, well-lit areas.

- Provide Bicycle Racks That Allow a Bike's Frame and at Least One Wheel to be Secured. The racks shown on the accompanying graphic are recommended. Avoid the toast and the comb design since the bike's frame cannot be secured and may be damaged. The wave is acceptable. However, if bikes are parked parallel rather than perpendicular to the rack, the capacity of the rack is reduced.

- Protect Bicycle Parking From Elements. Use a shelter, overhang, awning, or other building feature to cover bicycle parking in areas that receive frequent precipitation.

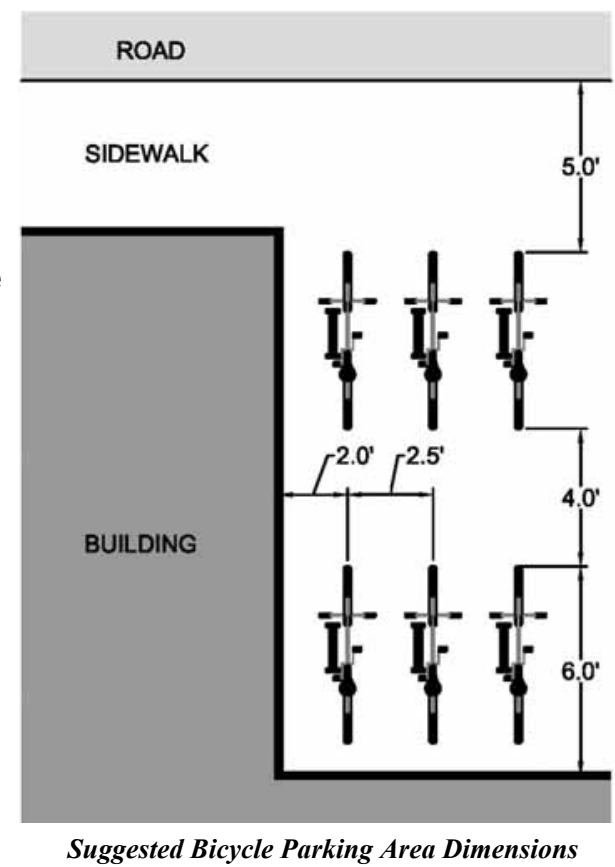

- Furnish Bicycle Lockers or a Bicycle Garage For Extra Security. If there is no opportunity to provide a sheltered area, or where there are security concerns, bicycle lockers are a potential solution. Bicycle lockers are generally rectangular in shape, and resemble oversized gym lockers.

In areas with significant bicycle usage, consider an indoor parking facility. Indoor facilities have various configurations of bicycle racks (floor, wall, ceiling), are mostly or completely covered, and can be coupled with other end-of-trip amenities. Indoor parking can be viewed as a major employee amenity and may create interest in bicycle commuting. Also, bicycle garages may completely eliminate bicycle theft and damage from exposure to the elements.

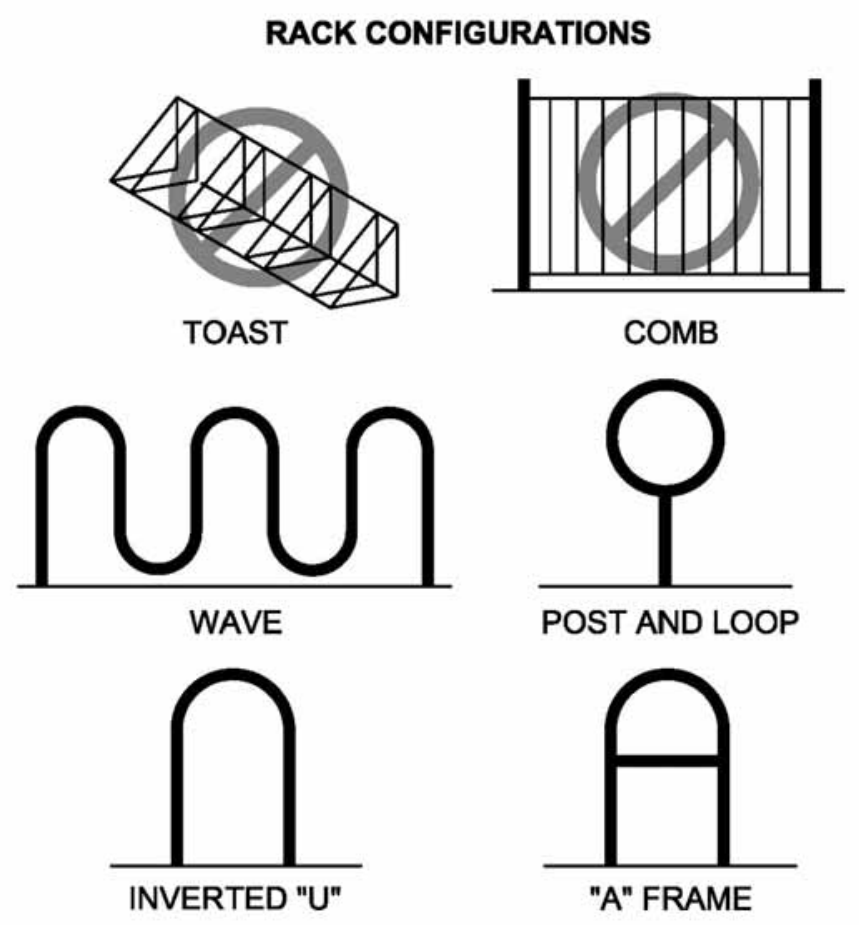

Figure Adapted from Bicycle Parking Guidelines (Association of Pedestrian and Bicycle Professionals, 2002). 


\section{Objective: Encourage Non-Motorized Commuting and Physical Activity by}

\section{Providing Shower and Changing Facilities}

On-site shower and changing facilities are vital to support employee use of non-motorized modes for commuting and physical activity when they remain at the site for extended periods of time.

\section{Guidelines}

- Ideally, Each Floor of Every Office Building Should Have Shower and Changing Facilies to Encourage Bicycling and Walking. Sometimes an office park may include an on-site fitness center or other recreation facility. In this instance, these facilities can be made available to those who choose to use nonmotorized transportation. A common rule of thumb is 1 shower per 100 employees. However, the accompanying table lists the number of total showers, water closets, and washbasins as a function of required long-term bicycle spaces.

- Change Rooms and Lockers Should be Included to Allow Storage of Wet and Dirty Clothes, and Other Personal Belongings for Those Who Choose to Walk or Bike.

\begin{tabular}{|c|c|c|c|}
\hline \multirow{2}{*}{$\begin{array}{c}\text { Required } \\
\text { Class A } \\
\text { Bike } \\
\text { Spaces }\end{array}$} & \multicolumn{3}{|c|}{ Minimum Number for Each Sex } \\
\hline & $\begin{array}{l}\text { Water } \\
\text { Closets }\end{array}$ & $\begin{array}{l}\text { Wash } \\
\text { Basins }\end{array}$ & Showers \\
\hline $0-3$ & 0 & 0 & 0 \\
\hline $4-29$ & 1 & 1 & 1 \\
\hline $30-64$ & 2 & 1 & 2 \\
\hline $64-94$ & 3 & 2 & 3 \\
\hline $90-129$ & 4 & 2 & 4 \\
\hline $130-159$ & 5 & 3 & 5 \\
\hline $160-194$ & 6 & 3 & 6 \\
\hline Over 194 & $6^{*}$ & $3^{*}$ & $6^{*}$ \\
\hline \multicolumn{4}{|c|}{ * plus 1 per each additional 30 bike spaces } \\
\hline \multicolumn{4}{|c|}{$\begin{array}{l}\text { Note: Values taken from Victoria Transport Policy Institute TDM } \\
\text { Encyclopedia (www.vtpi.org) }\end{array}$} \\
\hline
\end{tabular}

\section{The Elements of Pedestrian Places (Common Space)}

It is recognized that office parks are places of work and are generally not places for the public to gather. However, with more emphasis being placed on walkability and mixing land uses, it is important for parks to provide elements that invite pedestrian travel. A walkable environment goes beyond simply having adequate walkways; it includes pedestrian "space" and amenities such as benches and other street furniture, shelter from the elements, and pedestrian wayfinding devices.

\section{Objective: Provide Supporting Street Furniture and Other Amenities.}

Seating is a necessary amenity for pedestrians. Seating provides a place for people to socialize and enjoy the outdoor environment, and a resting place for disabled or elderly pedestrians. Another element of pedestrian places is features that provide refuge from the elements. Windswept plazas and other gathering places are undesirable. Wayfinding devices are also needed to make a complete pedestrian place. Signage and kiosks can be used, along with informal devices.

\section{Guidelines}

- Provide Formal and Informal Seating in Common Spaces. Recognize that not all seating 
needs to be formal. Informal seating in the form of a ledge of a planter or fountain, and the top of a wall can also be considered.

- Provide Frequent Seating to Benefit Older Pedestrians And Other Pedestrians Who Are Sensitive To Distance.

- Provide Supporting Street Furniture and Other Amenities. While seating is a key element of pedestrian places, there are other types of street furniture that can enhance the pedestrian experience. Trash receptacles, newspaper boxes, drinking fountains, and public art can be useful in creating a pedestrian place.

- Provide Supporting Services In or Near Common Spaces. Service amenities such as food stands, outdoor cafes, and newsstands all give pedestrians an incentive to use common space. Lack of these service amenities will

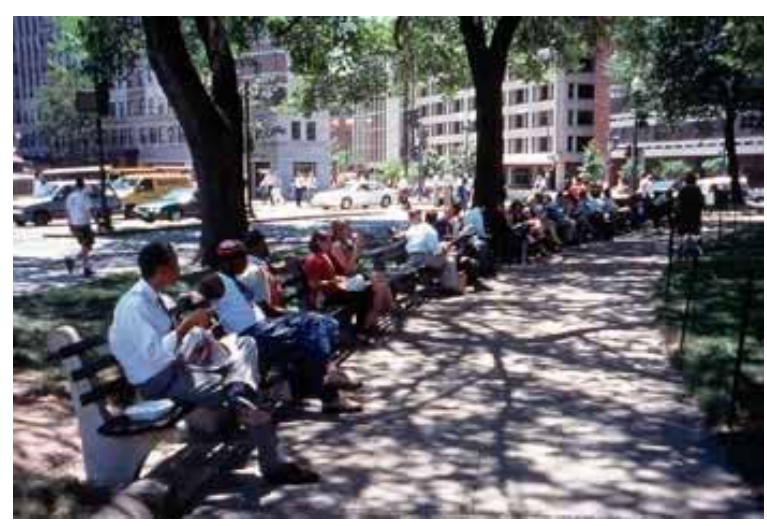

Pedestrian Place

This row of benches located under shade trees is an ideal place for workers to eat their lunch during a break. Notice that the benches do not protrude into the pedestrian traveled way (source: www.pedbikeimages.org / Burden). most likely result in a less-frequently used common space.

- Provide Awnings and Building Overhangs to Shelter Pedestrians From the Elements.

- Seating and Street Furniture Should Not Interfere With Pedestrian and Bicyclist Paths. Position benches and other supporting street furniture so as not to encroach into the pedestrian travel zone.

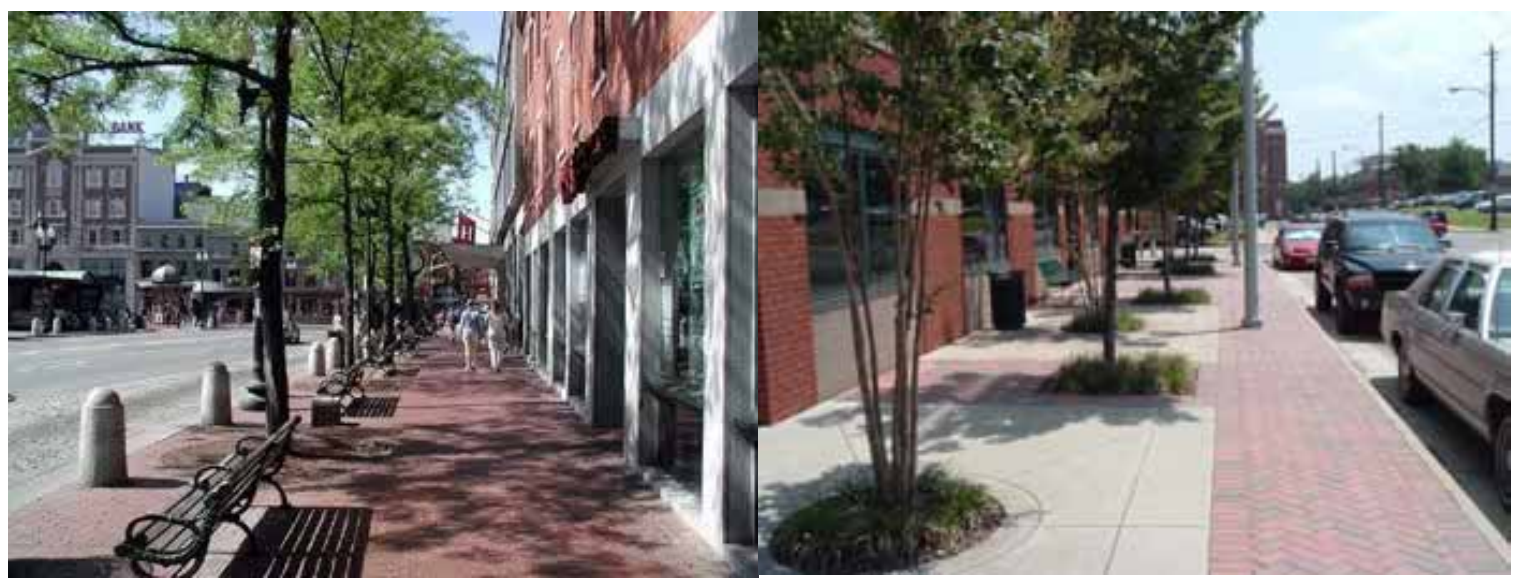

Good and Bad Street Furniture Placement

At left, benches, shade trees, and trash receptacles are placed out of the pedestrian traveled way (source: www.pedbikeimages.org / Burden). By contrast, the picture on the right demonstrates poor placement of trees (and associated planters) and utility poles, relative to the walkway.

- Supply Wind Breaks to Provide Refuge for Pedestrians in Wind-Swept Places.

Impenetrable barriers, such as fences, walls, earth berms, and buildings are useful in deflecting and rerouting winds. Vegetation can be used as a penetrable barrier (see also "Landscaping", later in this section). 
- Think "Small" and "Intimate" When Creating Common Spaces. When planning an office park, land should be allocated for common space, or pedestrian places. Human-scaled places 2,500 square feet or smaller are appropriate for office park applications (FHWA, 2000). Common space should be located in an area that has plenty of sun exposure and protection from wind. Enclosing the common space by buildings on two sides is desirable, however precautions for wind shelter on the two open sides must be considered.

- Avoid Abrupt Grade Changes in Common Spaces. Generally speaking, pedestrians prefer to be at grade or elevated above their surrounding environment. Thus, it is not desirable to create common space that is recessed or sunken below the surrounding grade.

\section{Objective: Use Wayfinding Techniques to Help Pedestrians Navigate the Site In an Efficient Manner}

Supply pedestrians with adequate, clear, and concise information to help them find their way around the site safely and efficiently.

\section{Guidelines}

- Provide Clear and Concise Signage Throughout an Entire Site to Assist Pedestrians in Wayfinding.

- For Large Sites, Position Kiosks Near Major Entrance Locations to Help Orient Automobiles and Non-Motorized Modes. Provide vehicular turnout areas and walkways for accessing kiosks. These kiosks should give pedestrians a sense of "bearings", notifying them of their location and the location of site buildings, parking lots, roads, and other prominent site features.

- Provide Appropriate Signs for Each Mode. The design and location of signs for motor vehicles should conform to the current edition of the Manual on Uniform Traffic Control Devices. However, larger sites should have informational signage for non-motorized modes located at more frequent intervals, at lower heights, and with more detail.

- Include Wayfinding Devices in Large Parking Areas to Assist Both Motorists and NonMotorized Modes. Use signage to direct all modes safely to a building or parking area.

- In Addition to Formal Signs, Use Informal Visual Cues (Such as Landscaping Features and Massed Building Entrances) to Help Guide Pedestrians Throughout a Site.

\section{Objective: Enhance Pedestrian and Bicyclist Safety Through Environmental Design and Emergency Communication Devices}

Enhance environments where non-motorized modes will be present by providing emergency communication devices, supplying adequate lighting levels, and maximum pedestrian visibility.

\section{Guidelines}

- Maintain Visibility and Openness on Pedestrian and Bicycle Routes. Just as it is important for pedestrians to feel the presence of "eyes on the street", it is equally important for pedestrians themselves to monitor the street. Open views are desirable along walkways and in pedestrian 
places, especially at nighttime. While landscaping and other amenities are intended to create pedestrian interest along walkways and in plazas, these features should not create security concerns for users.

- Use Pedestrian-Scale Lighting. Pedestrian lighting should be provided at heights of 8 to 15 feet. Also, ground lights, bollard lights, and track lighting can be decorative or a functional part of the overall lighting plan. Minimum lighting levels should be in the range of 1 to 5 foot-candles (Lighting Design Lab Website, 2004).

- Provide Pedestrian Emergency Communication Devices in Campus-Style Environments. Consider using pedestrian emergency communication devices positioned at strategic locations throughout a campus environment. In many newer pedestal-style emergency devices, the pedestrian depresses a button that activates a flashing beacon and audible alarm. Also,

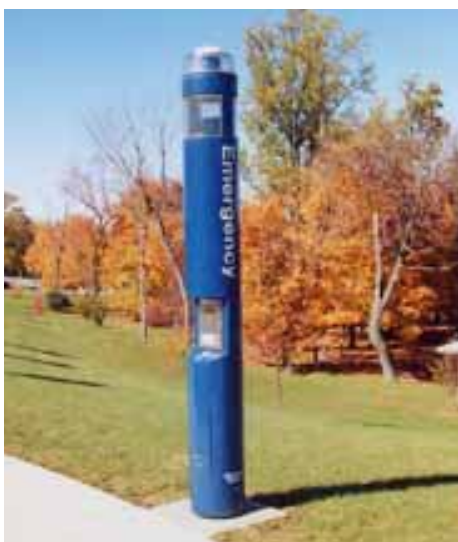

Pedestal Mounted Emergency Communication Device some of these devices have the capability to communicate with security personnel (provided they are available).

\section{Landscaping}

\section{Objective: Enhance the Aesthetics of Non-Motorized Modes}

Use landscaping features that are not only attractive, but also a functional part of the nonmotorized infrastructure.

\section{Guidelines}

- Interrupt Landscaping

Features to Permit Pedestrian Connections.

Determine desired pedestrian connection points between adjacent properties and nearby walkways and provide breaks in landscaping features at these locations.

- Use Landscaping to Channelize Pedestrian Connections Landscaping can be used not only for aesthetics, but

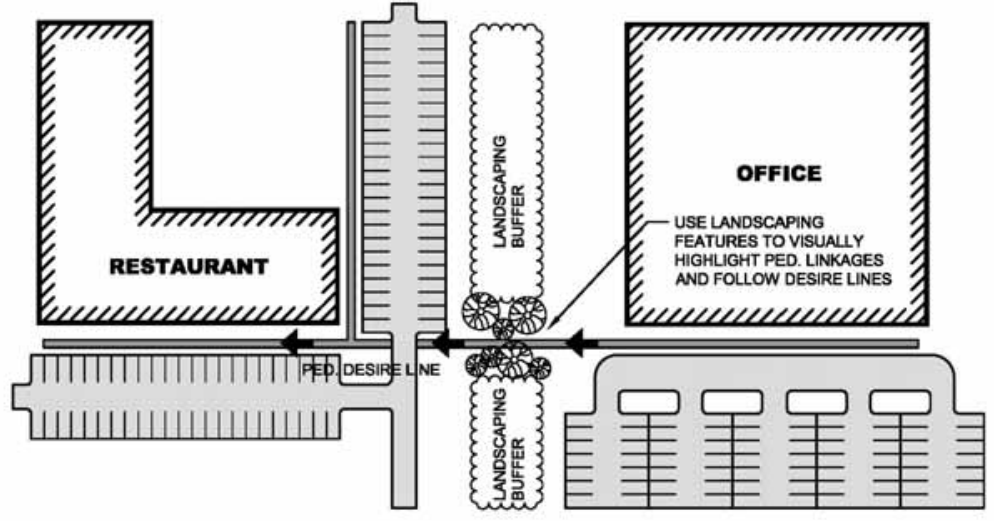

Landscaped Pedestrian Connections

Use landscaping to highlight pedestrian connections and channelize pedestrians. also as a means of giving visual cues to pedestrians about the location of walkways and off-site connections. Examples include: 
- Using landscaping to identify pedestrian walkways within parking lots. Landscaping can be used to lead, or channelize pedestrians towards landscaped pedestrian connections to adjacent properties. Landscaping can be used to enhance these connection points.

- Using landscaping to keep pedestrians out of areas where they should not go.

- Using landscaping at crosswalks to channelize pedestrians towards curb ramps and crosswalks.

- Using low-slung plantings at bulb-outs and corner bulges to aesthetically enhance and channelize pedestrians.

- Use Trees Along Streets and Main Walking Routes to Provide Shade and Protection From Wind. Closely spaced trees can provide limited cover along walkways. The shadows that trees create can make a long walk more comfortable in high temperatures. Also, trees with dense canopies can shelter pedestrians from significant amounts of rainfall. The type of trees selected for the purpose of providing shade and/or shelter is important. Evergreen trees offer year-round protection and deciduous trees offer seasonal protection when foliated.

- Avoid Creating Enclosed Areas That Can Cause Security Concerns.

- Use Earth Berms to Conceal Parking Lots and Service Areas. As shown here, a planted earth berm can help to conceal and visually enhance a parking lot or service area.

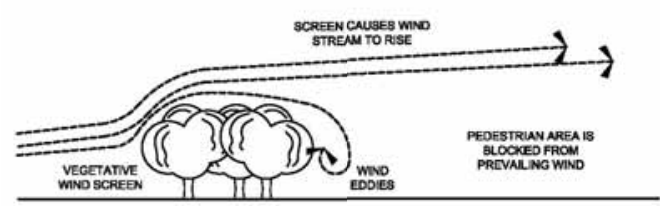

ELEVATION VIEW OF VEGETATIVE WIND SCREEN

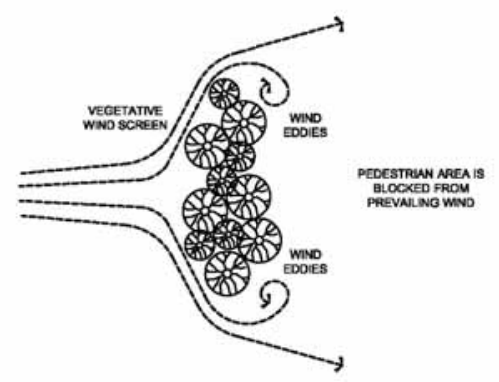

PLAN VIEW OF VEGETATIVE WIND SCREEN

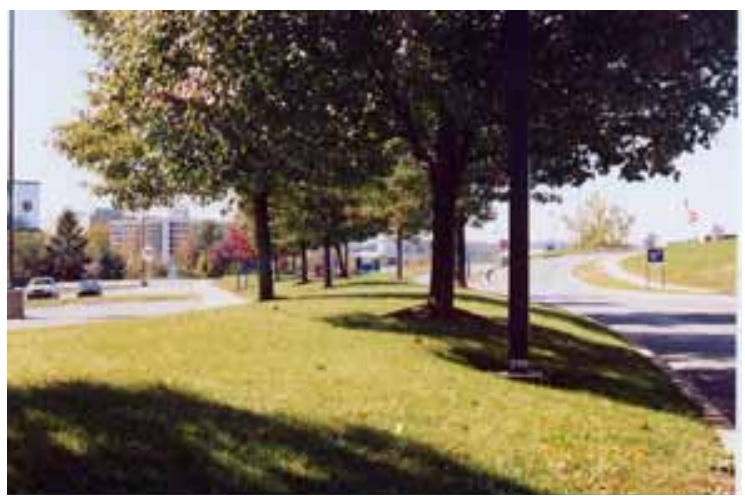

Objective: Select Landscaping Features That Do Not Obstruct or Inhibit Vehicular or Non-Motorized Travel

\section{Guidelines}

- Be Aware Of Tree Characteristics That Affect Non-Motorized Modes. The following criteria should be considered in selecting tree species for areas where pedestrians will be present:

- Canopy Height - The canopy should not protrude into walkways or obstruct motorist view. The bottom of a canopy should be at least 8 feet above the walking path.

- Light Permeability - Trees that offer good shade from direct sunlight should be selected along pedestrian routes. 
- Root Wad - The root structure of a tree should not upheave adjacent walkways or other non-motorized route surfaces. Select tree species that have an appropriate root structure for urban environments. Consult an arborist or landscape architect for specific information.

- Canopy Size - Trees canopies should not be so large as to encroach on power lines, light poles, buildings, or other nearby objects. Tree size should be proportioned to its surrounding street environment.

- Ground Covers Should Not

Exceed 2 Feet In Height In

Parking Lots Or Other

Areas Where Pedestrians Interact With Vehicular

Traffic. Motorist sight lines can be affected when ground cover heights exceed 2 feet. Keep landscaping and other vegetation at least two feet from the edge of the walkway or road. Also, a vertical zone 2 to 8 feet in height should be kept clear of landscaping elements.

- Do Not Create Sight Obstructions at Entrances, Driveways, and Curves. Place landscaping features away from these areas so that sight distances for motorists and non-motorists are not restricted.

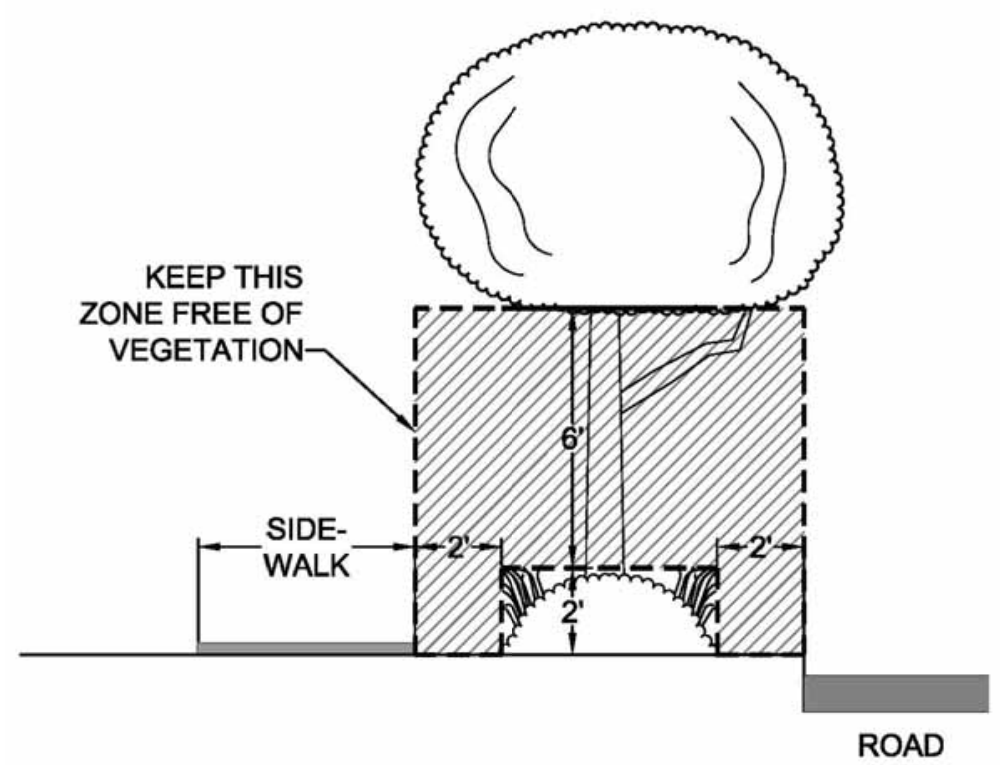

Vegetation Zone

Do not allow vegetation to encroach into the zone that lies between 2 feet above grade to 8 feet above grade. Also, design landscaping so that it does not lie within 2 feet of a non-motorized path or roadway.

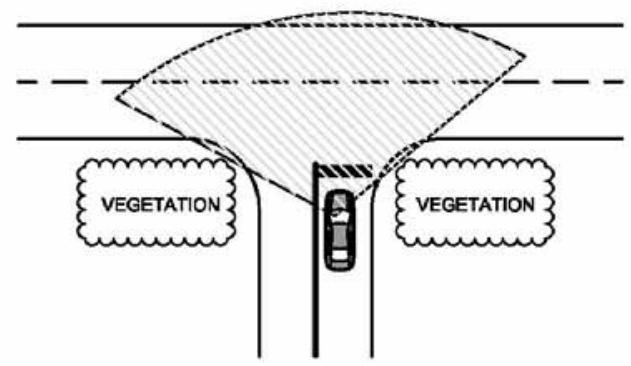

VEGETATION RESTRICTS DRIVER SIGHT DISTANCE AT INTERSECTION.

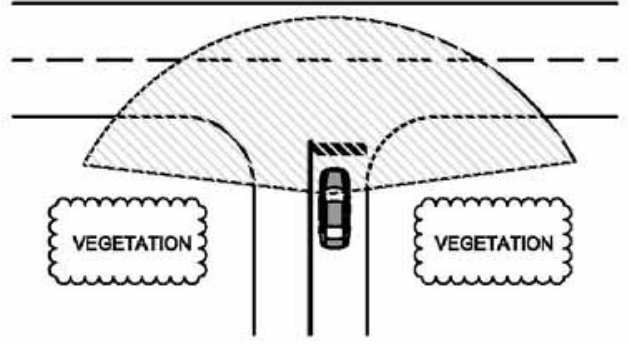

VEGETATION IS OFFSET FROM THE INTERSECTION, INCREASING DRIVER SIGHT DISTANCE. 
- Use Large Planting Areas in Parking Lots. Coordinate landscaping with desired pedestrian travel routes and common space areas. Avoid scattering small planting areas throughout large impervious surfaces such as parking lots and plazas. While there are benefits to having small landscaping islands in parking lots (as discussed in the next section), try to give preference to larger landscaped areas, such as the median/pedestrian walkway illustrated below.

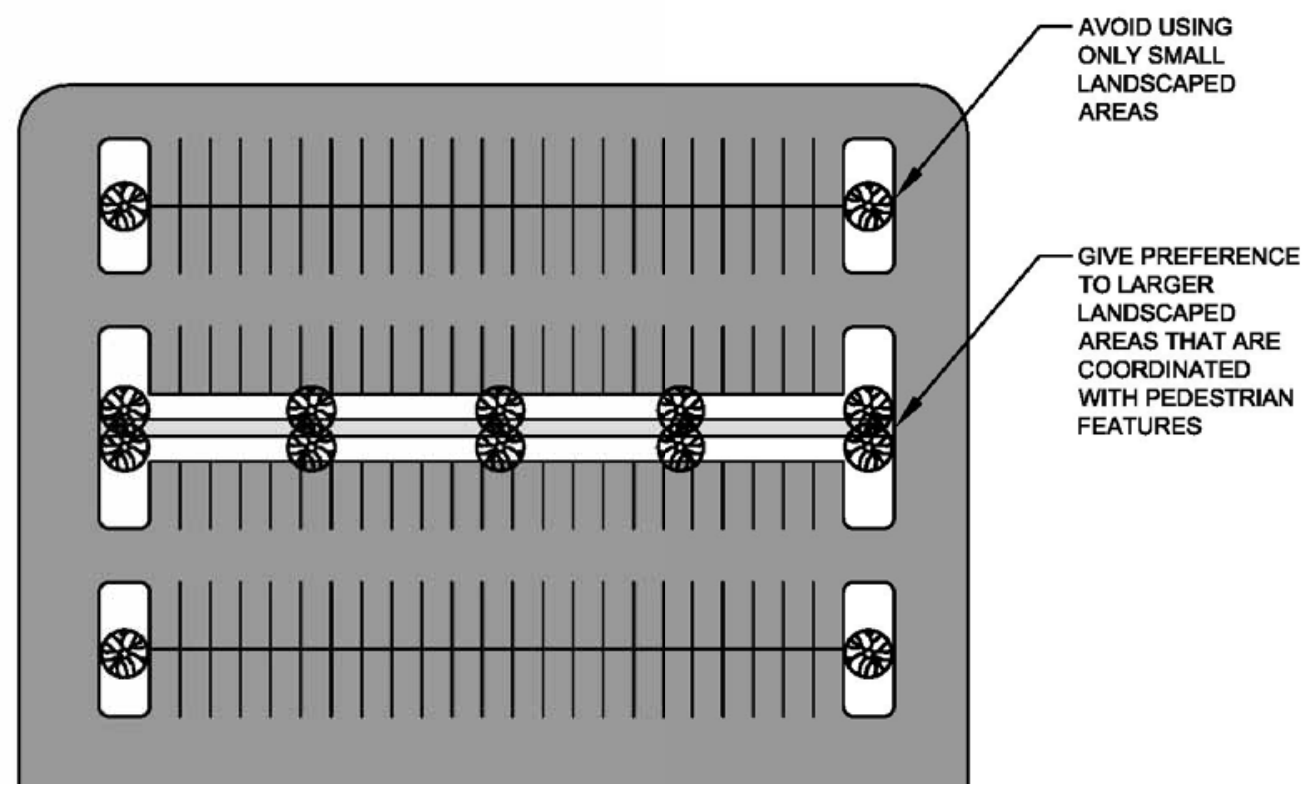

Vegetation in Parking Areas

While small curbed planting islands are encouraged in parking lots, favor should be given to larger planting medians. Large areas offer a better environment to establish vegetation (due to larger surface area of pervious ground cover). Also, large planting areas can be coordinated with sidewalks to provide safe and pedestrian-friendly routes through parking lots. 


\section{C: Site Infrastructure for Vehicular and Non-Motorized}

\section{Transportation}

\section{External Office Park Pedestrian and Bicycle Access}

Pedestrian and bicycle connections at the periphery of the office park should be provided to link interior buildings with exterior destinations. Lack of connections means long walking distances, and can force pedestrians to travel through parking lots, landscaping, around walls, and other physical barriers or to shift to motorized modes to reach a destination.

\section{Objective: Look for Opportunities to Connect the Office Park's Pedestrian}

Facilities with Existing Pedestrian Facilities and/or Land Uses OffSite.

\section{Guidelines}

- There should be connections between sidewalks within the office park and sidewalks or pedestrian facilities outside the park's boundaries. The presence of sidewalks to/from suburban office parks can support pedestrian travel and have an influence on mode choice.

- When Bicycle Facilities are Present on Existing Roads, it is Desirable to Provide Bicycle Lanes, Wide Curb Lanes, or Paved Shoulders on the Main Access Road to an Office Park. Connect to, and continue bike lanes if

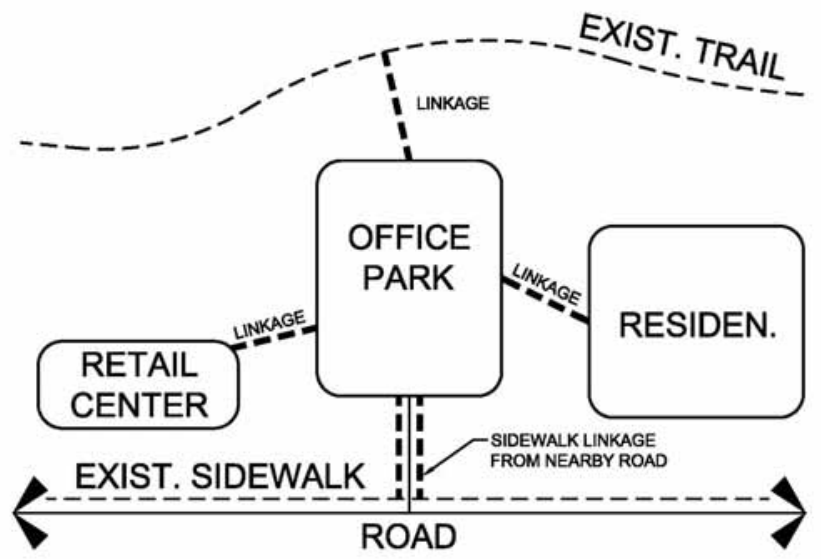

Linking an Office Park to Existing Land Uses they are present along any of the roadways adjacent to the development. Even if there are no formal bike lanes, bicyclists may travel on a road, or along the shoulder of a road. Thus, it is still desirable to provide either bike lanes, or at least a paved shoulder along the main access road of an office park.

- Look For Opportunities To Connect To Nearby Trails, Greenways, Or Other Paths. Connecting to a trail may encourage office park employees to use these trails for exercise during their lunch hour, or to use the trails to commute to/from the office park.

- Paths Worn in Grassy Areas are Indicators of Pedestrian Desire Lines and Probably Warrant a Formal Connection. A path worn from a building through a landscaped area to an off-site land use frequented by workers during lunch hours is a visual indicator of the route that pedestrians prefer.

- Coordinate Pedestrian Linkages With Adjacent Landowners. Look beyond property 
boundaries to see if a linkage would benefit adjacent land users. Identify connections that are mutually beneficial for adjacent properties and coordinate the construction of the linkage. Terms of maintenance and construction cost-sharing should be defined at the planning stage.

- Use Landscaping to Channelize Pedestrian Connections. Additional details related to this guideline was presented in Section 3B.

\section{Internal Pedestrian and Vehicle Circulation}

In addition to vehicular traffic, non-motorized modes of transportation should be considered when planning and designing internal circulation routes. These roads should be designed to consider transit circulation, desirable pedestrian routes, and safe bicycle routes, in addition to personal automobile and commercial vehicle travel.

\section{Objective: Internal Roads Should Be Designed to Encourage Low Vehicular Speeds.}

\section{Guidelines}

- Use geometry to control driver speeds. While it is not desirable to make roadway geometry unsafe for motorists, it is desirable to keep the geometry restrictive enough to discourage high speeds, while providing for safe motor vehicle operation. Roadway vehicular traveled way widths should be kept to 10 or 11 feet per lane. Additional width should be provided for bicycle lanes.

- Design Turning Radii for Slow Vehicular Speeds. The accompanying table (p.30) contains recommended curb radii at

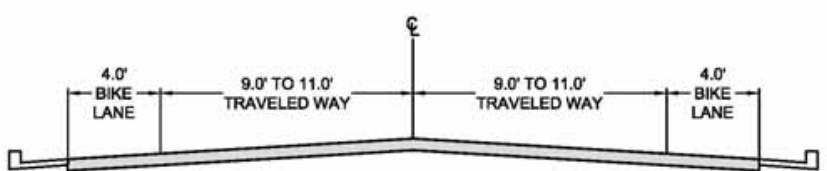

ROAD CROSS SECTION WITH CURB AND GUTTER

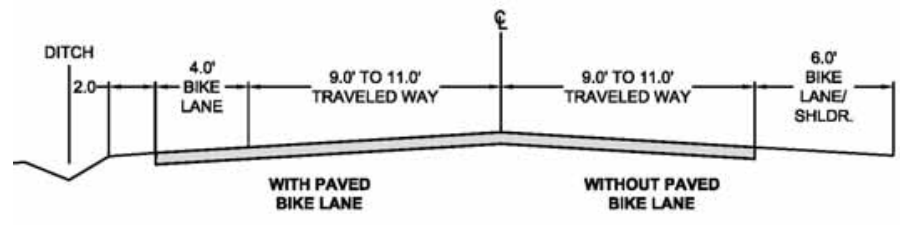

ROAD CROSS SECTION WITHOUT CURB AND GUTTER intersections and driveway entrances.

- Allow Passage of Emergency Vehicles at Intersections and Driveways, While Maintaining Pedestrian-Scale Streets. Narrow vehicular traveled way and small turning radii can make emergency vehicle passage difficult. Thus the designer should take measures to allow emergency vehicle access. The practice of using mountable curbs, or no curbs at all (specifically at intersections and driveways) allow tight roadway geometry to be maintained, while providing pedestrian-scale streets.

- For Parks With Significant Commercial Vehicle Traffic, Provide A Service Access With Appropriate Dimensions For Service And Emergency Vehicles. These access points should not be the primary access point for pedestrians and other non-motorized modes. 


\begin{tabular}{|c|c|c|c|c|c|c|}
\hline \multicolumn{7}{|c|}{$\begin{array}{l}\text { Driveway Entry Width (ft.) as a Function of Offset and Curb Return Radius, Passenger } \\
\text { Car, } 90 \text { Degree Right Turn, Creep Forward Speed }\end{array}$} \\
\hline \multirow{2}{*}{$\begin{array}{l}\text { Vehicle Offset from } \\
\text { Face of Curb, or } \\
\text { Edge of Pavement, } \\
\text { Prior to Turn (ft) }\end{array}$} & \multicolumn{6}{|c|}{ Curb Return Radius } \\
\hline & 0 & 5 & 10 & 15 & 20 & 25 \\
\hline 0 & $\mathrm{a}$ & a & $23^{\mathrm{b}}$ & 20 & 17 & 14 \\
\hline 2 & a & $24^{\mathrm{b}}$ & 20 & 17 & 14 & 14 \\
\hline 4 & $24^{b}$ & $21^{\mathrm{b}}$ & 17 & 14 & 14 & 14 \\
\hline 6 & $21^{b}$ & 18 & 15 & 14 & 14 & 14 \\
\hline 8 & 19 & 16 & 14 & 14 & 14 & 14 \\
\hline \multicolumn{7}{|c|}{ a: an inappropriately wide throat width is required } \\
\hline \multicolumn{7}{|c|}{ b: A combination of narrower width and longer radius is a better design. } \\
\hline \multicolumn{7}{|c|}{ Table Adapted from Stover and Koepke (2002) } \\
\hline
\end{tabular}

\section{Objective: Internal Road Networks Should Minimize Travel Distances and}

\section{Create Direct Routes Between Internal and External Destinations.}

\section{Guidelines}

- Facilitate the Safe and Efficient Movement of Pedestrians, Bicyclists, Transit Vehicles, and Automobiles by Laying Out Access Roads in the "Grid" or "Hybrid" Configurations.

- Grid - The grid is the optimum configuration for non-motorized transportation. It allows streets to be fully connected. This layout is more conducive for pedestrian and bicycle travel and transit circulation within a site.

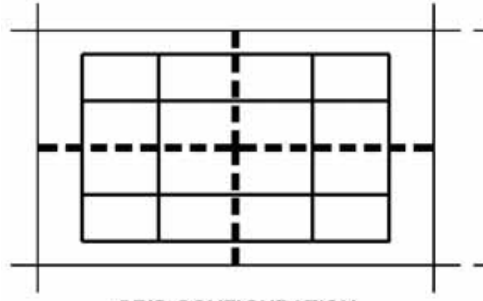

GRID CONFIGURATION

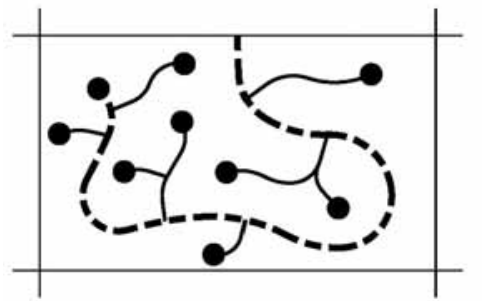

CURVILINEAR CONFIGURATION

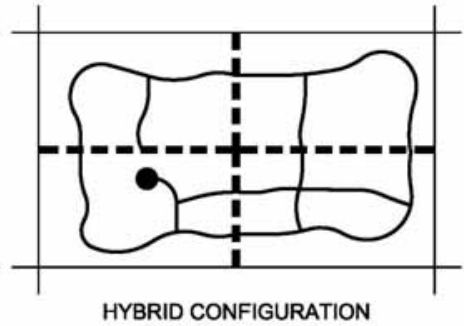

HYBRID CONFIGURATION

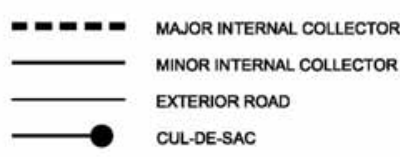


- Curvilinear - Curvilinear roads may appeal to those who favor a campus-like setting, and may also minimize earthwork in rolling terrain. However, this configuration is the least desirable in terms of non-motorized accessibility since roadways terminate in culde-sacs, and destinations are separated by long walking distances.

- Hybrid - The hybrid has elements of both the grid and the curvilinear configurations. It offers a level of street connectivity, while still maintaining a suburban character.

- Minimize Pedestrian/Vehicle Conflicts on Main Internal Roads. Do not configure internal roads in a manner that bisects heavily traveled non-motorized routes. For instance, it is undesirable to locate a connector road between a building and a parking lot.

- Avoid One-Way Roads Since they Can Encourage High Speeds and Increase Travel Distances for Bicyclists.

- Minimize Long Tangent Sections Where Internal Roads Pass in Front of Buildings and Near Heavily Used Crosswalks or Shared Use Path Crossings. Long, uninterrupted sections of road encourage high vehicle speeds and should be avoided; especially in locations where there are high volumes of non-motorized users. Stover and Koepke (2002) recommend limiting tangent distances to 400 feet.

- Minimize the Number of Driveways. While more driveways provide more direct access to parking and loading facilities, they also increase disruption for pedestrians and bicyclists traveling on adjacent streets and sidewalks. Shared driveways increase convenience for site users and minimize impact on non-motorized modes.
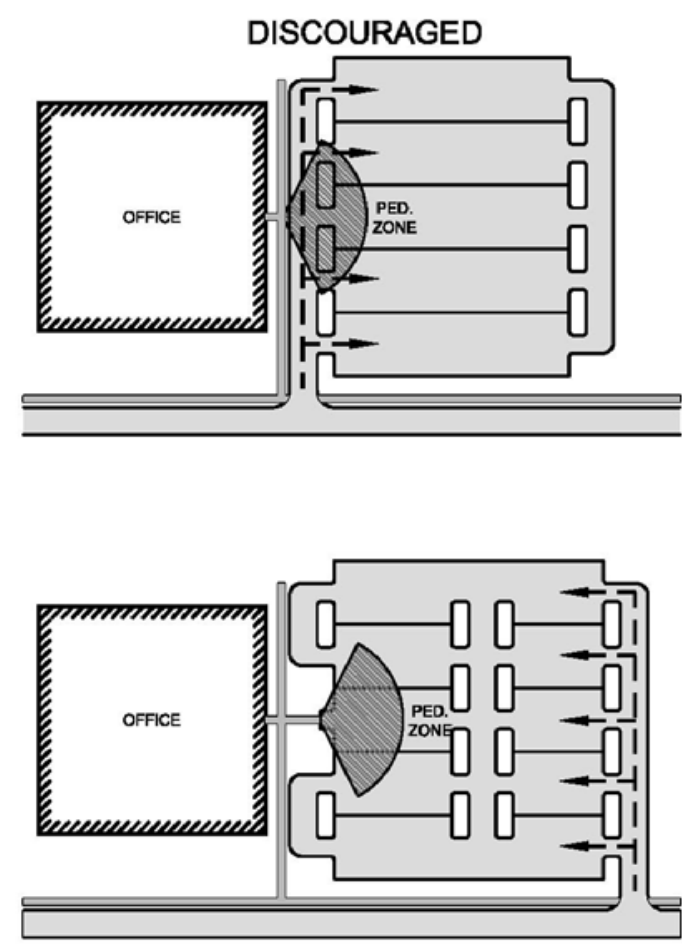

PREFERRED

\section{Objective: Use Design Standards that are Pedestrian and Bicycle-Friendly.}

Everyone who travels to an office park is a pedestrian at some point during their journey. Thus, it is imperative to use design standards that are pedestrian and bicycle friendly.

\section{Guidelines}

- Design Non-Motorized Facilities that Recognize That Pedestrians Always Take the Path of Least Resistance. Internal pedestrian circulation routes should follow desired pedestrian routes as closely as possible. Additionally, sidewalks and secondary pedestrian routes within individual parcels of land should be linked to main pedestrian circulation routes.

- Provide Direct Pedestrian Connections for Continuous, Convenient Pedestrian Infrastructure That Links Destinations Within an Office Park. Identifying the most direct, efficient route that requires the least expenditure of energy is key when determining where 
connections should occur throughout an office park site. Non-motorized modes are sensitive to distance, so connections should follow the path of least resistance and pedestrian desire lines whenever possible.

- Provide at Least a 5-Foot Wide Pedestrian Traveled Way for Sidewalks (Two-Way Paths Should be at Least 10 Feet Wide). 5 feet is the minimum width that accommodates two pedestrians walking side-by-side.

Refer to AASHTO's Guide for the Development of Bicycle Facilities (1999) as a guideline for establishing traveled way widths for bicycle or mixed-use paths.

- Maximum Sidewalk Cross Slope is 1:48 (or 2 Percent). This is a requirement of the ADA Accessibility Guidelines (www.access-board.gov/ adaag/html). If this value is exceeded, traversing a walkway becomes difficult and hazardous for those who must travel by walker, cane, or wheelchair.

- Provide a 4 to 6-Foot Wide Buffer Area Adjacent to Sidewalks that Parallel Roadways. Buffer strips not only separate pedestrian traffic from vehicular traffic, but also provide an area for landscaping and snow

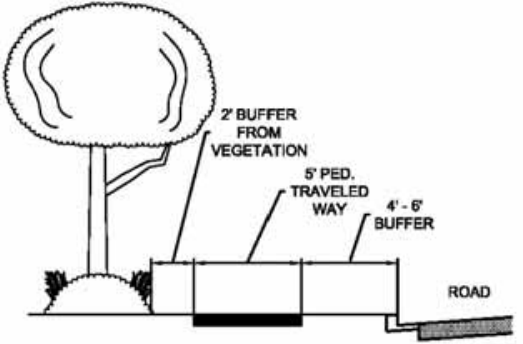
SIDEWALK CROSS SECTION ADJOINING ROAD

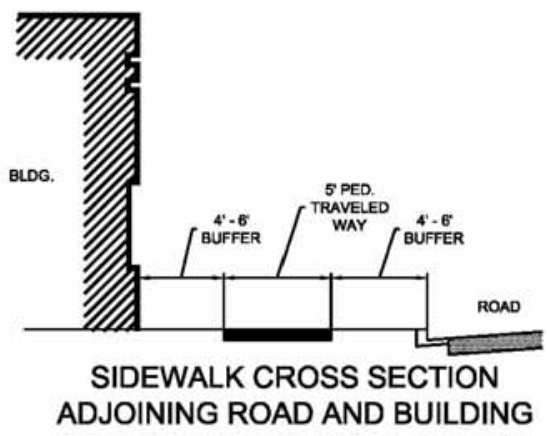
storage, a place for street furniture, and a good location for utility corridors.

- Sidewalks and other Walkways Must Have Smooth, Stable, and Slip Resistant Surfaces. This is a requirement of the ADA Accessibility Guidelines.

- Locate Drainage Grates, Utility Covers, and Other Hazards Outside of Pedestrian Traveled Ways. Where this cannot be avoided, covers and grates should have slip-resistant properties. Grates and covers should be flush with walking surfaces. ADAAG requires that grate openings not exceed $1 / 2$-inch and be oriented perpendicular to the traveled way.

\section{Objective: Provide Safe Crossing Points for Non-Motorized Modes}

Crosswalks should offer safe and convenient locations for pedestrians to cross vehicle traveled ways.

\section{Guidelines}

- Internal Roadway Intersections Should Meet at 90Degree Angles. This is optimal from a driver perceptionreaction standpoint and shortens crossing distances for pedestrians. Skewed angles require head turning to check for oncoming traffic.

- Use Small Curb Radii at Intersections to Slow Vehicles.

- Use Road Narrowings at Mid-Block and Intersection Locations for Traffic Calming Benefits and to Reduce Crossing Distances. Narrowings help to highlight pedestrian crossing locations and shorten road crossing distances.
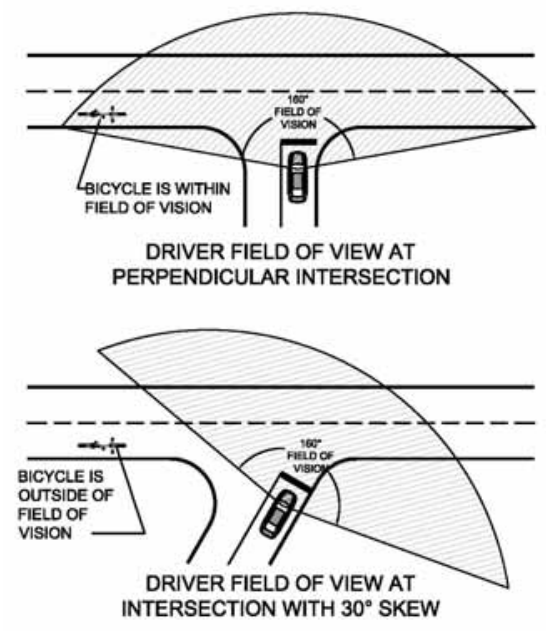
- Do Not Use Speed Bumps On Roads Or In Parking Lots. Speed bumps indicate poor design, and are a hazard for motor vehicles, bicycles, and pedestrians. Speed bumps produce driver discomfort at low speeds, and can be self-defeating at higher speeds. Speed bumps can cause vehicle damage and adversely affect emergency vehicle response. They are susceptible to damage from snow plows. Speed bumps are particularly dangerous for bicyclists. Speed bumps are also dangerous for pedestrians since their abrupt design could potentially catch a pedestrian's toe and create a "trip" and fall. Instead, consider speed humps as a traffic calming technique.

- Mark Crosswalks In Accordance with the Manual on Uniform Traffic Control Devices (MUTCD). Warrants (whether to mark a crosswalk or not) for mid-block crosswalks are contained in Safety Effects of Marked and Unmarked Crosswalks at Uncontrolled Locations (Zeeger, et al., 2002).

- Consider Multiple Viewpoints When Selecting Surface Treatments at Crosswalks. Selection of surface treatments is a complex subject due to multiple objectives to be met (aesthetics, initial cost, maintenance, durability, safety, and accessibility). The table below summarizes the advantages and disadvantages of some of the more commonly used surface treatments.

To accommodate the disabled, walking

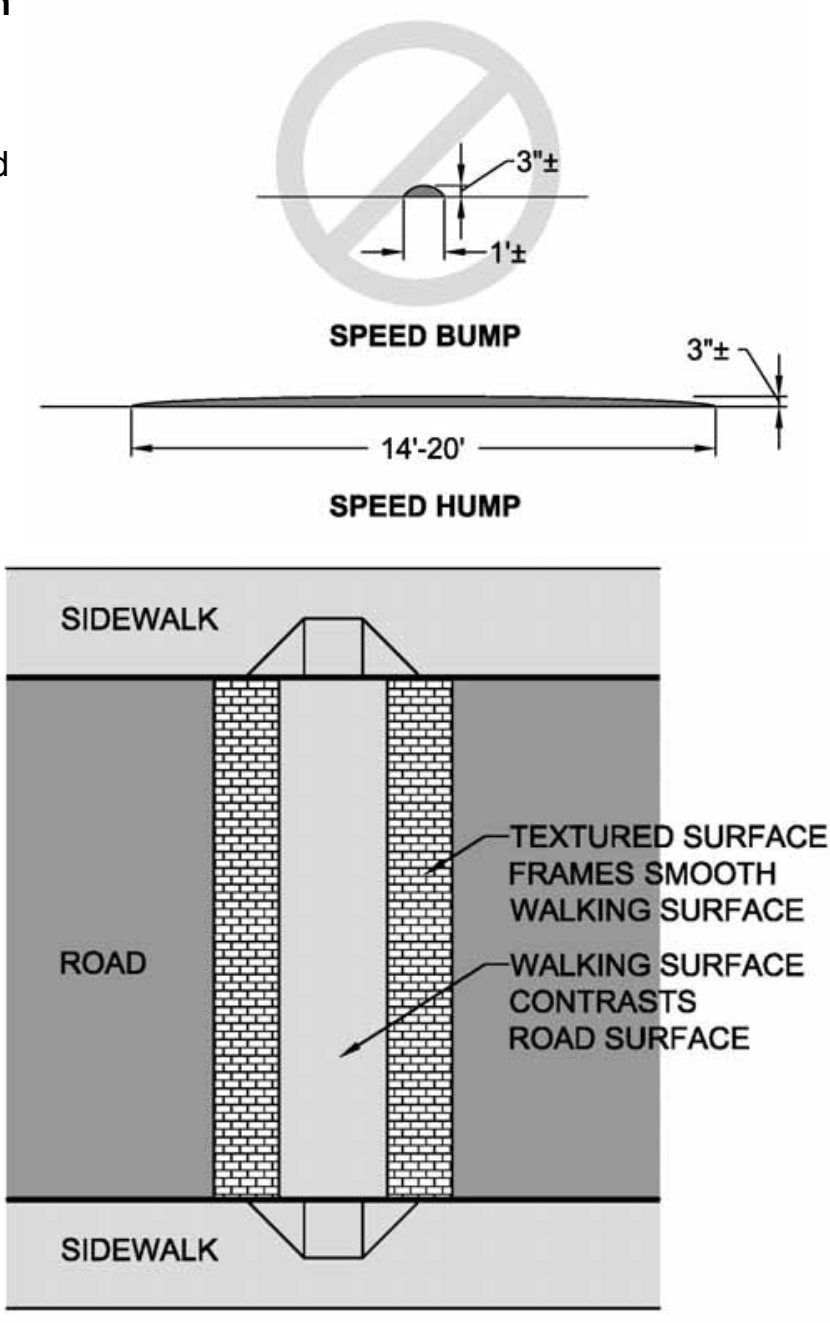

Crosswalk Texture and Contrast

Pavers can be used to frame a crosswalk for aesthetics. They should not be placed directly in the pedestrian traveled way. surfaces should be smooth. If a texture or pattern is sought for aesthetics, desirably it should be used as a border to frame the walkway.

\begin{tabular}{|ccc|}
\hline \multicolumn{2}{|c|}{ Comparison of Surface } & Materials for Pedestrian \\
Surface & Advantages & Disadvantages \\
\hline Asphalt & Smooth Surface & Edge Raveling \\
\hline Concrete & Durable, Smooth Surface & Cracking, Joint Problems \\
\hline Paver Stones & Aesthetics & Heaving, Settlement, Rough \\
\hline Bricks & Aesthetics & Heaving, Settlement, Rough \\
Stamped Concrete & Aesthetics & Rough Surface \\
\hline
\end{tabular}


- Consider Raised Crosswalks Where Mid-Block Crosswalks Are Warranted. The road surface is brought to the sidewalk elevation using a speed table. In addition to slowing vehicular traffic and making road crossing easier for pedestrians, raised crosswalks increase the conspicuity of pedestrians by placing them at a higher elevation. Traffic Calming: State of the Practice (Ewing, 1998), contains detailed design information about raised crosswalks and other traffic calming devices.

- Desirably, Sidewalk Grade, Cross Slope, and Surface Type Should be Continuous Across Driveways.

- Curb Ramps Must Comply With ADAAG Standards. Current ADDAG standards for curb ramps can be found at www.access-board.gov.

- Clear Sight Lines at Intersections and Driveways Permit Motorists to See Approaching Pedestrians and Vice Versa. Signs, parked cars, bus shelters, vegetation, and other street furniture should not block pedestrian and motorist sight lines. Landscaping in the vicinity of crossings should be limited to a maximum height of two feet.

- Roadway Medians Help Crossing Pedestrians By Providing Refuge for Those Who Cannot Cross the Road at One Time. Medians not only offer refuge to those with mobility impairments, they also contribute to overall aesthetics and have traffic calming benefits.

\section{Parking}

Even if pedestrian/bicycle-supportive facilities are provided, for the near term, the automobile will remain the primary mode of transportation to suburban office parks. Thus, parking is a necessary component of suburban office park design. It is important that parking facilities consider not only the needs of motor vehicles, but also consider the needs of pedestrians, bicyclists, and transit users.

Discussion here is limited to off-street parking facilities.

\section{Objective: Minimize the Impact of Parking on Non-Motorized Modes.}

\section{Guidelines}

- Locate Parking at the Side or

Rear of Buildings (or Below

Grade). Doing so facilitates easy

building access for pedestrians

who arrive via transit or nonmotorized modes, helps to create a pedestrian-friendly atmosphere, and enhances security.

- Orient Parking Aisles

Perpendicular to Buildings. Generally speaking, it is desirable to orient rows of parking stalls to "point" towards their destination. When the long dimension of parking aisles "point" towards the

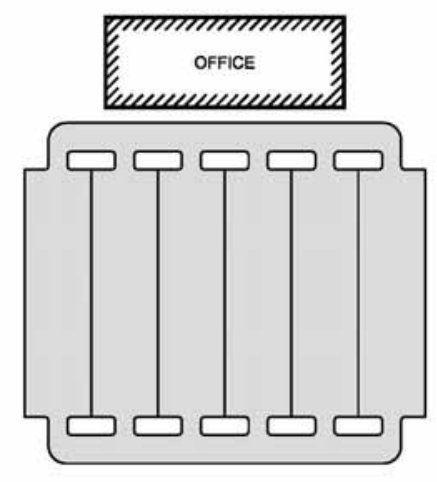

PREFERRED

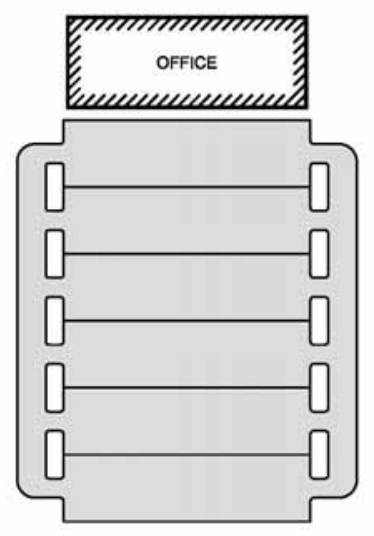

DISCOURAGED 
destination, it provides more direct pedestrian and bicycle travel lines, and reduces the number of pedestrian/vehicle conflict points with vehicles. Midblock crossings at various intervals can be used for parking aisles that are not perpendicular to buildings. This helps to create safer pedestrian paths on the interior of parking bays.

- Smaller Distributed Parking Lots Are

Preferable to One Large Lot. When a surface parking lot exceeds 50 to 100 stalls, separate, smaller parking lots should be considered (Canadian Institute of Transportation Engineers, 2003). Some sources indicate 300 to 500 stalls as the practical maximum (Alroth, 1988). Breaking parking areas up into smaller modularized areas helps to discourage diagonal movements, speeding, and other erratic vehicle maneuvers in parking lots.

- Facilitate Safe Pedestrian Travel In Parking Lots. While providing pedestrian routes within parking lots is sometimes a difficult task, protected routes provide convenient and safe travel for pedestrians. Look for opportunities for centrally located pedestrian routes, and highlight them with landscaping features.

- Use End-Of Aisle Treatments and Medians to Reduce High-Speed Diagonal Vehicular Movements. End islands limit access points and delineate parking aisles, which may help to eliminate erratic vehicle movements in parking lots. Additionally, end islands increase sight lines at internal parking lot intersections. They also act as refuge areas for pedestrians and fixed objects such as signs, fire hydrants and light poles. Curbed end islands should be given preference over painted end islands since painted islands make it easy for drivers to violate circulation patterns and travel diagonally across parking rows, which is undesirable and dangerous for motorists and non-motorists.

- Locate Gates or Other Parking Control Structures to Prevent Queuing Across Sidewalks or Into Bike Lanes.

- Discourage the Use of Wheel-Stops Through Alternate Designs. Wheel stops are sometimes used in parking lots to keep

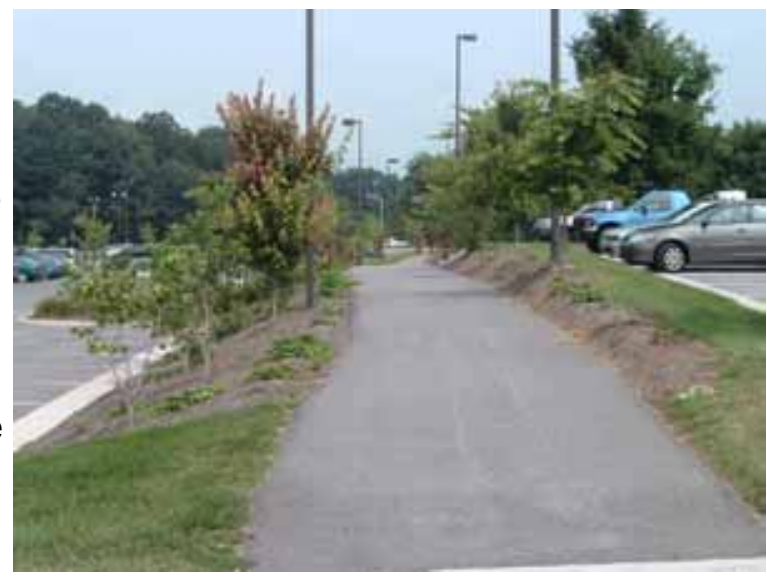

A Walkway Through a Parking Area Punctuated with Landscaping Features

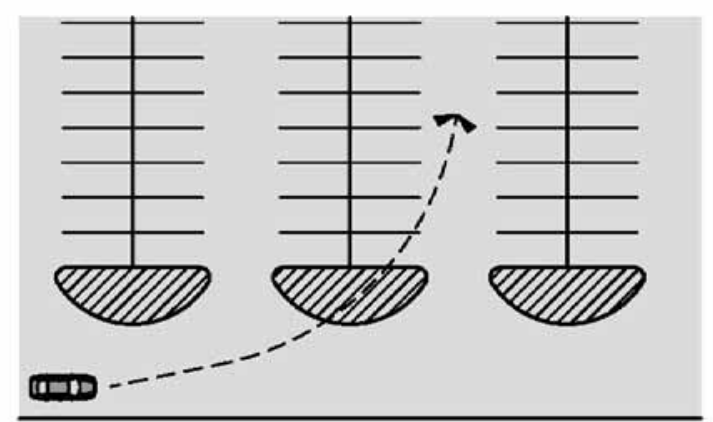

PAVEMENT MARKINGS ALLOW VEHICLES TO MAKE HIGH-SPEED DIAGONAL MOVEMENTS

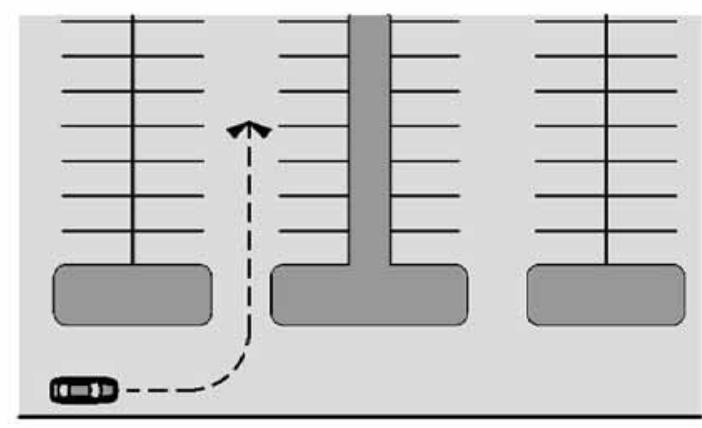

CURBED ISLANDS AND MEDIANS HELP PROMOTE ORDERLY VEHICULAR MOVEMENTS AT LOWER SPEEDS 
vehicles from overhanging an adjoining sidewalk or parking stall. Wheel stops present a tripping hazard for pedestrians, can trap debris, and can interfere with maintenance operations such as snow plowing and sweeping.

In place of wheel stops, other physical measures should be considered, such as adding two-to-three feet of width to a sidewalk to compensate for the lost effective width.

- Consider a Parking Structure To Minimize Land

Consumed by Surface Lots. Parking structures can help to create a compact urban form since land not paved can be more efficiently used. Aesthetics are enhanced since a welldesigned parking structure is less visually intrusive than a surface parking lot. There are opportunities to mix uses by placing retail and commercial establishments on the ground

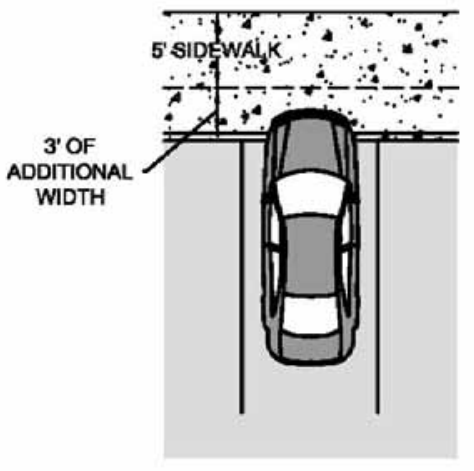

ADDITIONAL SIDEWALK WIDTH floor of parking structures. Also, a centrally located parking structure presents the opportunity for multiple users to share parking.

\section{Objective: Avoid an Oversupply of Parking and Make Ridesharing Attractive and Convenient}

\section{Guidelines}

- Encourage Ridesharing Among Employees. Ridesharing discourages commuting by single occupant vehicles (SOV) and encourages commute modes such as carpooling, vanpooling, and any modes that are considered high-occupancy vehicles (HOV). By getting more people to commute in the same vehicle, an effective ridesharing program can decrease parking demand. Section 3A provides additional information on ridesharing and TDM strategies.

- Give Priority Parking to Rideshare Vehicles. Provide secure, well-marked parking in the most convenient area of the parking lot.

- Strive to Supply Parking According to Actual Needs. Gruen + Gruen Associates and the Urban Land Institute (1986) examined office park parking supply and found that actual parking spaces needed per 1000 square feet of gross leasable floor area (GLA) were well under (high - 5.8; average - 2.8; and low 1.2) that prescribed by conventional zoning codes (usually 4 spaces per 1000 square feet of GFA). A large percentage of parking spaces were underutilized (high $-60.6 \%$; average $-46.8 \%$; and low $-28.0 \%$ ).

- Encourage Shared-Use of Parking Facilities. Encourage sharing parking facilities with hotels, restaurants, movie theaters, and other complementary land uses whose traffic peaks do not coincide with commercial office uses (typically daytime peaks).

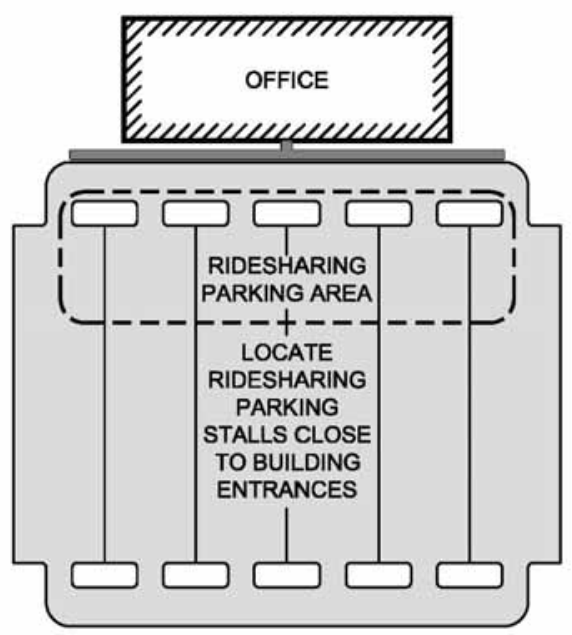

Ridesharing Parking Locations Locate ridesharing stalls in the most convenient locations for building users. 
- Consider "Green" Parking Solutions and Spillover Lots. Large areas of impervious land dedicated to surface parking are generally unattractive and increase storm water runoff. Turf reinforcement technologies allow parking on "green" surfaces. Green parking improves the aesthetics of surface lots and reduces storm water runoff. This type of paving system is an application that can be used for spillover parking, used to accommodate unforeseen parking demand.

\section{Objective: Design and Locate Service / Loading Areas in a Manner that}

\section{Accommodates Truck Access While Avoiding Conflicts with Non-}

\section{Motorized Modes}

Office parks need loading/service areas for pick-up and delivery purposes to ship or receive goods, as well as to accommodate service vehicles (e.g., trash collection and maintenance trucks). It is important that provisions be made to design these areas in a way that allows maneuver room for large trucks, while at the same time avoids conflicts with nearby non-motorized traffic.

\section{Guidelines}

- Provide Good Sight Lines and Visibility at Service/Loading Area Access Points.

- Separate Service/Loading Areas from Vehicular and Non-Motorized Traffic. Locate loading/service areas away from primary building entrances, parking areas, and areas with highpedestrian or vehicular volumes.

- Screen Service/Loading Areas with Vegetative or Impenetrable Barriers. These areas are typically unsightly and thus can detract from the pedestrian environment. Where feasible, consider a service court arrangement or underground loading areas.

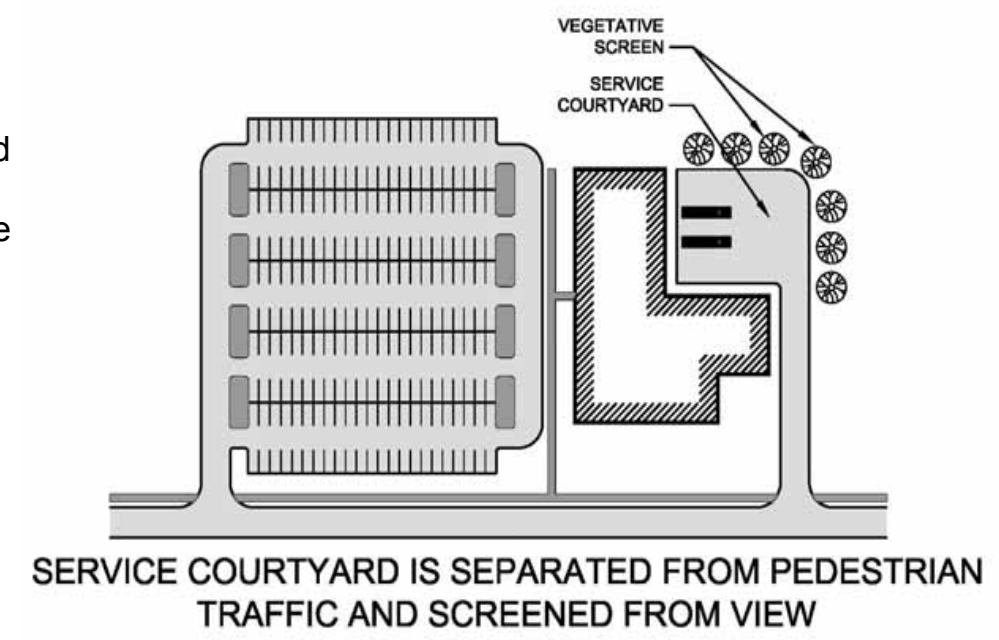




\section{Public Transportation / Transit Connections}

Efforts should be made to develop suburban office parks in a manner that facilitates the incorporation of transit service. Although some suburban areas are underserved, or not served at all by transit, office parks that lie along a transit route should facilitate transit service. Transit supportive sites maximize walkability, eliminate barriers to and from transit stops, and include conveniently located transit stops.

\section{Objective: Create a Site that is Transit Supportive}

\section{Guidelines}

- Design the Internal Transportation System to Accommodate Transit, Even if There is No Service Initially. Whether public transit, internal circulation transit, or paratransit modes, simple design features can lay a foundation to build on in the future. Internal roads should be simple and direct, but above all, the necessary pedestrian linkages should be in place to encourage alternate modes of transportation. If initial planning and design efforts do not consider transit, retrofitting a site for transit may prove costly in the future.

- Provide Conveniently Located Transit Stops that Serve Multiple Buildings. Locate transit stops and bus turnouts that can serve multiple buildings while minimizing walking distances.

- Space Transit Stops Between $\mathbf{6 0 0}$ to $\mathbf{2 5 0 0}$ Feet Apart for Convenient Pedestrian Access. Closely spaced transit shelters may provide easier pedestrian access, thereby making transit a more attractive travel option. However, stop placement is a tradeoff, as short walking distances create more frequent stops and longer bus trips.

- Provide Direct Pedestrian Linkages from Transit Stops to Nearby Buildings. Locate transit stops near building entrances and in areas that are heavily utilized by pedestrians, such as a cluster of office buildings or other high pedestrian traffic areas.

- Create Safe Transit Stops. Locate the stops where they are visible. Do not allow landscaping, buildings, or other fixed objects to obscure sight lines. Use clear surfaces for transit shelter walls.

- Provide Illumination Levels Between 2 to 5 Foot-Candles at Transit Stops. Well-lit areas give waiting passengers sense of comfort and security. Provide similar levels of illumination along pedestrian routes that lead to transit stops.

- Provide Pedestrian Access and Mobility in and Around Transit Shelters. Consult ADA guidelines when designing transit stops.

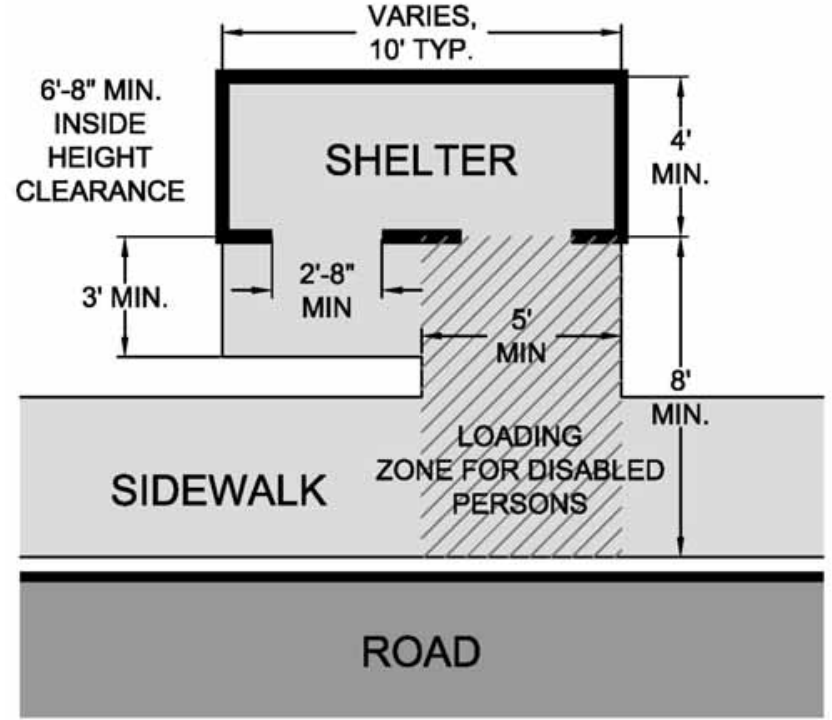

Recommended Dimensions for Transit Shelters Source: Guidelines for the Location and Design of Bus Stops (Texas Transportation Institute and Texas A\&M Research Foundation, 1996). 
- Locate Transit Shelters and Other Seating Out of the Pedestrian Traveled Way.

- Consider Climate in Configuring and Orienting Transit Shelters. See accompanying figure for placement considerations.

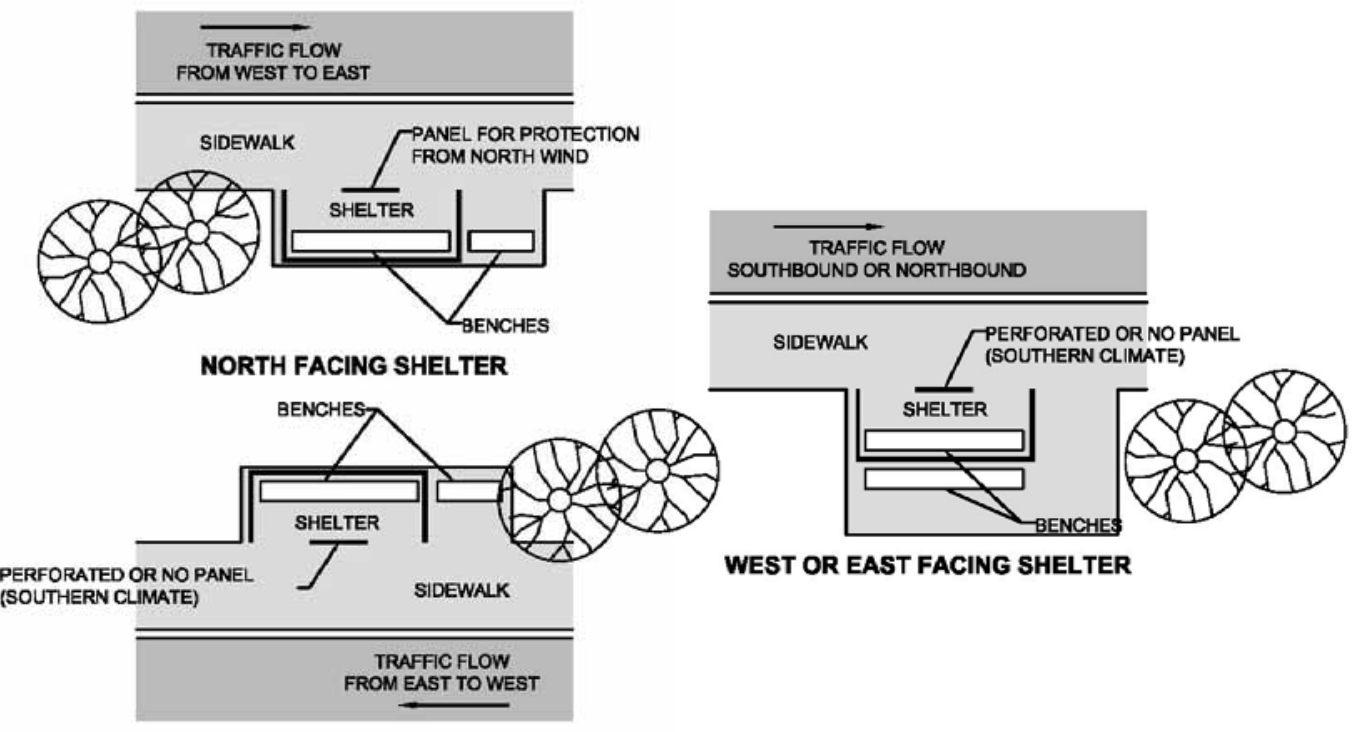

SOUTH FACING SHELTER

Take Climate and Orientation Into Consideration When Locating Transit Stops

Figure adapted from Guidelines for the Location and Design of Bus Stops (Texas Transportation Institute and Texas A\&M Research Foundation, 1996).

- Provide Formal and Informal Seating at Transit Stops. Benches and other forms of formal seating are desirable, as well as planter box ledges, low walls, and other informal seating. The amount of seating varies with transit usage.

- Include Trash Receptacles, Informational Kiosks, and Other Amenities at Transit Stops.

- Facilitate "Bike-and-Ride" Opportunities by Providing Bicycle Storage Near Transit Stops.

- Provide Passenger Information at Transit Stops. This can be accomplished by using interior panels or signage to display route and schedule information. 


\section{Selected Bibliography}

Access Board, ADA Accessibility Guidelines (ADAAG), The US Access Board, www.accessboard.gov.

American Association of State Highways and Transportation Officials, AASHTO Guide for the Development of Bicycle Facilities, AASHTO, Washington DC, 1999.

Alroth, Willard A., Employment Center Parking Facilities: An ITE Information Report, Institute of Transportation Engineers, Washington DC, 1988.

Association of Pedestrian and Bicycle Professionals, Bicycle Parking Guidelines, www.bicyclinginfo.org/pdf/bikepark.pdf, 2002.

Booth, Norman, Basic Elements of Landscape Architectural Design, Waveland Press, Illinois, 1983.

Brooks, R. Gene, Site Planning: Environment, Process and Development, Prentice Hall Career and Technology, Englewood Cliffs, New Jersey, 1988.

Burden, Dan, "Building Communities with Transportation”, Distinguished Lecture Presentation, Transportation Research Board, Washington DC, 2001.

Canadian Institute of Transportation Engineers, The Canadian Guide to Promoting Sustainable Transportation Through Site Design: Draft Guidelines, Canadian Institute of Transportation Engineers, 2003.

Cervero, Robert, America's Suburban Centers: The Land Use - Transportation Link, Unwin Hyman, London, 1989.

Cervero, Robert, Suburban Gridlock, Center for Urban Policy Research, New Brunswick, NJ, 1986.

City of Portland Offices of Transportation, Bicycle Parking Facilities Guidelines, The City of Portland Offices of Transportation, www.trans.ci.portland.or.us/ bicycles/ parkingguide.htm.

Ewing, Reid, Pedestrian and Transit-Friendly Design: A Primer for Smart Growth, Smart Growth Network, Washington DC, 1999.

Ewing, Reid, Traffic Calming: State of the Practice, Institute of Transportation Engineers, Washington DC, 1999.

Federal Highway Administration, FHWA Course on Bicycle and Pedestrian Transportation, Federal Highway Administration, Taken from the Pedestrain/Bicycle Safety Resource Set: Version 1.0, FHWA-SA-00-005, 2000.

Federal Highway Administration, Manual on Uniform Traffic Control Devices: Third Edition, Federal Highway Administration, U.S. Department of Transportation, Washington DC,

www.mutcd.fhwa.dot.gov/, 2003.

Federal Highway Administration, A Guidance Manual for Implimenting Effective Employer-Based Transportation Demand Management Programs, (http://ntl.bts.gov/docs/474.html).

Frej, Anne, Marvin Christensen, William D’Elia, Mark Eppli, Libby Howland, James Musbach, Frank Spink, and Dorothy Verdon, Business Park and Industrial Development Handbook, Urban Land Institute, Washington DC, 2001. 
Gause, Jo Allen, Mark Eppli, Michael Hickok, and Wade Ragas, Office Development Handbook: Second Edition, Urban Land Institute, Washington, DC, 1998.

Gruen + Gruen Associates and Urban Land Institute, Employment and Parking in Suburban Business Parks: A Pilot Study, Urban Land Institute, Washington, DC, 1986.

ITE Smart Growth Task Force, Smart Growth Transportation Guidelines: An ITE Proposed Recommended Practice, Institute of Transportation Engineers, Washington DC, 2003.

Lighting Design Lab Website, http://lightingdesignlab.com/articles/pedestrian/pedestrian.htm, accessed 8/04.

Litman, Todd, Pavement Busters Guide: Why and How to Reduce the Amount of Land Paved for Roads and Parking Facilities, Victoria Transport Policy, Victoria, BC, 2000.

Litman, Todd, Robin Blair, Bill Demopoulos, Nils Eddy, Anne Fritzel, Danelle Laidlaw, Heath Maddox and Katherine Forster, Pedestrian and Bicycle Planning: A Guide to Best Practices, Victoria Transport Policy Institute, Victoria, BC, 2002.

Motlock, John, Introduction to Landscape Design: Second Edition, John Wiley \& Sons, Inc., New York, 2001.

Prince William County Comprehensive Plan, lllustrative Design Guidelines for Office Development, www.pwcgov.org/docLibrary/PDF/001876.pdf, accessed 10/8/04.

Schwanke, Dean, Patrick L. Phillips, Frank Spink, Charles Lockwood, David Versel, Steven Fader, Leslie Holst, Oliver Jerschow, Deborah Myerson, Mixed-Use Development Handbook, Urban Land Institute, Washington DC, 2003.

Smart Growth Network, Getting to SmartGrowth: 100 Policies for Implementation, Smart Growth Network, International City/County Management Association, 2002.

Stover, Virgil G. and Frank J Koepke, Transportation and Land Development, Institute of Transportation Engineers, Washington DC, 2002.

Texas Transportation Institute and Texas A\&M Research Foundation, TCRP Report 19: Guidelines for the Location and Design of Bus Stops, Transit Cooperative Research Program and Transportation Research Board, National Academy Press, Washington DC, 1996.

Urban Land Institute and the National Parking Association, The Dimensions of Parking: Fourth Edition, Washington DC, 2000.

Environmental Protection Agency, Parking Alternatives: Making Way for Urban Infill and Brownfields Redevelopment, U.S. Environmental Protection Agency, Washington DC, 1999.

Victoria Transport Policy Institute, Online TDM Encyclopedia, www.vtpi.org/tdm/.

Zeeger, Charles V., Richard Stewart, Herman H. Huang, and Peter A. Lagerwey, Safety Effects of Marked and Unmarked Crosswalks at Uncontrolled Locations, Executive Summary and Recommended Guidelines, Federal Highway Administration, Washington DC, 2002.

Note: All figures, tables, and photos by Keith Bryant (author), unless otherwise noted. Cover photos (at bottom of page) from www.pedbikeimages.org / Burden. 


\section{Curriculum Vitae}

\section{Keith B. Bryant}

Mr. Bryant was born in Botetourt County, Virginia, on August 13, 1976. He attended James River High School in Buchanan, Virginia, graduating in the Spring of 1994. Upon graduation, Bryant accepted a baseball scholarship to attend Bluefield State College (BSC) in Bluefield, West Virginia. At BSC, Bryant double-majored in Architectural Engineering and Civil Engineering Technology, graduating in the spring of 1999.

Upon completion of his undergraduate degrees, Bryant began working as a Civil/Site Design Engineer at Hayes, Seay, Mattern \& Mattern (HSMM); a consulting engineering firm located in Roanoke, Virginia. Bryant worked on a multitude of commercial, and state and federal governmental site design and highway engineering projects while at HSMM.

Bryant began his graduate education in the Department of Civil and Environmental Engineering at West Virginia University in the Spring semester of 2003, majoring in transportation systems engineering. His main areas of interest in graduate school were traffic engineering and pedestrian and bicycle transportation. Bryant was employed part-time by the West Virginia Transportation Technology Transfer (WVT2) Center while attending graduate school. As the WVT2 Center's technical assistant, Bryant assisted in an array of projects including parking lot design, site design, software training, and other engineering-related duties.

Bryant is currently working as a project engineer at Thrasher Engineering, in Clarksburg, West Virginia. There, he is a lead design engineer for residential and commercial site planning projects, as well as transportation and traffic engineering projects. 